\title{
Simulating gait in patients with knee osteoarthritis
}

Citation for published version (APA):

Oomen, P. (2019). Simulating gait in patients with knee osteoarthritis. [Doctoral Thesis, Maastricht University]. ProefschriftMaken Maastricht. https://doi.org/10.26481/dis.20190131po

Document status and date:

Published: 01/01/2019

DOI:

10.26481/dis.20190131po

Document Version:

Publisher's PDF, also known as Version of record

\section{Please check the document version of this publication:}

- A submitted manuscript is the version of the article upon submission and before peer-review. There can be important differences between the submitted version and the official published version of record.

People interested in the research are advised to contact the author for the final version of the publication, or visit the DOI to the publisher's website.

- The final author version and the galley proof are versions of the publication after peer review.

- The final published version features the final layout of the paper including the volume, issue and page numbers.

Link to publication

\footnotetext{
General rights rights.

- You may freely distribute the URL identifying the publication in the public portal. please follow below link for the End User Agreement:

www.umlib.nl/taverne-license

Take down policy

If you believe that this document breaches copyright please contact us at:

repository@maastrichtuniversity.nl

providing details and we will investigate your claim.
}

Copyright and moral rights for the publications made accessible in the public portal are retained by the authors and/or other copyright owners and it is a condition of accessing publications that users recognise and abide by the legal requirements associated with these

- Users may download and print one copy of any publication from the public portal for the purpose of private study or research.

- You may not further distribute the material or use it for any profit-making activity or commercial gain

If the publication is distributed under the terms of Article $25 \mathrm{fa}$ of the Dutch Copyright Act, indicated by the "Taverne" license above, 


\section{SIMULATING GAIT IN PATIENTS WITH KNEE OSTEOARTHRITIS}

Pieter Oomen 
The research presented in this thesis was conducted at CAPHRI Care and Public Health Research Institute and NUTRIM School of Nutrition and Translational Research in Metabolism, Department Nutrition and Movement Sciences and Department of Orthopaedic Surgery, of Maastricht University. CAPHRI participates in the Netherlands School of Public Health and Care Research CaRe. The publication of this thesis was financially supported by Maastricht University and Clinical Trial Center Maastricht BV.

\section{Colofon}

(C) Pieter Oomen, Maastricht 2018. All rights reserved.

Printed by ProefschriftMaken || www.proefschriftmaken.nl

Cover design Pieter Oomen

Layout Pieter Oomen

ISBN

9789463801744 


\title{
SIMULATING GAIT IN PATIENTS WITH KNEE OSTEOARTHRITIS
}

\author{
Proefschrift \\ ter verkrijging van de graad van doctor aan de Universiteit Maastricht, \\ op gezag van de Rector Magnificus, Prof. dr. Rianne M. Letschert \\ volgens het besluit van het College van Decanen, \\ in het openbaar te verdedigen \\ op donderdag 31 januari 2019 om 14.00 uur \\ door \\ Petrus Wilhelmus Oomen \\ Geboren op 29 april 1986, te Oirschot, Nederland
}




\section{Promotor}

Prof. dr. L.W. van Rhijn

\section{Copromotores}

Dr. K. Meijer

Dr. ir. M.R. Drost

\section{Beoordelingscommissie}

Prof. dr. H.H.C.M. Savelberg (voorzitter)

Prof. dr. ir. H.F.J.M. Koopman (Universiteit Twente)

Prof. dr. M. Poeze

Dr. ir. D. Janssen (Radboud universitair medisch centrum)

Dr. M.A. Witlox 


\section{Table of contents}

page

\begin{tabular}{|c|c|}
\hline Chapter 1 & General Introduction \\
\hline Chapter 2 & $\begin{array}{l}\text { Obese knee OA patients have increased knee adduction } \\
\text { moments during gait }\end{array}$ \\
\hline Chapter 3 & $\begin{array}{l}\text { The mediolateral component of knee joint loading as } \\
\text { predicted by musculoskeletal models is increased in } \\
\text { patients with mild knee osteoarthritis }\end{array}$ \\
\hline Chapter 4 & $\begin{array}{l}\text { Development and validation of a rule-based streng } \\
\text { scaling method for musculoskeletal modelling }\end{array}$ \\
\hline Chapter 5 & $\begin{array}{l}\text { Comparison of in vivo muscle volumes of the lou } \\
\text { extremity to cadaveric data sets }\end{array}$ \\
\hline Chapter 6 & $\begin{array}{l}\text { Personalised muscle strength for musculoskelet } \\
\text { modelling of locomotion, a proof of concept study }\end{array}$ \\
\hline Chapter 7 & General Discussion \\
\hline \multirow[t]{6}{*}{ Chapter 8} & Samenvatting \\
\hline & Summary \\
\hline & Valorisation \\
\hline & Dankwoord \\
\hline & About the Author \\
\hline & \\
\hline
\end{tabular}

List of publications 

CHAPTER

General introduction

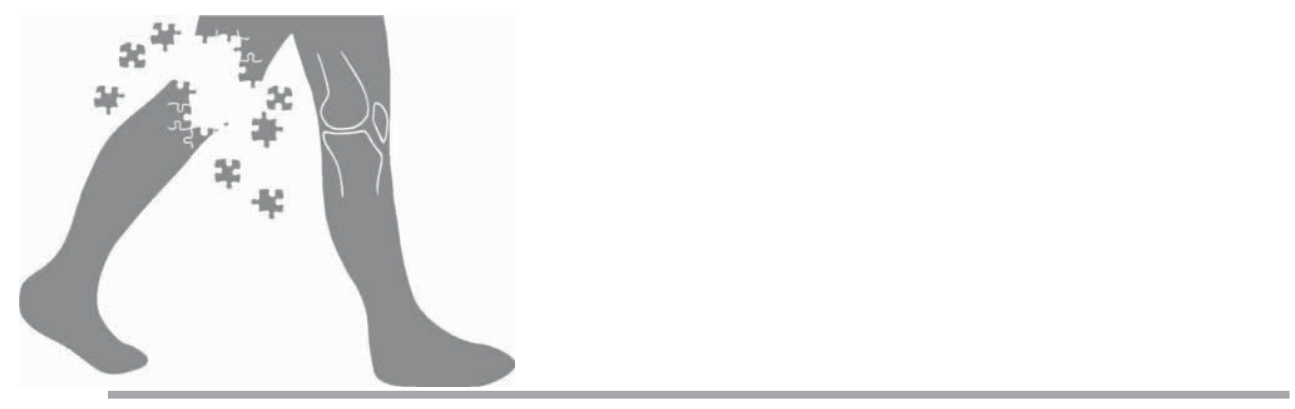




\section{Introduction}

Bipedal gait is one of the key traits of the evolution of the human species. ${ }^{1}$ Walking and running are the two basic forms of locomotion and humans automatically transfer from one to the other when speed of propulsion increases. ${ }^{2}$ Walking is the most important way of unsupported transport and an activity most common in daily life. ${ }^{3}$ Walking is characterized as energy efficient; gait at optimal walking speed requires very little muscular activity. The mechanism behind walking is often explained by two coupled pendula: the stance leg behaves like an inverted pendulum moving around the stance foot, and the swing leg rotates around the hip. In this walking model little energy is required to maintain the pendular movement, only the redirection of the centre of mass during the double support phase requires work. ${ }^{4}$

The simplistic inverted pendulum model captures the basics of human bipedal movement but does not account for the intricacies of the sub movements and loading of the complete musculoskeletal system. For instance, the lower extremities contain about 60 bones, over 100 muscles and over 200 ligaments. In addition, the musculoskeletal system is driven by a complex neurological network. Many different musculoskeletal disorders exist that alter normal gait. For example, knee osteoarthritis (OA) in the tibiofemoral joint alters normal gait and is the main cause of pain and disability in the elderly. ${ }^{5,6}$ Therefore, this dissertation focuses on patients with early stage knee OA. To date, it is assumed that patients with knee OA have an altered gait pattern, which is related to high joint loading in regions of the knee that are not adapted to these loads. ${ }^{7}$ Consequently, these high joint contact forces contribute to cartilage deterioration. Gait analysis gives the opportunity to investigate gait changes that are associated with the initiation and progression of knee OA. In order to understand the complexities involved in locomotion of the musculoskeletal system and possible pathologies associated with it, musculoskeletal computer models are helpful tools for evaluations.

\section{Osteoarthritis of the knee}

Knee $\mathrm{OA}$ is a degenerative disease of the cartilage in the knee, effecting mostly elderly women. ${ }^{8}$ Knee OA has a high burden of disease and is affecting more than half a million patients in the Netherlands and is still rising. ${ }^{5,6}$ A complex combination of risk factors is associated with the initiation and progression of knee OA. To name a few, the female sex, aged above 50 years, obesity, previous traumas, abnormal cell biology and altered joint mechanics are all associated with knee OA. ${ }^{9-14}$ 
In persons with healthy cartilage, walking results in a repetitive load distributed over the medial and lateral condyles. Furthermore, healthy cartilage can maintain homeostasis by adjusting cartilage thickness in those regions with higher loads. ${ }^{7}$ The paradigm to explain knee OA introduced by Andriacchi et al. hypothesised that an alteration of joint mechanics, for instance due to injuries, results in a shift of loading to a region at the medial compartment (Figure 1.1). ${ }^{7}$ When the cartilage is not adapted to the increased load it can result in a degenerative cartilage response. ${ }^{7}$ Therefore, it is important to evaluate alterations in joint mechanics during activities of daily living.

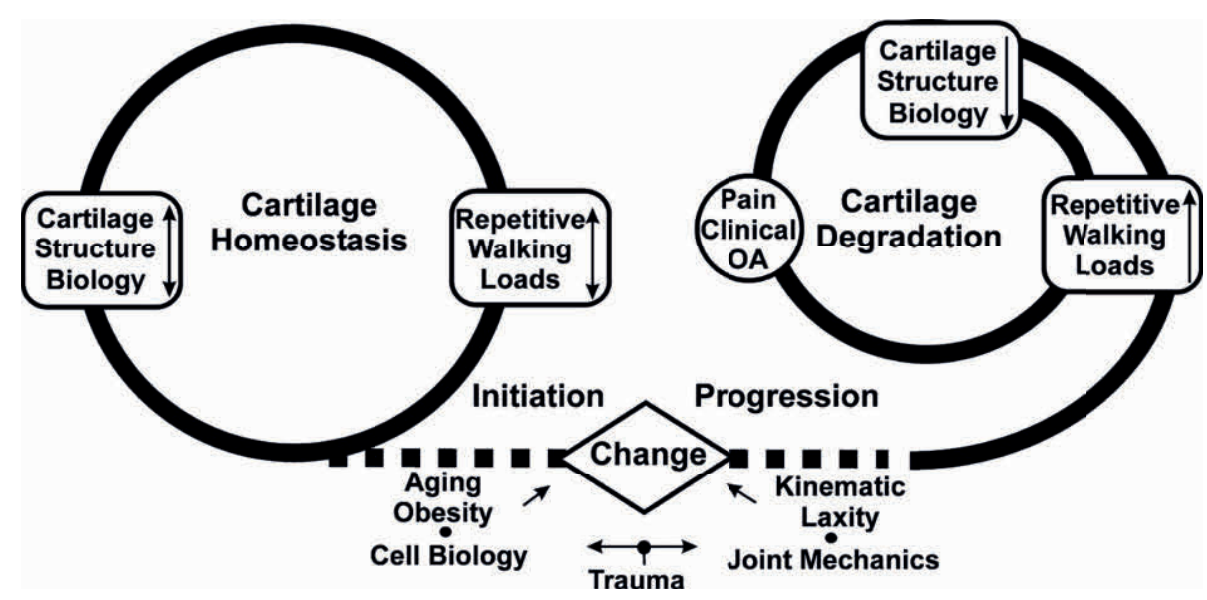

Figure 1.1 The paradigm of Andriacchi et al. explaining the initiation and progression of knee $\mathrm{OA}^{7}{ }^{7}$ Healthy cartilage can maintain homeostasis by adjusting cartilage structure in regions with higher loads. A complex combination of changes is associated with the initiation of knee OA. In the progression of knee OA cartilage will responds negatively to higher loads.

\section{Gait analysis}

Three dimensional motion analysis of human gait is able to detect pathological gait and can possibly identify individuals prone to develop knee OA. ${ }^{15}$ Motion capture of gait is typically performed using reflective markers tracked by multiple cameras surrounding the subject (Figure $1.2 \mathrm{~A}$ and $\mathrm{B}$ ). Consequently, the reflective markers can be threedimensional reconstructed within a computational program. Ground reaction forces and muscle activity can be measured simultaneously using force platforms and electromyography, respectively. The computational program will process the marker 


\section{Chapter 1}

tracks and ground reaction force in order to calculate external joint loading by inverse dynamics (explanation of inverse dynamics in the next paragraph "Musculoskeletal modelling" and Figure 1.3). In conclusion, analysing human movement by means of motion capture can detect alterations in gait (e.g. external joint loading).

For some time now, the external knee adduction moment is considered to be an important indicator of future knee pain and $O A .{ }^{16,17}$ The magnitude of the external knee adduction moment is dependent on the ground reaction force, and the moment arm of the ground reaction force about the knee joint centre. An increased knee adduction moment can originate from joint laxity or varus alignment of the knee joint in patients with knee $\mathrm{OA}^{18,19}$ As a result, the knee joint might open laterally which relocates the complete load to the medial compartment of the knee. ${ }^{13}$ However, body weight might be a confounding factor contributing to an increased knee adduction moment. ${ }^{20}$ For example, the studies of Mundermann et al., Landry et al. and Thorp et al. have shown that patients with (more severe) knee OA have increased knee adduction moments, and an increased body weight compared to healthy (less severe OA) peers. ${ }^{21-23}$ For that reason, there is a need for a study including clearly defined groups of patients evaluating the separate effect of knee OA and body weight on the external knee adduction moment (chapter 2).
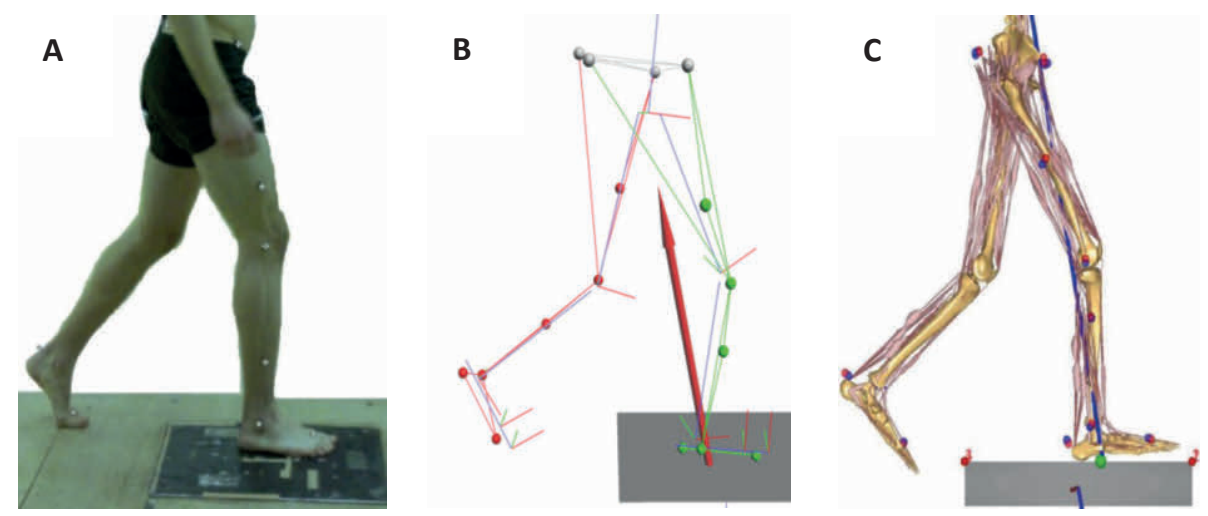

Figure 1.2 Workflow from gait analysis to musculoskeletal model; A) motion capture: retroreflective markers and a force plate enable gait analysis; B) a three-dimensional reconstruction of the markers within motion capture software, the vector of the ground reaction force is included by a red arrow; C) a musculoskeletal model representing the data derived from motion capture. 
Several strategies are presented in the literature that aimed to reduce the external knee adduction moment in patients with knee OA. For example, weight loss has been shown to be an important investment in order to directly decrease joint loads. ${ }^{24}$ On the other hand, studies using orthotic treatments and walking pole have shown to be less effective. ${ }^{25,26}$ Furthermore, no conclusive improvements on the knee adduction moment were found using other gait modifications (e.g. trunk sway, walking speed, toe-out gait). ${ }^{27}$ In addition to these strategies, some patients use additional lateral muscle co-contraction to increase joint stability; though, this results in increased total joint reaction forces and possibly further degeneration of knee cartilage. ${ }^{28}$

Although gait analysis is able to detect external parameters of gait, these parameters are not directly translatable to internal joint forces; since internal joint reaction forces also dependent on muscle and ligament forces. ${ }^{29}$ Taking these internal forces into account using regular three-dimensional motion analysis is challenging. However, musculoskeletal modelling software has the potential to contribute to a better understanding of these issues. $^{30}$

\section{Musculoskeletal modelling}

The definition of a model is a simplified mathematical system, used to assist calculations and predictions. ${ }^{31}$ Models of human movement can be as basic as the inverted pendulum model (see §Introduction), but should include physiological details in order to reveal underlying mechanisms. ${ }^{32}$ Advanced musculoskeletal models represent the essential elements of the human musculoskeletal system in order to predict internal joint loading and muscle forces or predict performance (Figure $1.2 \mathrm{C}$ ).

Either a forward or an inverse dynamic approach can be implemented in musculoskeletal modelling (Figure 1.3)..$^{33}$ Inverse dynamics uses the measured movement and external forces to estimate the necessary muscle forces. Inverse dynamics is useful in order to evaluate differences in internal loading as a result of an intervention or pathology. ${ }^{34}$ Inverse dynamics will be used in this dissertation to investigate knee joint loading in patients with knee OA. Forward dynamics follows the opposite path by predicting the resulting movement from the imposed muscle forces (Figure 1.3). These forward dynamic models offer the possibility to answer "what if" questions. For example, it can predict how performance will change if a joint or muscle is altered. A disadvantage using forward dynamics is that the prediction of movement appears to be difficult, because of the amount of constraints that are necessary to obtain a stable model. ${ }^{33}$ 


\section{Chapter 1}

In musculoskeletal models bones are represented as rigid segments, connected to each other by a specific joint, set in motion through several muscles. These elements are numerically described by many adjustable variables within the model. A muscle, for example, can be described by its attachment points, tendon length, muscle fibre length, physiological cross-sectional area and shape around the bones. Furthermore, the muscle indeterminacy problem can be solved by muscle recruitment algorithms that are incorporated in musculoskeletal models. Multiple algorithms exist that determine muscle recruitment for a given task based on optimization criterion, such as minimizing muscle fatigue ${ }^{35}$ or minimizing maximum muscle activity, ${ }^{36}$ which is suitable for respectively low demanding activities (e.g. walking) and high demanding activities (e.g. sprint or one repetition maximum).

In summary, a musculoskeletal model can facilitate in simulations of inverse dynamics by fast calculations. Moreover, models can estimate internal contact and muscle forces that are impossible to measure non-invasively. Therefore, we will investigate if musculoskeletal models have added value beyond gait analysis to show differences in joint loading between patients with knee OA and healthy volunteers (chapter 3 ).

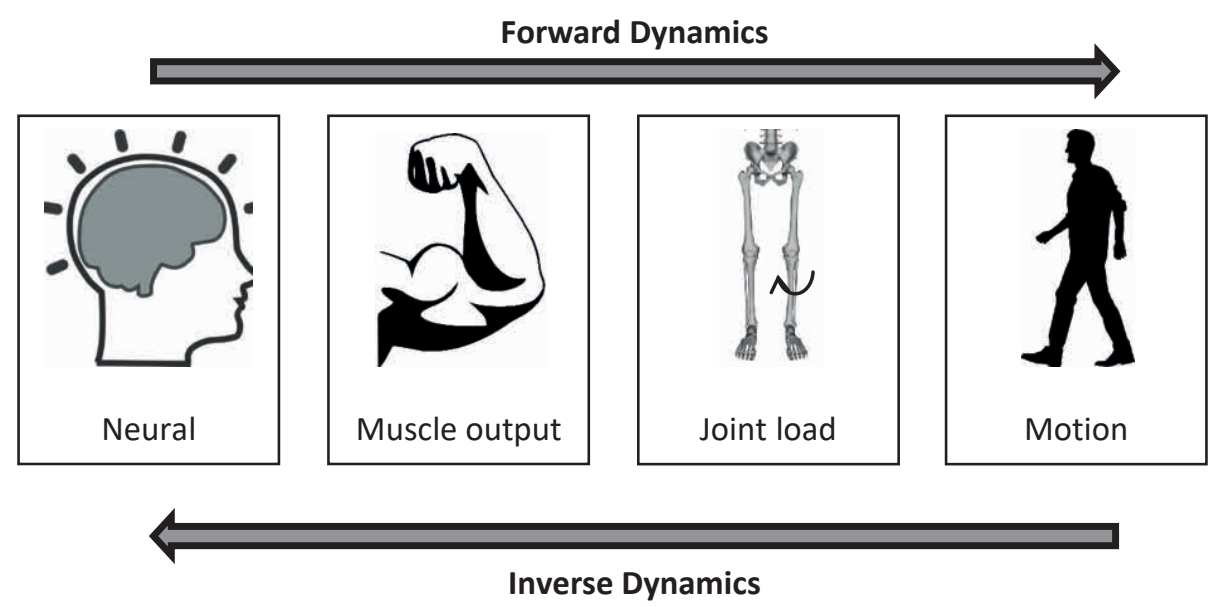

Figure 1.3 Inverse vs forward dynamics approaches towards musculoskeletal modelling. 


\section{Subject specific musculoskeletal models}

The major challenge for realistic musculoskeletal models is obtaining accurate input parameters, since outcomes of these models highly depend on these variables. Moreover, variation between individuals needs to be addressed in these models to obtain accurate outcomes. Therefore, personalisation is hypothesised to be essential to obtain valid subject-specific musculoskeletal models. The main elements that needs personalisation in musculoskeletal models are bone geometry, joint kinematics, muscle paths, and muscle architecture. ${ }^{37}$ Typically these parameters are derived from cadaveric datasets ${ }^{38}$ and subsequent personalisation can be applied.

In order to investigate the necessary level (accuracy) of personalisation, sensitivity analyses are helpful tools for evaluations. For example, Carbone et al. found that the attachment sites of some muscles have a considerable effect on force prediction. ${ }^{39}$ Furthermore, sensitivity analyses have shown that muscle strength is more dependent on tendon slack length than muscle moment arms. ${ }^{40}$ Furthermore, muscle strength, which is proportional to physiological cross-sectional area, has been shown to be one of the most important parameters predicting joint loading that needs personalisation. ${ }^{41}$ The physiological cross-sectional area is an important parameter for muscle architecture, which is defined as the arrangement of muscle fibres relative to the axis of force generation. ${ }^{42}$ In addition, the functional properties of the muscle depend considerably on its architecture. ${ }^{42}$ Although previous studies provided us with relevant insights to improve subject specific musculoskeletal models, it is still unknown how changes in muscle strength influences model outcomes. ${ }^{37}$

Personalisation of muscle strength can be achieved by relative simple mathematical approximation or by measuring the muscle volume directly. For example, uniform strength scaling is a straight forward method to personalise multiple muscle volumes at once. ${ }^{43,44}$ On the other hand, magnetic resonance imaging is able to directly measure muscle volumes in vivo. ${ }^{45} \mathrm{~A}$ complete different strategy is to obtain musculoskeletal parameters by means of calibration experiments, for example, dynamometer experiments. ${ }^{46}$

Typically, current strength scaling methods correct muscle strength for length, mass and fat percentage. ${ }^{44}$ They are cheap and easy to use for personalising muscle strength. However, they do not account for other determinants of muscle strength, such as age and gender. $^{47-51}$ Therefore, we hypothesize that rule-based strength scaling techniques that incorporate these variables increase personalisation and accuracy (chapter 4). 


\section{Chapter 1}

A more advanced approach in personalising muscle strength is by means of imaging. Since, uniform strength scaling personalises muscles evenly across subjects and/or segments, imaging enables non-uniform personalisation by measuring individual muscles. Morphological MRI scans have been shown to be suitable for quantifying muscle volume (chapter 5). ${ }^{45,52}$ Moreover, previous studies used similar approaches in order to personalise individual muscle strength. ${ }^{53}$ However, the effect of different strength personalisation approaches on internal forces needs to be addressed in the lower extremities (chapter 6). 


\section{Aim and outline of dissertation}

The primary aim of this dissertation is to investigate knee joint loading during gait in patients with knee $\mathrm{OA}$, and to evaluate the impact of personalised muscle strength on the predictions made by musculoskeletal models. To achieve this aim, three research questions are examined in this thesis:

1. Can musculoskeletal modelling improve our knowledge on knee joint loading in OA patients beyond traditional gait analysis? (chapter $2 \& 3$ )

2. Can we improve current strength scaling methods for better personalised musculoskeletal models of the lower extremities? (chapter 4)

3. Is the assessment of muscle volumes of added value for strength personalisation in musculoskeletal models? (chapter 5 \& 6)

Chapter 2 describes a cross-sectional study focusing on the pathomechanics of knee OA. Three groups were assessed using traditional gait analysis: lean knee OA patients, obese osteoarthritis and a healthy control group. In this study the independent effect of knee OA, body weight and walking speed on the external knee adduction moment was evaluated. To further explore the pathomechanics of knee OA a subset of participants of this study was used in chapter $\mathbf{3}$ employing musculoskeletal modelling. Internal loading and muscle activations were simulated by musculoskeletal modelling, in order to evaluate possible differences between patients with OA and healthy controls. Together, chapters 2 and 3 investigate the first research question of this thesis "Can musculoskeletal modelling improve our knowledge on knee joint loading in OA patients above traditional gait analysis?"

Since muscle force is an important determinant to joint reaction forces, chapter 4 evaluates a new method to personalise muscle strength by means of a rule-based strength scaling technique. Therefore, we used easy to access parameters of anthropometrical data that potentially influence muscle strength, such as age, length, mass, gender and segment geometries. This newly developed strength scaling technique was compared to current available strength scaling techniques, in order to answer the second research question of this thesis "Can we improve current strength scaling methods for better personalised musculoskeletal models of the lower extremities?"

Imaging might be an important tool to obtain non-uniform personalised musculoskeletal models. Therefore, chapter 5 explores the uniformity of muscle volumes. Therefore, we obtained an in-vivo measured dataset of the lower limbs and compare this with frequently used cadaveric datasets in musculoskeletal models. Moreover, chapter 6 demonstrates by 


\section{Chapter 1}

means of a proof of concept study, what the influence is of personalising individual muscle volumes on musculoskeletal models. Hence, muscle activities and internal joint forces are evaluated using different levels of personalisation. Accordingly, Chapter 5 and 6 evaluate the third research question of this thesis "Is the assessment of muscle volumes of added value for strength personalisation in musculoskeletal models?"

Finally, this dissertation concludes with a general discussion (chapter 7), describing the main outcomes in a broader perspective and elaborates on future perspectives. 


\section{References}

1. Niemitz C. 2010. The evolution of the upright posture and gait--a review and a new synthesis. Naturwissenschaften 97:241-63.

2. Ruina A, Bertram JE, Srinivasan M. 2005. A collisional model of the energetic cost of support work qualitatively explains leg sequencing in walking and galloping, pseudo-elastic leg behavior in running and the walk-to-run transition. J Theor Biol 237:170-92.

3. Craig R, Mindell J, Hirani V, (eds). Health Survey for England 2008. Volume1: Physical activity and fitness. The NHS Information Centre, 2009.

4. Kuo AD, Donelan JM, Ruina A. 2005. Energetic consequences of walking like an inverted pendulum: step-to-step transitions. Exerc Sport Sci Rev 33:88-97.

5. Jordan KM, Arden NK, Doherty M, et al. 2003. EULAR Recommendations 2003: an evidence based approach to the management of knee osteoarthritis: Report of a Task Force of the Standing Committee for International Clinical Studies Including Therapeutic Trials (ESCISIT). Ann Rheum Dis 62:1145-55.

6. Volksgezondheidenzorg.info. 2016.2 Available from: https://www.volksgezondheidenzorg.info/onderwerp/artrose/cijferscontext/huidige-situatie\#node-prevalentie-en-aantal-nieuwe-gevallen-vanartrose.

7. Andriacchi TP, Koo S, Scanlan SF. 2009. Gait mechanics influence healthy cartilage morphology and osteoarthritis of the knee. J Bone Joint Surg Am 91 Suppl 1:95101.

8. van Saase JL, van Romunde LK, Cats A, et al. 1989. Epidemiology of osteoarthritis: Zoetermeer survey. Comparison of radiological osteoarthritis in a Dutch population with that in 10 other populations. Ann Rheum Dis 48:271-80.

9. Daniel DM, Stone ML, Dobson BE, et al. 1994. Fate of the ACL-injured patient. A prospective outcome study. Am J Sports Med 22:632-44.

10. Fujisawa T, Hattori T, Takahashi K, et al. 1999. Cyclic mechanical stress induces extracellular matrix degradation in cultured chondrocytes via gene expression of matrix metalloproteinases and interleukin-1. J Biochem 125:966-75.

11. Grotle M, Hagen KB, Natvig B, et al. 2008. Obesity and osteoarthritis in knee, hip and/or hand: an epidemiological study in the general population with 10 years follow-up. BMC Musculoskelet Disord 9:132.

12. Prieto-Alhambra D, Judge A, Javaid MK, et al. 2014. Incidence and risk factors for clinically diagnosed knee, hip and hand osteoarthritis: influences of age, gender and osteoarthritis affecting other joints. Ann Rheum Dis 73:1659-64.

13. Schipplein OD, Andriacchi TP. 1991. Interaction between active and passive knee stabilizers during level walking. J Orthop Res 9:113-9.

14. Barenius B, Ponzer S, Shalabi A, et al. 2014. Increased risk of osteoarthritis after anterior cruciate ligament reconstruction: a 14-year follow-up study of a randomized controlled trial. Am J Sports Med 42:1049-57.

15. Sharma L, Hurwitz DE, Thonar EJ, et al. 1998. Knee adduction moment, serum hyaluronan level, and disease severity in medial tibiofemoral osteoarthritis. Arthritis Rheum 41:1233-40. 
16. Miyazaki T, Wada M, Kawahara H, et al. 2002. Dynamic load at baseline can predict radiographic disease progression in medial compartment knee osteoarthritis. Ann Rheum Dis 61:617-22.

17. Amin S, Luepongsak N, McGibbon CA, et al. 2004. Knee adduction moment and development of chronic knee pain in elders. Arthritis Rheum 51:371-6.

18. Lewek MD, Rudolph KS, Snyder-Mackler L. 2004. Control of frontal plane knee laxity during gait in patients with medial compartment knee osteoarthritis. Osteoarthritis Cartilage 12:745-51.

19. Messier SP, Pater M, Beavers DP, et al. 2014. Influences of alignment and obesity on knee joint loading in osteoarthritic gait. Osteoarthritis Cartilage 22:912-7.

20. Browning RC, Kram R. 2007. Effects of obesity on the biomechanics of walking at different speeds. Med Sci Sports Exerc 39:1632-41.

21. Mundermann A, Dyrby CO, Andriacchi TP. 2005. Secondary gait changes in patients with medial compartment knee osteoarthritis: increased load at the ankle, knee, and hip during walking. Arthritis Rheum 52:2835-44.

22. Landry SC, McKean KA, Hubley-Kozey CL, et al. 2007. Knee biomechanics of moderate $\mathrm{OA}$ patients measured during gait at a self-selected and fast walking speed. J Biomech 40:1754-61.

23. Thorp LE, Sumner DR, Block JA, et al. 2006. Knee joint loading differs in individuals with mild compared with moderate medial knee osteoarthritis. Arthritis Rheum 54:3842-9.

24. Aaboe J, Bliddal H, Messier SP, et al. 2011. Effects of an intensive weight loss program on knee joint loading in obese adults with knee osteoarthritis. Osteoarthritis Cartilage 19:822-8.

25. Parkes MJ, Maricar N, Lunt M, et al. 2013. Lateral wedge insoles as a conservative treatment for pain in patients with medial knee osteoarthritis: a meta-analysis. JAMA 310:722-30.

26. Bechard DJ, Birmingham TB, Zecevic AA, et al. 2012. The effect of walking poles on the knee adduction moment in patients with varus gonarthrosis. Osteoarthritis Cartilage 20:1500-6.

27. van den Noort JC, Schaffers I, Snijders J, Harlaar J. 2013. The effectiveness of voluntary modifications of gait pattern to reduce the knee adduction moment. Hum Mov Sci 32:412-24.

28. Mills K, Hunt MA, Leigh R, Ferber R. 2013. A systematic review and meta-analysis of lower limb neuromuscular alterations associated with knee osteoarthritis during level walking. Clin Biomech (Bristol, Avon) 28:713-24.

29. Meyer AJ, D'Lima DD, Besier TF, et al. 2013. Are external knee load and EMG measures accurate indicators of internal knee contact forces during gait? J Orthop Res 31:921-9.

30. Bolsterlee B, Veeger DH, Chadwick EK. 2013. Clinical applications of musculoskeletal modelling for the shoulder and upper limb. Med Biol Eng Comput 51:953-63.

31. Press OU. 2018. Ofxord English Dictionary.

32. Full RJ, Koditschek DE. 1999. Templates and anchors: neuromechanical hypotheses of legged locomotion on land. J Exp Biol 202:3325-32. 
33. Otten E. 2003. Inverse and forward dynamics: models of multi-body systems. Philos Trans R Soc Lond B Biol Sci 358:1493-500.

34. Erdemir A, McLean S, Herzog W, van den Bogert AJ. 2007. Model-based estimation of muscle forces exerted during movements. Clin Biomech (Bristol, Avon) 22:131-54.

35. Crowninshield RD, Brand RA. 1981. A physiologically based criterion of muscle force prediction in locomotion. J Biomech 14:793-801.

36. Rasmussen J, Damsgaard M, Voigt M. 2001. Muscle recruitment by the $\mathrm{min} / \mathrm{max}$ criterion -- a comparative numerical study. J Biomech 34:409-15.

37. Blemker SS, Asakawa DS, Gold GE, Delp SL. 2007. Image-based musculoskeletal modeling: applications, advances, and future opportunities. J Magn Reson Imaging 25:441-51.

38. Klein Horsman MD, Koopman HF, van der Helm FC, et al. 2007. Morphological muscle and joint parameters for musculoskeletal modelling of the lower extremity. Clin Biomech (Bristol, Avon) 22:239-47.

39. Carbone V, van der Krogt MM, Koopman HF, Verdonschot N. 2012. Sensitivity of subject-specific models to errors in musculo-skeletal geometry. J Biomech 45:2476-80.

40. Ackland DC, Lin YC, Pandy MG. 2012. Sensitivity of model predictions of muscle function to changes in moment arms and muscle-tendon properties: a MonteCarlo analysis. J Biomech 45:1463-71.

41. Navacchia A, Myers CA, Rullkoetter PJ, Shelburne KB. 2016. Prediction of In Vivo Knee Joint Loads Using a Global Probabilistic Analysis. J Biomech Eng 138:4032379.

42. Lieber RL. Skeletal muscle structure and function: implications for physical therapy and sports medicine. . Wilkins W, editor. Baltimore1992.

43. D'Souza S, Rasmussen J, Schwirtz A. 2012. Multiple linear regression to develop strength scaled equations for knee and elbow joints based on age, gender and segment mass. International Journal of Human Factors Modelling and Simulation 3:32-47.

44. Rasmussen J, de Zee M, Damsgaard M, et al, editors. A General Method for Scaling Musculo-Skeletal Models. International Symposium on Computer Simulation in Biomechanics; 2005; Ohio, USA.

45. Carbone V, Fluit R, Pellikaan P, et al. 2015. TLEM 2.0 - a comprehensive musculoskeletal geometry dataset for subject-specific modeling of lower extremity. J Biomech 48:734-41.

46. De Groote F, Van Campen A, Jonkers I, De Schutter J. 2010. Sensitivity of dynamic simulations of gait and dynamometer experiments to hill muscle model parameters of knee flexors and extensors. J Biomech 43:1876-83.

47. Amara CE, Rice CL, Koval JJ, et al. 2003. Allometric scaling of strength in an independently living population age 55-86 years. Am J Hum Biol 15:48-60.

48. Delbaere K, Bourgois J, Witvrouw EE, et al. 2003. Age-related changes in concentric and eccentric muscle strength in the lower and upper extremity: A cross-sectional study. Isokinet Exerc Sci 11:145-51. 
49. Jubrias SA, Odderson IR, Esselman PC, Conley KE. 1997. Decline in isokinetic force with age: muscle cross-sectional area and specific force. Pflugers Arch 434:24653.

50. Lindle RS, Metter EJ, Lynch NA, et al. 1997. Age and gender comparisons of muscle strength in 654 women and men aged 20-93 yr. J Appl Physiol (1985) 83:1581-7.

51. Lynch NA, Metter EJ, Lindle RS, et al. 1999. Muscle quality. I. Age-associated differences between arm and leg muscle groups. J Appl Physiol (1985) 86:188-94.

52. Handsfield GG, Meyer CH, Hart JM, et al. 2014. Relationships of 35 lower limb muscles to height and body mass quantified using MRI. J Biomech 47:631-8.

53. Bolsterlee B, Vardy AN, van der Helm FC, Veeger HE. 2015. The effect of scaling physiological cross-sectional area on musculoskeletal model predictions. J Biomech 48:1760-8. 


\section{Obese knee OA patients have increased knee adduction moments during gait}

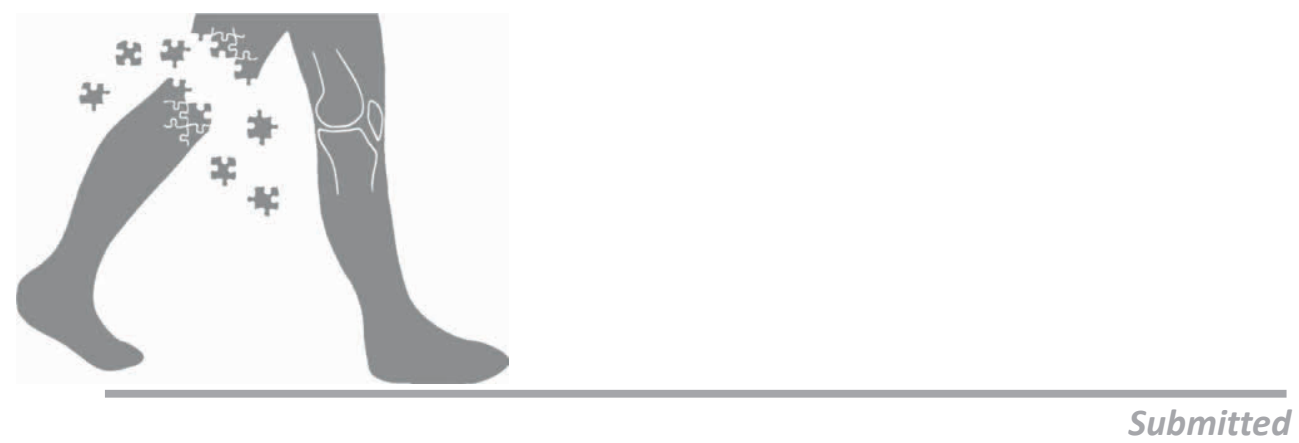

Pieter Oomen \& Loek Verlaan, Twan Schmitz, Wai-Yan Liu, Marloes Peters, Pieter Emans, Lodewijk van Rhijn, Maarten Drost, Kenneth Meijer 


\section{Abstract}

Background Medial knee osteoarthritis (OA) is a common cause of immobility and is characterized by pain and limitation of daily activities. The external knee adduction moment (EKAM) is related to the onset and progression of knee OA and can be estimated by gait analysis. Furthermore, body weight is an important risk factor for the development of knee OA and is also related to EKAM. Therefore, this study aims to evaluate the independent effect of knee OA, bodyweight and walking speed to EKAM.

Methods This case-control study included 15 obese knee OA patients, 18 lean knee OA patients and 22 lean controls. All participants performed gait trials at self-selected and a standardised walking speed $\left(1.5 \mathrm{~m} \cdot \mathrm{s}^{-1}\right)$. MRI was performed to evaluate severity of knee cartilage degeneration. Standard gait analysis was used to calculate three-dimensional lower extremity joint kinematics and kinetics.

Results At self-selected speed obese knee OA patients walked slower and EKAM was significantly increased compared to the lean groups. Standardised speed was faster compared to self-selected speed in all groups and resulted in a larger difference in EKAM between obese patients and the lean groups. The results of the lean OA group showed no statistical significant differences in maximal and total EKAM loading compared to the weight-matched controls.

Discussion The results of this study indicate that weight in combination with OA has a more prominent effect on EKAM compared to the presence of knee OA alone. In order to reduce peak knee loading patients, and especially obese patients, walk slower and implement smaller steps. 


\section{Introduction}

Osteoarthritis (OA) is a common musculoskeletal disease, which is characterized by degradation of cartilage and can occur in any joint. According to the World Health Organization, osteoarthritis has become the fourth leading cause of immobility. ${ }^{1,2}$ The knee joint is most commonly affected and it is clinically characterized by pain, limitation of movement, tenderness, and local inflammation. ${ }^{3}$ Age, gender, and weight are known as contributors to the progression of knee OA. ${ }^{4}$ Prevalence of knee OA increases with age, especially in people aged 50 years and older and this effect is elevated in females. ${ }^{5}$ Furthermore, obese subjects with a BMI between 30 and $35 \mathrm{~kg} / \mathrm{m}^{2}$ have almost four times the risk of developing knee OA compared to subjects with a BMI below $25 \mathrm{~kg} / \mathrm{m}^{2}$. 3,6-11 Other risk factors for knee OA include muscle weakness, gait abnormalities and physical inactivity. $^{3,8}$

In most knee OA patients the medial side is affected. ${ }^{12}$ Due to lateral laxity and varus alignment of the knee joint, the medial compartment transfers substantially higher loads compared to the lateral compartment. ${ }^{10}$ This imbalance in cartilage homeostasis could potentially result in deterioration of the cartilage tissue. ${ }^{13}$ Especially during walking, the medial compartment of the knee is repeatedly exposed to high joint contact forces. Therefore, the evaluation of knee mechanics during walking is of importance to understand the development of knee OA. ${ }^{14}$ Several studies have examined the external knee adduction moment (EKAM) in patients with knee OA. ${ }^{15-18} \mathrm{~A}$ high EKAM is related to the onset and progression of knee OA. ${ }^{14,19}$ Especially the peak load in early stance and the cumulative load of a full gait cycle are strong predictors of the presence, severity and rate of progression of medial compartment knee OA. ${ }^{8,20}$ However, we suggest that these studies might overestimate the effect of knee OA on EKAM, since groups are not completely comparable in body weight. For example, Landry et al., Mundermann et al., and Thorp et al. included groups of patients with unequal body weight or severity. ${ }^{8,17,20}$ Body weight is an important factor contributing to joint loading; it has been shown that obese subjects have an increased EKAM compared to normal-weighted controls. ${ }^{21}$ Furthermore, systemic factors from adipose tissue could accelerate knee cartilage degeneration in obese subjects. ${ }^{22,23}$ Therefore, the current study aims to carefully include specific groups of patients for the independent effect of knee OA and body weight on EKAM.

In order to reduce high joint loading, obese subjects and knee OA patients demonstrate similar adaptations in their walking pattern. ${ }^{21}$ These adaptations are strategies to redirect or decrease the amount of ground reaction force, or to influence alignment of the knee joint. For example, reducing walking speed is a comprehensive strategy to decrease ground 
reaction force. It has been shown that especially patients with mild knee OA benefit from reducing walking speed in order to reduce the maximal EKAM. ${ }^{24}$ In addition, obese subjects also use slower walking speeds to decrease joint loading. ${ }^{21,25}$ On the other hand, toe-out gait is a strategy to influence the alignment of the knee joint. Previous studies showed that a high toe-out gait was able to decrease EKAM during stance. ${ }^{26,27} \mathrm{~A}$ greater toe-out angle seems to shift the load closer to the centre of the knee joint, resulting in lower EKAM values. Therefore, toe-out angle should be taken into account, considering EKAM in patients with knee OA.

The purpose of this study was to evaluate the independent effect of knee OA and body weight on EKAM. Therefore, we aim to carefully include three groups of female subjects: lean OA patients, weight matched healthy control subjects and obese knee OA patients. Our secondary aim is to evaluate the effect of walking speed and toe-out angle that are associated with the EKAM.

\section{Materials and Methods}

\section{Study population}

This case control study (Level of Evidence: III) was approved by the Maastricht University Medical Ethical Committee. Three groups were included consisting of an obese knee OA group (BMI: $30-40 \mathrm{~kg} \cdot \mathrm{m}^{-2}$ ), a lean knee OA group (BMI: $20-25 \mathrm{~kg} \cdot \mathrm{m}^{-2}$ ) and a healthy control group (BMI: $20-25 \mathrm{~kg} \cdot \mathrm{m}^{-2}$ ). Only women with an age between 50 and 65 years were included. Since knee OA is more common in women and appears often after the age of 50 years. The cut-off point at the age of 65 years was used because of higher risks of comorbidities in these patients. Knee OA patients were recruited by the 'Artrose Kliniek' Maastricht at the Maastricht University Medical Center (MUMC+). Healthy subjects were recruited through the department of Human Movement Sciences, the department of Physical Therapy (MUMC+) and through local physical therapy clinics in Maastricht.

Clinical exclusion criteria were any inflammatory arthritis, trauma, OA at any other joint including tibiofemoral $\mathrm{OA}$ on the lateral site, patellofemoral $\mathrm{OA}$, anterior cruciate ligament injury, medial and collateral ligament injury, psychiatric illness (patients are excluded on this point when such a diagnosis is present in the patient's medical file according to the DSM classification criteria for psychiatric illnesses). Healthy subjects were included when they were non-obese (BMI: 20-25 $\mathrm{kg} \cdot \mathrm{m}^{-2}$ ), did not have knee OA (according to the 
American College of Rheumatology classification criteria) and did not meet any of the exclusion criteria.

\section{Radiological imaging}

Roentgenography and MRI of the knee was performed in order to evaluate the knee cartilage. An X-ray was used for screening purpose; patients were included when they had a Kellgren-Lawrence-knee score between 1 and 3 at the medial tibiofemoral site. Two orthopaedic surgeons assessed the x-rays individually.

All subjects received an MRI of the knee joint. The knee joints were analysed using a 3T Philips Intera scanner (Philips Medical Systems, Best, The Netherlands). Scanning sequences included fat saturated proton density-weighted turbo spin echo.

The severity of knee OA was evaluated based on the MRI Osteoarthritis Knee Score (MOAKS). ${ }^{28}$ In this semi-quantitative scoring system the articular cartilage of the knee was scored for 14 regions. The 14 sub-regions included the patella, the femur and the tibia: the medial and lateral patella; the medial and lateral trochlea, the medial and lateral central femur and the medial and lateral posterior femur; the medial and lateral anterior tibia, the medial and lateral central tibia and the medial and lateral posterior tibia. The articular cartilage score provided separate scores for the size and depth of cartilage damage in each of the sub-regions. The size of any cartilage loss (partial and full-thickness loss) as well as the size of full-thickness cartilage loss was scored as a \% of surface area as related to the size of each individual region as either 0 (none), 1 ( $<10 \%$ of region of cartilage surface area), 2 (10-75\% of region of cartilage surface area), 3 ( $>75 \%$ of region of cartilage surface area) or $\mathrm{N}$ (no score possible).

\section{Measurements}

Gait analysis took place at the Motion Laboratory of Maastricht University. A three dimensional motion capture system (Vicon 6 MX3 and 2 T20 cameras, Oxford Metric, UK) and a force platform $(9081 E, 1000 \mathrm{~Hz}$, Kistler Instruments $A G$, Winethur, Switzerland) were used simultaneously within the Nexus software. Sixteen retroreflective markers were placed on the subject's lower extremities in order to use the 3D motion capture system according as defined by the plug-in-gait marker placement manual: both sides on the spina iliaca anterior superior, spina iliaca posterior superior, thigh (the line between the trochantor major and lateral epicondyle of femur), lateral epicondyle of femur, lower leg (the line between the lateral epicondyle of femur and lateral malleolus), lateral malleolus, tuber calcanei and art. metatarsophalangeale II. Inverse dynamics was performed using ground reaction forces and motion analysis, in order to calculate joint torques. 
Furthermore, anthropometrical data such as height, mass, leg length, knee and ankle width were obtained.

The subjects walked barefooted during the gait analysis. Gait analysis was performed at self-selected walking speed and a standardised walking speed of approximately $1.5 \mathrm{~m} \cdot \mathrm{s}^{-1}$ (trials were acceptable between $1.4 \mathrm{~m} \cdot \mathrm{s}^{-1}$ and $1.6 \mathrm{~m} \cdot \mathrm{s}^{-1}$ ). Subject where instructed to walk without aiming for the force platform in such a way that the fifth step landed completely on the force platform (the affected leg in the OA groups or dominant leg in the control group) and they continued to walk for at least three steps after hitting the force platform. Walking speed was monitored by two electronic timing gates. Per subject five correct trials per speed condition were obtained.

\section{Data analysis}

Three dimensional ankle, knee and hip joint angles and torques were processed via the dynamic pipeline of VICON Nexus software (version 1.8.5). Subsequent data analysis was performed in Microsoft Excel 2013 and IBM SPSS statistics 23. One-way analysis of variance (ANOVA) was used to detect an overall significant difference between groups. In addition, post hoc Bonferroni tests were performed for multiple comparisons. The kinetic and kinematic data of the fifth step of each trial at both self-selected and standardised speed were normalized in $0-100 \%$ of stance phase with intervals of $0.5 \%$. Our primary outcome measure was the magnitude of EKAM. Therefore, the early and late EKAM peaks were obtained for each trial. Furthermore, the dip between de peaks was determined and the EKAM impulse was calculated by numerical integration.

\section{Statistics}

Significance in anthropometric data between groups was calculated using independent samples t-test. Averages over the different trials per subject were calculated for knee, ankle, foot progression, and hip angles all in $x-y-z$ direction, EKAM and flexion-extension moment. Data per group is presented as mean \pm standard deviation. Standard speed and self-selected speed were compared by paired samples T-test. Differences in EKAM pattern between groups were tested by one-way ANOVA using Bonferroni correction for multiple comparisons. Two-way repeated measures ANOVA was used to examine speed, group and their interaction, using LSD correction for multiple comparisons. Finally, toe-out angle and hip rotation angle were tested for their correlation with EKAM. 


\section{Results}

\section{Anthropometrical and spatiotemporal characteristics}

In total 55 subjects were included in three groups (Table 2.1). No statistical differences were found for age, height, weight or BMI between the lean OA and control group. The obese OA group was significantly shorter and heavier compared to the lean groups. The Kellgren-Lawrence grade and MOAKS indicated no differences in severity of knee OA between the lean and obese knee OA group.

At self-selected pace obese OA patients walked on average slower than lean OA and control subjects (respectively. 1.11, 1.28, $1.34 \mathrm{~m} \cdot \mathrm{s}^{-1}$ ). All groups walked slower at selfselected speed compared to standardised walking speed $\left(1.5 \mathrm{~m} \cdot \mathrm{s}^{-1}\right)$. Obese patients walked with significantly shorter strides at both speeds $(-0.08 \mathrm{~m})$; and increased stride frequency with $7 \%$ at standardised speed compared to healthy subjects.

Table 2.1 Anthropometric and spatiotemporal data between groups. Data is displayed as mean \pm standard deviation; *: significant difference compared to Control group $(p<0.05)$; \#: significant difference compared to Lean OA group ( $p<0.05)$. BMI: Body Mass Index; KL: Kellgren-Lawrence; ${ }^{\dagger}$ Inter observer reliability: $\mathrm{R}^{2}$ Lean OA: 0.905, $\mathrm{R}^{2}$ Obese OA: 0.739.

\begin{tabular}{|c|c|c|c|c|}
\hline & Group & $\begin{array}{l}\text { Healthy } \\
\text { subjects }\end{array}$ & $\begin{array}{l}\text { Lean knee } \\
\text { OA patients }\end{array}$ & $\begin{array}{l}\text { Obese knee } \\
\text { OA patients }\end{array}$ \\
\hline & Number & 22 & 18 & 15 \\
\hline & Height $(\mathrm{cm})$ & $166 \pm 4.2$ & $166 \pm 5.4$ & $161 \pm 5.4^{* \#}$ \\
\hline & Weight (kg) & $62 \pm 5.9$ & $65 \pm 7.5$ & $84 \pm 11.7^{* \#}$ \\
\hline & $\mathrm{BMI}\left(\mathrm{kg} \cdot \mathrm{m}^{-2}\right)$ & $22.7 \pm 1.8$ & $23.6 \pm 2.2$ & $32.6 \pm 3.8^{*^{\#}}$ \\
\hline & Age (years) & $58 \pm 4.3$ & $59 \pm 3.0$ & $58 \pm 5.1$ \\
\hline & $\mathrm{KL} \mathrm{grade}^{+}$ & $0: 22$ & $1: 3 ; 2: 10 ; 3: 5^{*}$ & $1: 0 ; 2: 9 ; 3: 6^{*}$ \\
\hline & $\begin{array}{l}\text { MOAKS } \\
\text { (score/items) }\end{array}$ & $0.50 \pm 0.09$ & $0.94 \pm 0.19 *$ & $1.03 \pm 0.16^{*}$ \\
\hline \multirow{4}{*}{$\begin{array}{c}\text { Self-selected } \\
\text { speed }\end{array}$} & Speed $(\mathrm{m} / \mathrm{s})$ & $1.34 \pm 0.15$ & $1.28 \pm 0.14$ & $1.11 \pm 0.14^{* \#}$ \\
\hline & Cadence (hz) & $1.98 \pm 0.15$ & $2.00 \pm 0.24$ & $1.91 \pm 0.19$ \\
\hline & Step length (m) & $0.67 \pm 0.05$ & $0.64 \pm 0.06$ & $0.59 \pm 0.06^{* \#}$ \\
\hline & Stepwidth (mm) & $167 \pm 26.3$ & $169 \pm 27.2$ & $196 \pm 31.0$ *\# \\
\hline \multirow{4}{*}{$\begin{array}{c}\text { Standardized } \\
\text { speed }\end{array}$} & Speed (m/s) & $1.51 \pm 0.05$ & $1.52 \pm 0.09$ & $1.48 \pm 0.07$ \\
\hline & Cadence (hz) & $2.13 \pm 0.12$ & $2.18 \pm 0.18$ & $2.28 \pm 0.14^{*}$ \\
\hline & Step length (m) & $0.71 \pm 0.05$ & $0.70 \pm 0.04$ & $0.65 \pm 0.05^{* \#}$ \\
\hline & Stepwidth (mm) & $171 \pm 27.6$ & $175 \pm 23.6$ & $183 \pm 30.8$ \\
\hline
\end{tabular}



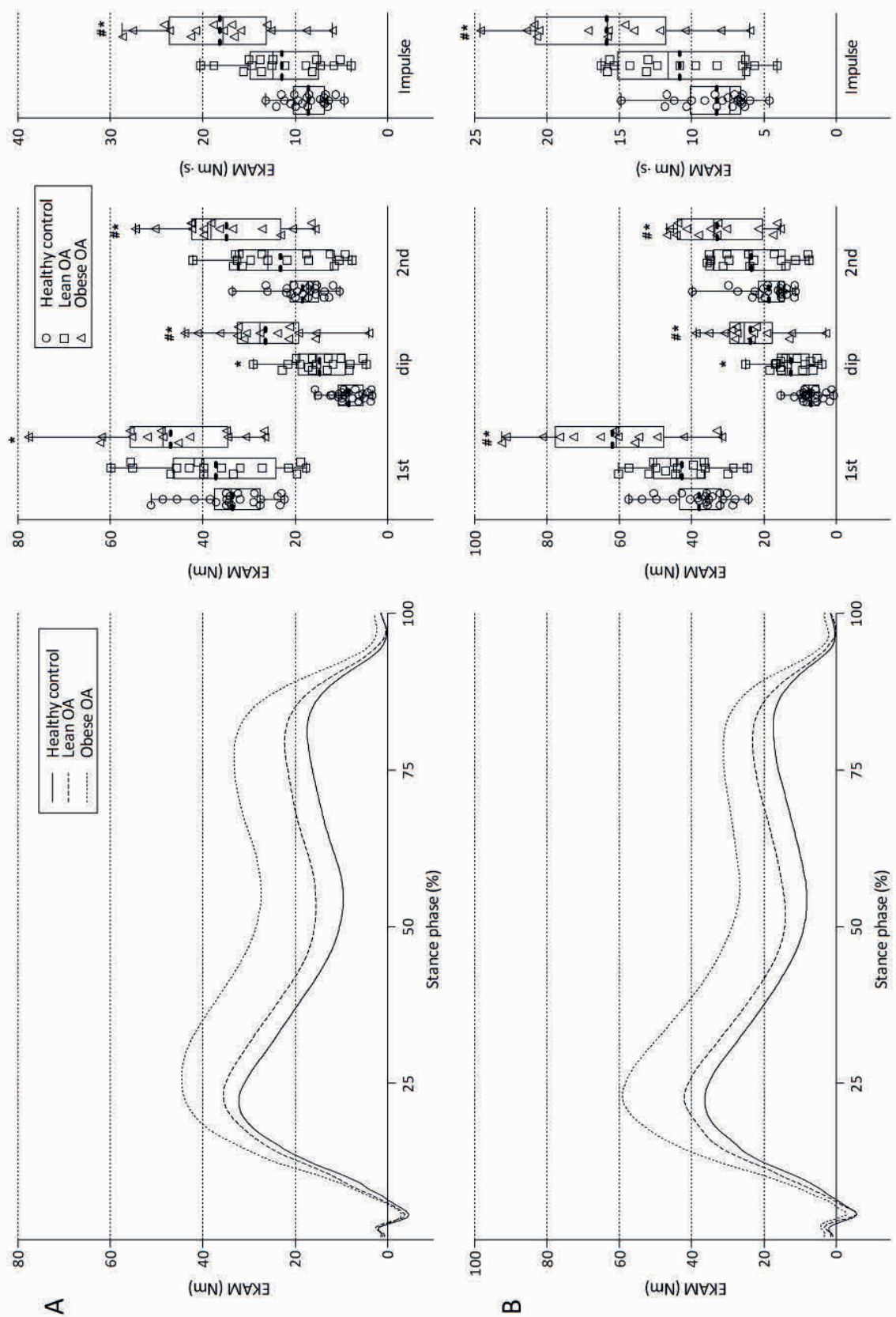

Figure 2.1 External knee adduction moment during $100 \%$ of stance phase divided per study group. Figures show mean curve per group (left); a box plot of first peak, dip and second peak (middle); and a box plot of impulse (right). Raw EKAM data is presented in A) at self-selected speed; and B) at standardised speed $(1.5 \mathrm{~m} / \mathrm{s})$. 

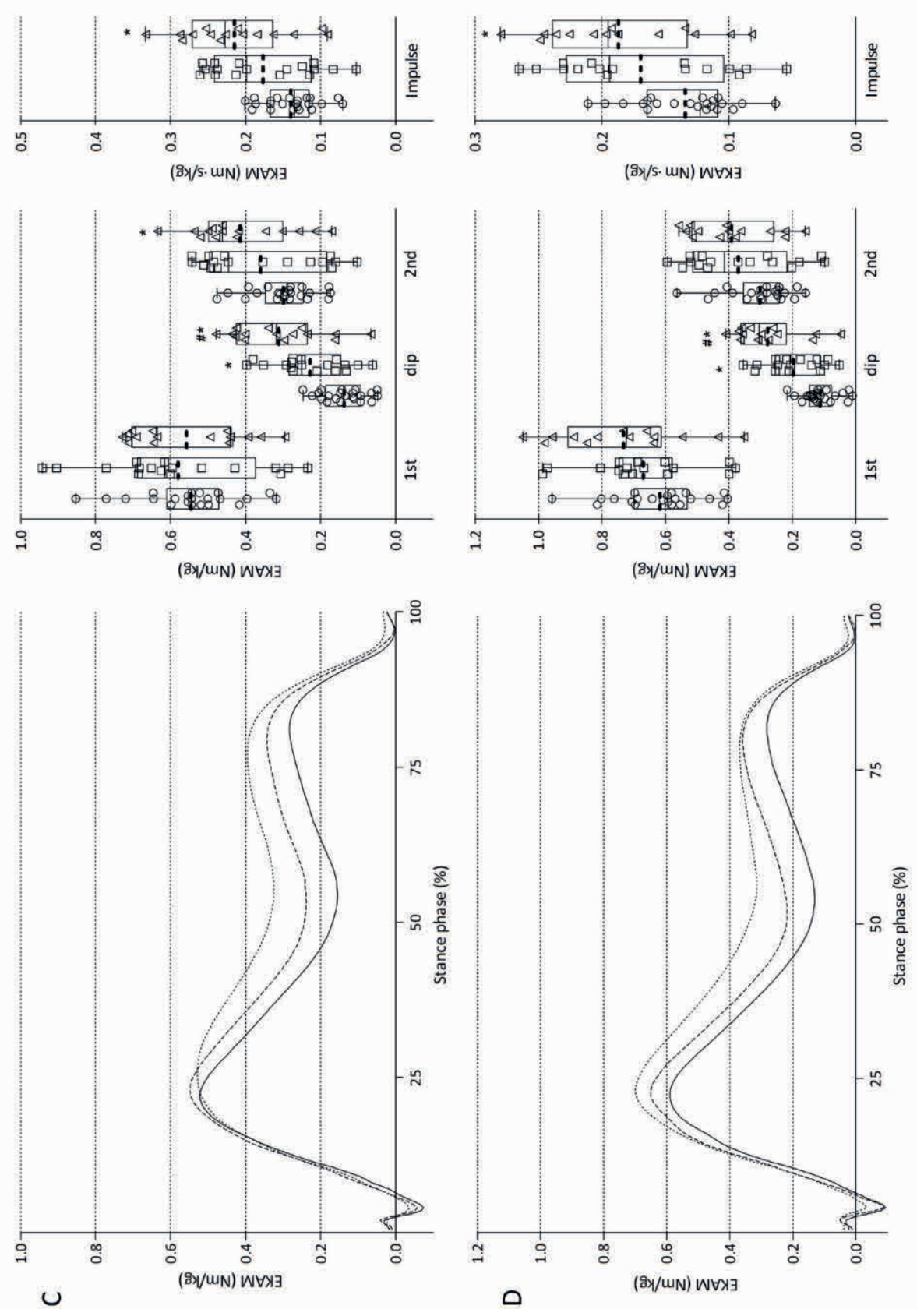

EKAM data normalized for body mass is presented in C) at self-selected speed; and D) at standardised speed $(1.5 \mathrm{~m} / \mathrm{s})$. *: significant difference compared to Control group $(p<0.05)$; \#: significant difference compared to Lean OA group ( $p<0.05)$. Boxplots show quartiles and individual mean, group mean is indicated by dotted line through boxplot. 


\section{EKAM between groups}

At self-selected speed, the first peak of EKAM during early stance was $40 \%$ higher for the obese knee OA group compared to healthy controls ( $p=0.004$ ) (Figure $2.1 \mathrm{~A}$ ). Moreover, no significant differences were found between the lean groups or between OA groups for the first peak of EKAM at self-selected speed. The second peak of EKAM showed significant differences between the obese OA group compared to the lean OA group and healthy control group (resp. $p=0.002$ and $p<0.001$ ), but no differences were found between the lean groups at self-selected speed. Furthermore, the mean EKAM impulse was increased by $59 \%$ for the obese group compared to the lean OA group at self-selected speed $(p<0.001)$. No statistical differences for EKAM impulse were found between the lean groups. The dip of EKAM at mid stance between the first and second peak was significant higher for the lean OA group compared to the healthy controls (76\%), moreover, a significant incremental effect for the obese OA group was found (75\%).

Walking at a faster standardised pace $\left(1.5 \mathrm{~m} \cdot \mathrm{s}^{-1}\right)$ resulted in similar significant differences compared to self-selected speed (Figure $2.1 \mathrm{~B}$ ). However, at the standardised walking speed we found the first peak of EKAM also statistically higher for obese OA compared to the lean OA group $(p<0.001)$.

Normalizing EKAM for body mass effectively removed the differences in the first peak of EKAM between the three groups at both walking speeds (Figure $2.1 \mathrm{C}$ and D). Furthermore, EKAM impulse and second peak were not significant different between OA groups after normalization for body mass.

\section{Correlations of EKAM to kinematic parameters}

Hip rotation was related to EKAM in the obese knee OA group at standard speed only; $1^{\circ}$ hip external rotation decreased EKAM impulse by $7.2 \mathrm{Nmm} \cdot \mathrm{s} / \mathrm{kg} \mathrm{R}^{2}=0.33(p=0.029)$. The other groups did not show correlations between EKAM and hip rotation. Furthermore, no correlations were found in any group between toe-out angle and EKAM at comfortable or standard speed $(p>0.1)$. 


\section{Discussion}

The primary aim of this study was to evaluate whether knee OA or obesity has a more prominent role in the magnitude of EKAM. Therefore we evaluated walking mechanics between clearly defined groups at different walking speeds. Our results showed overall significantly higher EKAM parameters for obese patients compared to lean OA patients and lean healthy controls. At higher walking speeds this difference was even more pronounced. Lean OA patients showed no significant differences in EKAM peaks and total impulse compared to weight matched healthy controls. Furthermore, walking speed did not influence EKAM significance between weight matched subjects. Therefore, we suggest that body weight has a more prominent role on EKAM compared to the presence of knee OA.

An elevated EKAM was associated with the onset and progression of knee OA. ${ }^{13,29,30}$ However, our results show that impulse and peaks of EKAM were not found statistically different between knee OA patients and weight matched healthy volunteers. Interestingly, our results on body mass normalized EKAM found significant higher EKAM impulse and second peaks in obese patients compared to healthy controls. This indicates that obesity remains an important determinant of EKAM, even if EKAM values were normalized for body mass. Current literature acknowledges the importance of body mass in relation to EKAM. ${ }^{31,32}$ Moreover, interventions targeting weight reduction show up to $12 \%$ reduced EKAM. $^{33,34}$

Spatiotemporal characteristics should be taken into account considering EKAM. First, walking speed is an important characteristic that influences EKAM; decreasing walking speed can substantially reduce EKAM. ${ }^{24,35}$ Our results show a significant decrease of 6.3$7.2 \%$ of EKAM at self-selected speed compared to standard speed in all groups. Second, obese OA patients implemented significantly smaller step length at both speeds, in order to reduce peak loading at the knee joint. In addition, they have the slowest self-selected pace and increase mainly stride frequency at standardised speed. These smaller steps decrease vertical acceleration, which decreases peak loading of EKAM. On the other hand, this strategy increased the dip of EKAM during mid stance.

A different strategy to decrease joint loading is to increase toe out angle. However, literature is not conclusive about toe out angle as possible strategy to decrease EKAM. ${ }^{36-39}$ Our results showed no correlation between toe-out angle and EKAM. Furthermore, hip exorotation seemed to lower total EKAM loading in the obese knee OA group; however, there were no correlations in the other groups. Van der Noort et al suggested an increased 
EKAM in early stance phase caused by hip exorotation, although no beneficial effects over the entire stance phase were found. ${ }^{36}$

In the present study both patients and healthy volunteers received MRI for MOAKS determination. Hence, healthy cartilage was confirmed in the control group; and obese and lean knee OA patients did not differ in cartilage degeneration. Taking the number of participants into account we were unable to use stratification for severity. Severity of knee OA was shown to be positively correlated to the magnitude of EKAM. ${ }^{8}$ Interestingly, in the aforementioned study of Mundermann et al. severe OA patients had an increased body mass $(+10 \mathrm{~kg})$ compared to the less severe patients. ${ }^{8}$ Our results suggest that body mass might contribute to this difference.

A limitation to our study design is the lack of a fourth group of weight matched obese control subjects. Therefore, we cannot determine the individual effect of obesity on EKAM. Literature already provided evidence that body weight without knee OA contributed significantly to a high EKAM magnitude. ${ }^{21}$ Nevertheless, our results should be taken carefully when interested in the sole effect of obesity on EKAM.

A second limitation is that we measured lower extremities only. Hence, we were unable to determine trunk sway. Literature has shown that trunk sway was able to decrease EKAM up to $65 \%{ }^{40}$ Future studies should take trunk sway into account in order to find possible gait adaptations.

In conclusion, this study included clearly defined groups in order to evaluate the effect of knee OA, Obesity and walking speed on EKAM. The results show that obesity combined with knee OA had more effect than knee OA pathology alone on EKAM peaks and impulse. Moreover, differences in EKAM were primarily found between the obese knee OA group and the lean groups and secondarily between knee OA patients and weight matched healthy subjects, which implies that knee OA pathology alone is not the major determinant of EKAM. The dip of EKAM during mid stance might be an interesting parameter in future research for knee OA pathology. The toe-out angle, hip endo/exorotation and speed did not correlate with EKAM in any group. Finally, in the evaluation of EKAM, spatiotemporal characteristics (e.g. walking speed and step length) should be taken into account. 


\section{References}

1. Poos MJJC, Gommer AM. 2007. Artrose: Prevalentie en incidentie naar leeftijd en geslacht. Available from: http://www.nationaalkomaps.nl.

2. Symmons D, Mathers C, Pfleger B. 2000. The global burden of rheumatoid arthritis in the year 2000. Available from: http://www3.who.int/whosis/menu.cfm?path=evidence,burden,burden_gbd2000d ocs\&language =english.

3. Jordan KM, Arden NK, Doherty M, et al. 2003. EULAR Recommendations 2003: an evidence based approach to the management of knee osteoarthritis: Report of a Task Force of the Standing Committee for International Clinical Studies Including Therapeutic Trials (ESCISIT). Ann Rheum Dis 62:1145-55.

4. Zhang W, Doherty M, Peat G, et al. 2010. EULAR evidence-based recommendations for the diagnosis of knee osteoarthritis. Ann Rheum Dis 69:483-9.

5. Arden N, Nevitt MC. 2006. Osteoarthritis: epidemiology. Best Pract Res Clin Rheumatol 20:3-25.

6. Anderson JJ, Felson DT. 1988. Factors associated with osteoarthritis of the knee in the first national Health and Nutrition Examination Survey (HANES I). Evidence for an association with overweight, race, and physical demands of work. Am J Epidemiol 128:179-89.

7. Coggon D, Reading I, Croft P, et al. 2001. Knee osteoarthritis and obesity. Int J Obes Relat Metab Disord 25:622-7.

8. Mundermann A, Dyrby CO, Andriacchi TP. 2005. Secondary gait changes in patients with medial compartment knee osteoarthritis: increased load at the ankle, knee, and hip during walking. Arthritis Rheum 52:2835-44.

9. Powell A, Teichtahl AJ, Wluka AE, Cicuttini FM. 2005. Obesity: a preventable risk factor for large joint osteoarthritis which may act through biomechanical factors. $\mathrm{Br}$ J Sports Med 39:4-5.

10. Schipplein OD, Andriacchi TP. 1991. Interaction between active and passive knee stabilizers during level walking. J Orthop Res 9:113-9.

11. Wearing SC, Hennig EM, Byrne NM, et al. 2006. Musculoskeletal disorders associated with obesity: a biomechanical perspective. Obes Rev 7:239-50.

12. Cicuttini F, Wluka A, Hankin J, Wang Y. 2004. Longitudinal study of the relationship between knee angle and tibiofemoral cartilage volume in subjects with knee osteoarthritis. Rheumatology (Oxford) 43:321-4.

13. Andriacchi TP, Koo S, Scanlan SF. 2009. Gait mechanics influence healthy cartilage morphology and osteoarthritis of the knee. J Bone Joint Surg Am 91 Suppl 1:95-101.

14. Andriacchi TP, Mundermann A, Smith RL, et al. 2004. A framework for the in vivo pathomechanics of osteoarthritis at the knee. Ann Biomed Eng 32:447-57.

15. Baliunas AJ, Hurwitz DE, Ryals $A B$, et al. 2002. Increased knee joint loads during walking are present in subjects with knee osteoarthritis. Osteoarthritis Cartilage 10:573-9.

16. Kaufman KR, Hughes C, Morrey BF, et al. 2001. Gait characteristics of patients with knee osteoarthritis. J Biomech 34:907-15. 
17. Landry SC, McKean KA, Hubley-Kozey CL, et al. 2007. Knee biomechanics of moderate $O A$ patients measured during gait at a self-selected and fast walking speed. J Biomech 40:1754-61.

18. Sharma L, Hurwitz DE, Thonar EJ, et al. 1998. Knee adduction moment, serum hyaluronan level, and disease severity in medial tibiofemoral osteoarthritis. Arthritis Rheum 41:1233-40.

19. Miyazaki T, Wada M, Kawahara H, et al. 2002. Dynamic load at baseline can predict radiographic disease progression in medial compartment knee osteoarthritis. Ann Rheum Dis 61:617-22.

20. Thorp LE, Sumner DR, Block JA, et al. 2006. Knee joint loading differs in individuals with mild compared with moderate medial knee osteoarthritis. Arthritis Rheum 54:3842-9.

21. Browning RC, Kram R. 2007. Effects of obesity on the biomechanics of walking at different speeds. Med Sci Sports Exerc 39:1632-41.

22. Trayhurn P, Wood IS. 2005. Signalling role of adipose tissue: adipokines and inflammation in obesity. Biochem Soc Trans 33:1078-81.

23. Bao JP, Jiang LF, Chen WP, et al. 2014. Expression of vaspin in the joint and the levels in the serum and synovial fluid of patients with osteoarthritis. Int J Clin Exp Med 7:3447-53.

24. Mundermann A, Dyrby CO, Hurwitz DE, et al. 2004. Potential strategies to reduce medial compartment loading in patients with knee osteoarthritis of varying severity: reduced walking speed. Arthritis Rheum 50:1172-8.

25. Spyropoulos P, Pisciotta JC, Pavlou KN, et al. 1991. Biomechanical gait analysis in obese men. Arch Phys Med Rehabil 72:1065-70.

26. Cho Y, Ko Y, Lee W. 2015. Relationships among foot position, lower limb alignment, and knee adduction moment in patients with degenerative knee osteoarthritis. J Phys Ther Sci 27:265-8.

27. Ogaya S, Naito H, Iwata A, et al. 2015. Toe-Out Gait Decreases the Second Peak of the Medial Knee Contact Force. J Appl Biomech 31:275-80.

28. Hunter DJ. 2011. Osteoarthritis. Best Pract Res Clin Rheumatol 25:801-14.

29. Amin S, Luepongsak N, McGibbon CA, et al. 2004. Knee adduction moment and development of chronic knee pain in elders. Arthritis Rheum 51:371-6.

30. Schmitz A, Noehren B. 2014. What predicts the first peak of the knee adduction moment? Knee 21:1077-83.

31. Messier SP, Pater M, Beavers DP, et al. 2014. Influences of alignment and obesity on knee joint loading in osteoarthritic gait. Osteoarthritis Cartilage 22:912-7.

32. Moyer RF, Birmingham TB, Chesworth BM, et al. 2010. Alignment, body mass and their interaction on dynamic knee joint load in patients with knee osteoarthritis. Osteoarthritis Cartilage 18:888-93.

33. Aaboe J, Bliddal H, Messier SP, et al. 2011. Effects of an intensive weight loss program on knee joint loading in obese adults with knee osteoarthritis. Osteoarthritis Cartilage 19:822-8.

34. Harding GT, Hubley-Kozey CL, Dunbar MJ, et al. 2012. Body mass index affects knee joint mechanics during gait differently with and without moderate knee osteoarthritis. Osteoarthritis Cartilage 20:1234-42. 
35. Robbins SM, Maly MR. 2009. The effect of gait speed on the knee adduction moment depends on waveform summary measures. Gait Posture 30:543-6.

36. van den Noort JC, Schaffers I, Snijders J, Harlaar J. 2013. The effectiveness of voluntary modifications of gait pattern to reduce the knee adduction moment. Hum Mov Sci 32:412-24.

37. Jenkyn TR, Hunt MA, Jones IC, et al. 2008. Toe-out gait in patients with knee osteoarthritis partially transforms external knee adduction moment into flexion moment during early stance phase of gait: a tri-planar kinetic mechanism. J Biomech 41:276-83.

38. Blazek K, Asay JL, Erhart-Hledik J, Andriacchi T. 2013. Adduction moment increases with age in healthy obese individuals. J Orthop Res 31:1414-22.

39. Uhlrich SD, Silder A, Beaupre GS, et al. 2018. Subject-specific toe-in or toe-out gait modifications reduce the larger knee adduction moment peak more than a nonpersonalized approach. J Biomech 66:103-10.

40. Mundermann A, Asay JL, Mundermann L, Andriacchi TP. 2008. Implications of increased medio-lateral trunk sway for ambulatory mechanics. J Biomech 41:16570 . 


\section{The mediolateral component of knee joint loading as predicted by musculoskeletal models is increased in patients with mild knee osteoarthritis}

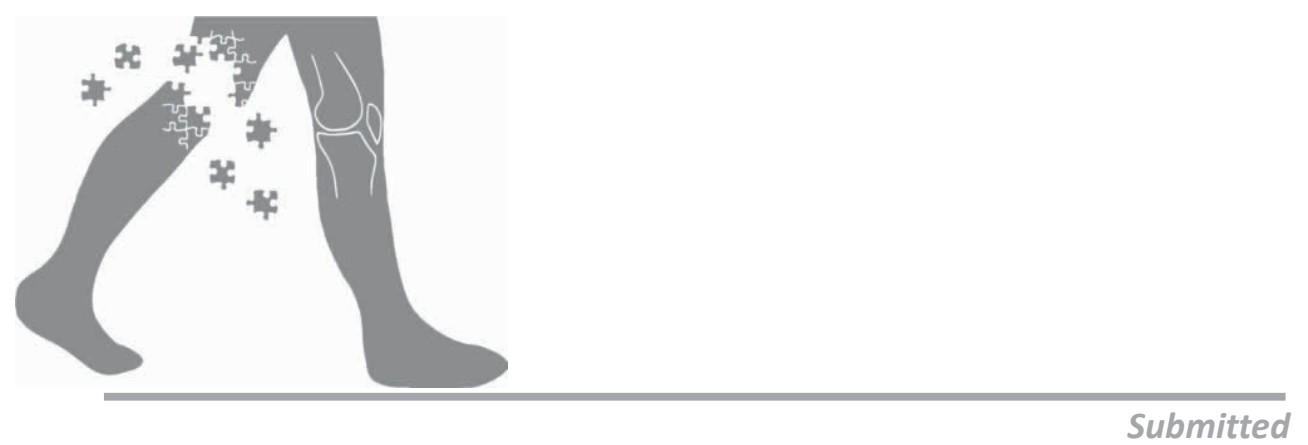

Pieter Oomen, Roberto Garcia van der Westen, Wai-Yan Liu, Lodewijk van Rhijn, Pieter Emans, Maarten Drost, Kenneth Meijer 


\section{Chapter 3}

\section{Abstract}

Background Understanding the differences in walking mechanics between patients with knee osteoarthritis and healthy subjects reveals possible strategies in managing early onset knee osteoarthritis. Therefore, this study investigated the mediolateral component of the joint reaction force at the knee, predicted by a musculoskeletal model, in selfselected and standard speed trials.

Methods In this case-control study, ten healthy subjects and ten patients with knee osteoarthritis performed gait trials. Afterwards, the motion capture was used as input for the musculoskeletal model in order to calculate mediolateral knee loading.

Results The first peak and area under the curve of the calculated mediolateral force was increased in both conditions for the knee osteoarthritis group (+37-45\%). The second peak of the calculated mediolateral force was only increased at standard speed for knee osteoarthritis patients ( $+25 \%)$. The external knee adduction moment, showed a significant increase only at standard speed for the second peak (osteoarthritis: $+44 \%$ ) and area under the curve (osteoarthritis: $+40 \%$ ).

Conclusion This study showed that musculoskeletal models have the potential to give more information on internal knee loading in addition to traditional gait analysis.

Furthermore, this study showed differences in the mediolateral component of internal knee forces derived from musculoskeletal models between a group of healthy subjects and a group of patients with mild osteoarthritis at multiple walking speeds. 


\section{Introduction}

Tibiofemoral knee osteoarthritis (knee OA) is the most common cause of pain and disability in the elderly. ${ }^{1}$ In particular, women above the age of 50 are prone to develop cartilage defects in the knee. ${ }^{2}$ Mechanical risk factors and abnormal cartilage metabolism are responsible for the initiation and progression of knee OA. ${ }^{3}$ To improve diagnosis and treatment it is important to understand the development of the pathological mechanics of knee OA.

It has been shown that patients with knee OA experience high internal joint reaction forces. ${ }^{4}$ The internal joint reaction force consists of a compression component in proximodistal direction; and shear components in anteroposterior and mediolateral direction. These components of the internal joint reaction force are difficult to quantify, since many structures (e.g. muscles and ligaments) influence the joint loading. ${ }^{5}$ Therefore, studies often use the external knee adduction moment (EKAM), which is related to the ratio of medial and lateral compressive forces, as a proxy for the internal knee forces. Several studies have shown that EKAM is associated with the severity of knee OA. ${ }^{6,7}$ Andriacchi et al. reported that EKAM is negatively associated with medial cartilage thickness in patients with knee OA, while healthy participants show a positive relation to a higher load. ${ }^{8}$ This poses the question whether EKAM accurately reflects internal knee joint forces that contribute to cartilage degeneration. The study of Meyer et al. also casted doubt on the utility of EKAM, they used a force measuring instrumented prosthesis to directly measure compressive forces in the knee joint while assessing EKAM and electromyography (EMG) simultaneously. ${ }^{5}$ They concluded that EKAM is not a strong indicator for the compressive forces on the medial condyle. Another study by Kutzner et al. using instrumented prostheses found similar results. ${ }^{9}$ These results indicate the limited use of EKAM in order to approximate internal knee loading.

Alternatively, musculoskeletal models can be used to estimate proximodistal, anteroposterior, and mediolateral components of internal joint loading, which in principle enables the evaluation of internal joint forces for various conditions. ${ }^{10-12}$ To date, several studies have addressed internal knee loading in patients with knee osteoarthritis in comparison to healthy volunteers using musculoskeletal models. ${ }^{13-15}$ However, most studies focus on the proximodistal component (i.e. compression) on the medial and lateral condyles, ignoring the mediolateral and anteroposterior components (i.e. shear forces) of the joint reaction force. Previous studies indicated that shear forces might contribute significantly to cartilage disruption. ${ }^{16,17}$ Therefore, our primary aim was to determine differences in the mediolateral component of the internal knee joint reaction force between early onset knee OA patients and healthy controls from musculoskeletal model 


\section{Chapter 3}

predictions. In addition, it was aimed to investigate EKAM and the other components of the joint reaction force and their relation to our primary outcome.

\section{Methods}

\section{Population}

This case-control study (Level of Evidence III) was part of a larger cross-sectional study and was approved by the Medical Ethical Committee of the University Hospital Maastricht and Maastricht University. Ten patients with early onset tibiofemoral OA at the medial compartment were recruited from the department of Orthopaedics of the Maastricht University Medical Centre. Only patients diagnosed with grade I or II OA radiographic status as defined by Kellgren/Lawrence criteria were included. ${ }^{12}$ Patients with patellofemoral, lateral compartment of the knee, hip or ankle OA or other impairments that modify walking patterns were excluded. Additionally, ten age-matched healthy female controls were included. Only female participants were included in order to exclude sex related differences. All participants had body mass indices (BMI) between 20 and 25 $\mathrm{kg} / \mathrm{m}^{2}$. Subject characteristics are listed in Table 3.1.

Table 3.1 Patient characteristics. Data displayed as mean ( \pm standard deviation).

\begin{tabular}{lll}
\hline & Healthy & OA \\
\hline Number & 10 & 10 \\
Affected leg in OA or & $(8: 2)$ & $(6: 4)$ \\
dominant leg in healthy (right : left) & & \\
Age (years) & $57.8( \pm 4.6)$ & $60.6( \pm 4.4)$ \\
Height $(\mathrm{m})$ & $1.66( \pm 0.05)$ & $1.65( \pm 0.06)$ \\
Mass $(\mathrm{kg})$ & $60.0( \pm 5.3)$ & $64.5( \pm 7.4)$ \\
BMI $\left(\mathrm{kg} / \mathrm{m}^{2}\right)$ & $21.8( \pm 1.3)$ & $23.5( \pm 1.8)^{*}$ \\
Varus $(+) /$ valgus $(-)$ angle $\left({ }^{\circ}\right)^{\#}$ & $-4.8( \pm 3.1)$ & $-1.1( \pm 2.7)^{*}$ \\
Kellgren-Lawrence score & 0 & $1 / 11(5 / 5)$ \\
\hline
\end{tabular}

* significant difference between healthy and OA $(p<0.05)$

\# varus/valgus angle of the affected or dominant leg measured with the VICON motion analysis system during standing, feet parallel and weight evenly distributed between feet 


\section{Experimental data collection}

Gait analyses were conducted in the department of Human Movement Science, Maastricht University. An eight camera VICON motion analysis system $(200 \mathrm{~Hz}$, Oxford Metrics Ltd., Oxford, UK) was used to capture the kinematics of gait at self-selected and standardized speed at approximately $1.5 \mathrm{~m} \cdot \mathrm{s}-1$. Trials were acceptable between $1.4 \mathrm{~m} \cdot \mathrm{s}-1$ and $1.6 \mathrm{~m} \cdot \mathrm{s}-1$ as determined by two light gates. A single Kistler $(9081 \mathrm{E}, 1000 \mathrm{~Hz}, \mathrm{Kistler}$ Instruments $A G$, Winethur, Switzerland) force plate was used to measure ground reaction forces. Marker configuration consisted of 16 retroreflective surface markers positioned on the lower extremities as defined by the plug-in-gait marker placement manual: anterior superior iliac spine, posterior superior iliac spine, lateral thigh, lateral femoral condyle, lateral tibia, lateral malleolus, posterior calcaneus and head of the second metatarsal. Muscle activity was measured using Delsys TrignoTM wireless surface EMG electrodes $(1000 \mathrm{~Hz}$, Delsys Inc., Boston, USA). EMG electrodes were placed on the patient's affected leg or dominant leg in the control group according to Seniam recommendations on the following muscles: rectus femoris, medial and lateral vastus, biceps femoris long head, semitendinosus, soleus, tibialis anterior medial and lateral gastrocnemius. For each muscle maximal voluntary contractions (MVC) were performed in accordance to SENIAM clinical test procedures to normalize muscle activation during gait tasks. ${ }^{19}$ Subjects performed three correct trials for both the self-selected speed and standardized speed gait trials.

\section{Data analysis and musculoskeletal modelling}

Marker data were labelled and processed automatically in the software package VICON Nexus (version 1.8.5,). A static calibration was used in order to determine the varus angle of the knee.

Inverse dynamics was used to calculate external moments (EKAM among others) during the gait trials. EMG for both MVC and gait trials were band-pass filtered $(20-450 \mathrm{~Hz})$ with a fourth order Butterworth filter, with the moving average calculated from the absolute signal (100 samples/second window). Finally, the EMG from the MVC trials was considered as 100 percent muscle activation; gait trials were normalized accordingly.

In this paper the internal knee joint force is defined as the three dimensional reaction force at the central section of the joint in between the medial and lateral condyle applied to the coordinate system of the tibia. Internal knee joint forces and muscle activations were determined in the musculoskeletal modelling software package AnyBody (Version 5.3, Anybody technology, Aalborg, Denmark). The Twente lower extremity model was used with a three-element Hill type muscle model. Muscle strength was scaled based on 
the length-mass-fat scaling method ${ }^{20}$ and a third degree polynomial muscle recruitment criterion was used to solve the muscle indeterminacy problem. ${ }^{21}$ Finally, a muscle activation pattern was calculated as percentage of the maximal muscle activation.

\section{Statistical analysis}

The following outcome variables were all processed for each trial individually using Matlab (version 7.14, the Mathworks, Inc, USA), EKAM, mediolateral, proximo-distal and anteroposterior forces. From all these outcome variables the first and second peaks were determined and the area under the curve, or impulse, was calculated by integrating the force signal over time. The mean of these values was then determined for each individual and for each condition separately. Significant differences between OA patients and healthy controls and standard versus self-selected speed were identified by paired sample $t$-tests. Pearson's correlations were used to examine the relationship between EKAM and the components of the knee joint reaction force. All analyses were performed using the statistical package SPSS (version 21, IBM SPSS Statistics). Statistical significance was defined as a $p$-value $<0.05$.

\section{Results}

Spatiotemporal characteristics (i.e. walking speed, cadence and stride length) were found to be similar between healthy controls and OA patients. Significant differences in spatiotemporal characteristics were only observed between the two speed conditions. In addition, self-selected speed was significantly slower compared to standard speed (OA: $0.19 \mathrm{~m} / \mathrm{s}$, Healthy: $-0.17 \mathrm{~m} / \mathrm{s}$ ); both OA patients and healthy subjects showed significantly reduced cadence and stride length at self-selected speed (Table 3.2).

At the self-selected speed, the measures of the EKAM waveform (i.e. impulse and peaks) were not significantly higher for OA patients. In contrast, at the standard speed, EKAM showed significantly elevated second peak (+44\%) and impulse values $(+39 \%)$ for OA patients compared to healthy controls (Table 3.2, Figure 3.1). Differences between standard and self-selected speed showed increased EKAM peaks at higher walking speeds (standard speed), whilst no difference was detected for EKAM impulse.

Internal knee forces were expressed into mediolateral, anteroposterior and proximodistal directions. For the mediolateral component, almost all measures were found to be significantly higher (range: $25 \%$ up to $45 \%$ increase) for OA patients compared to healthy controls (Table 3.2, Figure 3.1). Only the second peak of mediolateral force at self-selected 
speed was not found to be significantly increased in OA patients. No statistical significance was found in the remaining components of internal knee forces (i.e. the proximodistal and anteroposterior direction); these were found to be comparable between OA patients and healthy volunteers. However, a non-significant consistent trend of approximately $10 \%$ decrease in OA patients was observed in all proximodistal and anteroposterior knee forces.

Table 3.2 Spatiotemporal characteristics, external knee adduction moments, and internal knee forces. Data displayed as mean ( \pm standard deviation).

\begin{tabular}{|c|c|c|c|c|}
\hline \multirow{2}{*}{$\begin{array}{l}\text { Speed } \\
\text { Group }\end{array}$} & \multicolumn{2}{|c|}{ Standard speed } & \multicolumn{2}{|c|}{ Self-selected speed } \\
\hline & Healthy & OA & Healthy & OA \\
\hline Walking speed $(\mathrm{m} / \mathrm{s})$ & $1.51( \pm 0.03)$ & $1.52( \pm 0.05)$ & $1.34( \pm 0.17)^{\#}$ & $1.33( \pm 0.18)^{\#}$ \\
\hline Cadence (steps/minute) & $130( \pm 6)$ & $129( \pm 8)$ & $121( \pm 9)^{\#}$ & $121( \pm 10)^{\#}$ \\
\hline Stride length (m) & $1.41( \pm 0.08)$ & $1.35( \pm 0.08)$ & $1.34( \pm 0.10)^{\#}$ & $1.29( \pm 0.09)^{\#}$ \\
\hline EKAM $1^{\text {st }}$ peak $(\mathrm{Nm} / \mathrm{kg})$ & $0.63( \pm 0.16)$ & $0.72( \pm 0.19)$ & $0.53( \pm 0.15)^{\#}$ & $0.60( \pm 0.21)^{\#}$ \\
\hline EKAM $2^{\text {nd }}$ peak $(\mathrm{Nm} / \mathrm{kg})$ & $0.27( \pm 0.05)$ & $0.39( \pm 0.14)^{*}$ & $0.27( \pm 0.07)$ & $0.35( \pm 0.14)^{\#}$ \\
\hline EKAM impulse ( $\left.\mathrm{Nm}^{*} \mathrm{~s} / \mathrm{kg}\right)$ & $0.13( \pm 0.04)$ & $0.18( \pm 0.06)^{*}$ & $0.14( \pm 0.04)$ & $0.18( \pm 0.06)$ \\
\hline ML $1^{\text {st }}$ peak (BW) & $0.20( \pm 0.07)$ & $0.29( \pm 0.07)^{*}$ & $0.19( \pm 0.06)$ & $0.26( \pm 0.07)^{* \#}$ \\
\hline$M L 2^{\text {nd }}$ peak (BW) & $0.32( \pm 0.06)$ & $0.40( \pm 0.10)^{*}$ & $0.31( \pm 0.06)$ & $0.36( \pm 0.10)$ \\
\hline ML impulse (BW*s) & $0.08( \pm 0.02)$ & $0.12( \pm 0.03)^{*}$ & $0.09( \pm 0.02)$ & $0.13( \pm 0.03)^{*}$ \\
\hline $\mathrm{PD} 1^{\text {st }}$ peak (BW) & $3.67( \pm 0.60)$ & $3.31( \pm 0.54)$ & $3.29( \pm 0.51)^{\#}$ & $2.90( \pm 0.45)^{\#}$ \\
\hline PD $2^{\text {nd }}$ peak (BW) & $4.25( \pm 0.66)$ & $4.01( \pm 0.76)$ & $4.00( \pm 0.63)$ & $3.67( \pm 0.63)$ \\
\hline PD impulse (BW*s) & $1.48( \pm 0.16)$ & $1.42( \pm 0.12)$ & $1.51( \pm 0.14)$ & $1.47( \pm 0.18)$ \\
\hline AP $1^{\text {st }}$ peak (BW) & $0.66( \pm 0.18)$ & $0.51( \pm 0.16)$ & $0.54( \pm 0.09)^{\#}$ & $0.43( \pm 0.13)$ \\
\hline AP $2^{\text {nd }}$ peak (BW) & $0.43( \pm 0.08)$ & $0.39( \pm 0.10)$ & $0.40( \pm 0.08)^{\#}$ & $0.37( \pm 0.07)$ \\
\hline AP impulse (BW*s) & $0.19( \pm 0.04)$ & $0.17( \pm 0.04)$ & $0.18( \pm 0.02)$ & $0.17( \pm 0.04)$ \\
\hline
\end{tabular}

EKAM: external knee adduction moment; ML: mediolateral knee force; PD: proximodistal knee force; AP: anteroposterior knee force; *Significant difference between OA and Healthy $(p<0.05)$; : Significant difference between self-selected and standard speed $(p<0.05)$

The correlation coefficients between the measures of EKAM and the mediolateral component of the internal knee force showed no relations in healthy volunteers. In OA patients, significant correlations were found at self-selected speed for all parameters (EKAM peak 1 - Mediolateral peak 1: $P=0.02, R^{2}$ 0.51; EKAM peak 2 - Mediolateral peak 2: $P=0.03, R^{2}$ 0.48; EKAM area - Mediolateral area: $\left.P=0.04, R^{2} 0.44\right)$. At standard speed, only the EKAM area and mediolateral area were significantly related for $O A$ patients $\left(P=0.03, R^{2}\right.$ 0.46). 
The model predicted correctly the timing of muscle activation of calf muscles $(70-75 \%$ of stance phase), hamstring muscles and the tibialis anterior muscle (0-20\% of stance phase). The vasti muscles showed activity in both measured EMG and model simulation in the first $50 \%$ of stance phase (Figure 3.2). However, a second peak for the vasti muscles in late stance was only found in the modelled gait trials; EMG measured muscle activity showed no second peak in late stance. The rectus femoris showed a completely different pattern, showing increased EMG activity in early stance phase, whilst muscle activity was recruited in late stance phase by the musculoskeletal model.
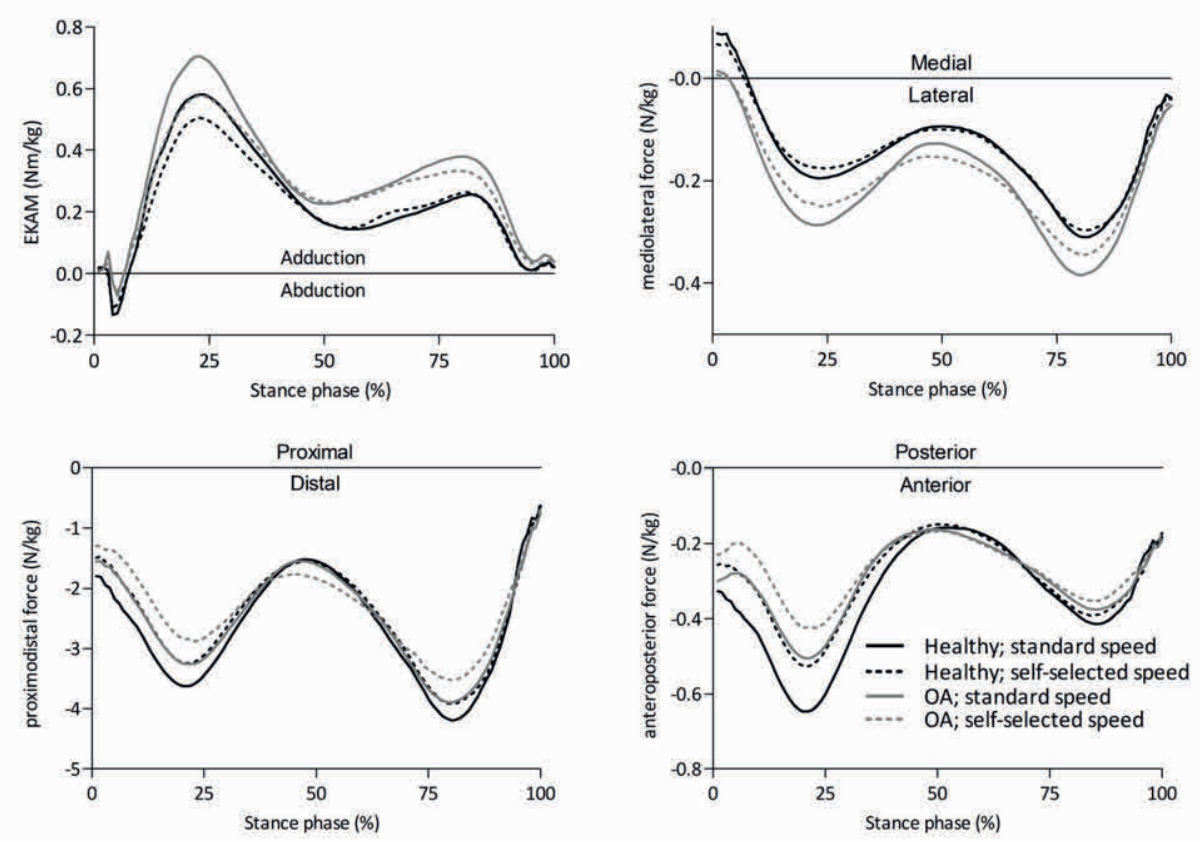

Figure 3.1 EKAM and internal knee forces during stance phase $(0 \%$ : heel strike $100 \%$ : toe off). Separate curves represent healthy controls (black), OA (grey), standard speed (solid) and self-selected speed (dashed).

EMG and model derived muscle activations differed considerably in magnitude; e.g. model derived muscle activation showed maximally $46 \%$ activation in the medial vastus muscle, whilst a maximum of $11 \%$ was measured by EMG. Although little differences were shown between the simulated muscle activities between OA patients and healthy controls, substantial differences were shown in the EMG measured muscle activities between these groups. OA patients showed up to $100 \%$ increased EMG activity in semitendinosus, quadriceps and calf muscles compared to healthy controls. 


\section{Discussion}

To the best of our knowledge, this is the first study to show differences in estimated mediolateral component of internal knee forces between patients with mild osteoarthritis and healthy controls using musculoskeletal models. For this purpose, OA patients and healthy controls performed gait trials at self-selected speed $(\sim 1.3 \mathrm{~m} / \mathrm{s})$ and standard speed ( $1.5 \mathrm{~m} / \mathrm{s})$. At both walking speeds EKAM and internal knee forces in mediolateral, proximodistal and anteroposterior directions were compared between healthy controls and OA patients. In general, our results showed increased EKAM and knee forces in mediolateral direction in OA patients compared to healthy controls at standard speed. Only the first peak of EKAM did not reach statistical significance. At slower self-selected speeds, differences in EKAM were less pronounced, though our results showed significantly increased knee forces in the mediolateral direction in knee OA patients.

At self-selected speeds no significant increase in EKAM parameters were found in OA patients compared to healthy controls. In contrast, mediolateral first peak and impulse were significantly increased in OA patients at self-selected speeds. Moreover, correlation coefficients between the mediolateral component of internal knee force and EKAM showed only significant associations within OA patients, in particular at self-selected speeds. These results suggest that EKAM might not be an ideal parameter to identify differences in loading between OA patients and healthy volunteers. In addition, internal loading in mediolateral direction derived from musculoskeletal models possibly adds valuable information to external parameters, such as EKAM. Walter et al. provided evidence for this by showing a poor relationship between EKAM and internal loading determined by a force-measuring implant. ${ }^{7}$ Although EKAM might be not an ideal parameter for identifying high internal knee loading, previous studies already found increased EKAM values in patients with medial knee OA. ${ }^{22-25}$ In these studies, the magnitude of EKAM is comparable to our results, taking into account the normalization for height and weight. Similar to other studies, our results showed that walking speed positively influenced the magnitude of EKAM peaks, ${ }^{23,26}$ whilst the impulse of EKAM was unaltered. ${ }^{27}$ 
Model

EMG
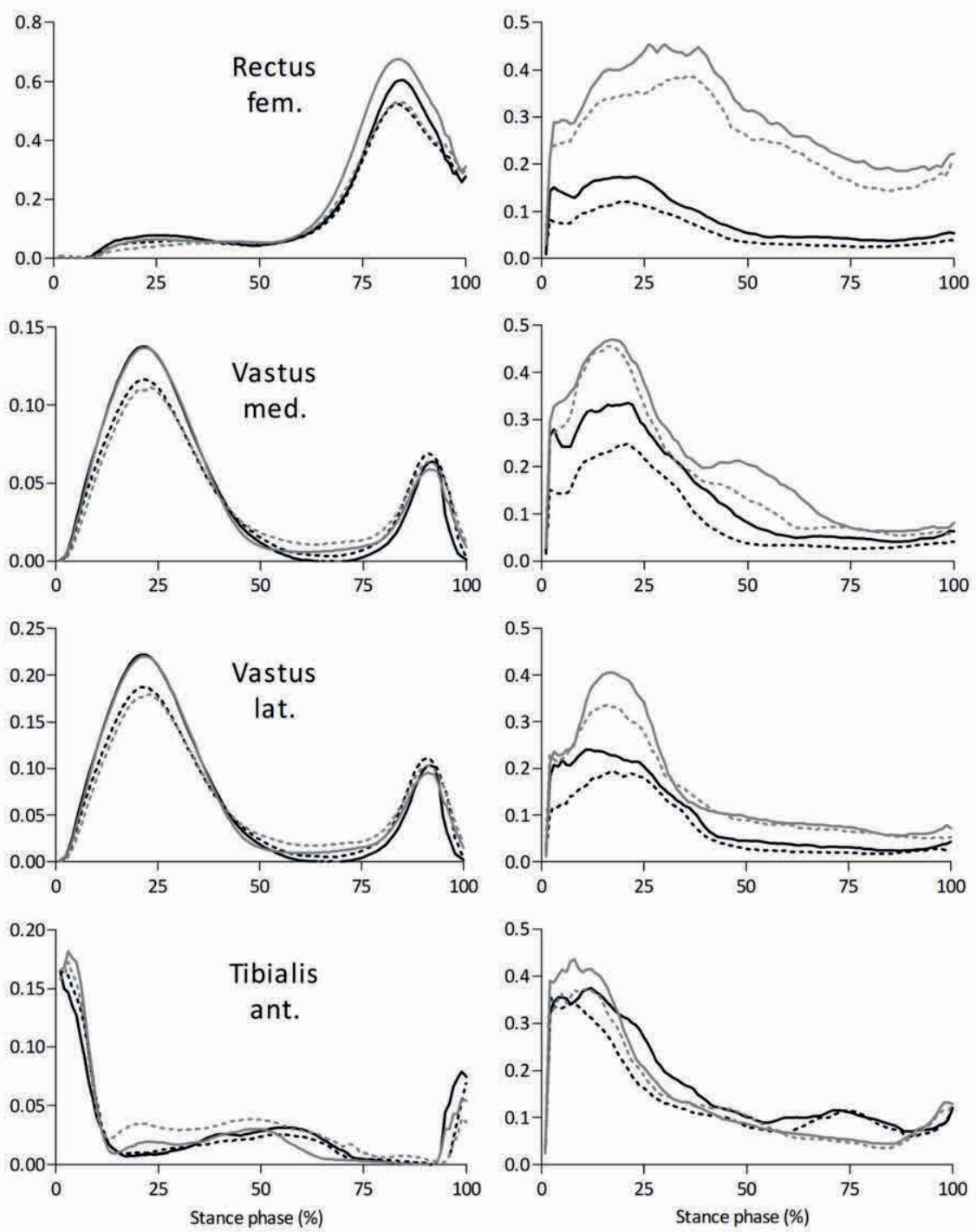

Figure 3.2 Mean muscle activations during stance phase simulated in the musculoskeletal model compared with measured electromyography (EMG). Separate curves are shown for healthy controls (black), OA (grey), standard speed (solid) and selfselected speed (dashed). $\mathrm{RF}=$ rectus femoris, $\mathrm{VM}=$ medial vastus, $\mathrm{VL}=$ lateral vastus, $\mathrm{TA}=$ tibialis anterior, $\mathrm{GM}=$ medial gastrocnemius, $\mathrm{GL}=$ lateral gastrocnemius, $\mathrm{BF}=$ biceps femoris, ST= semitendinosus 
Model
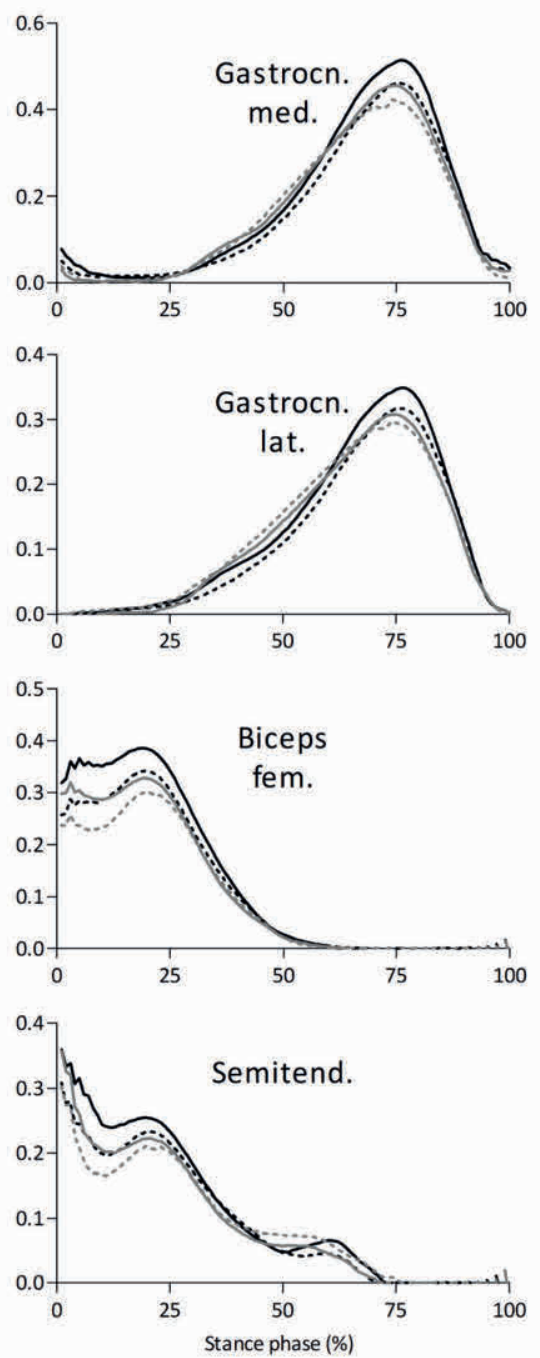

EMG
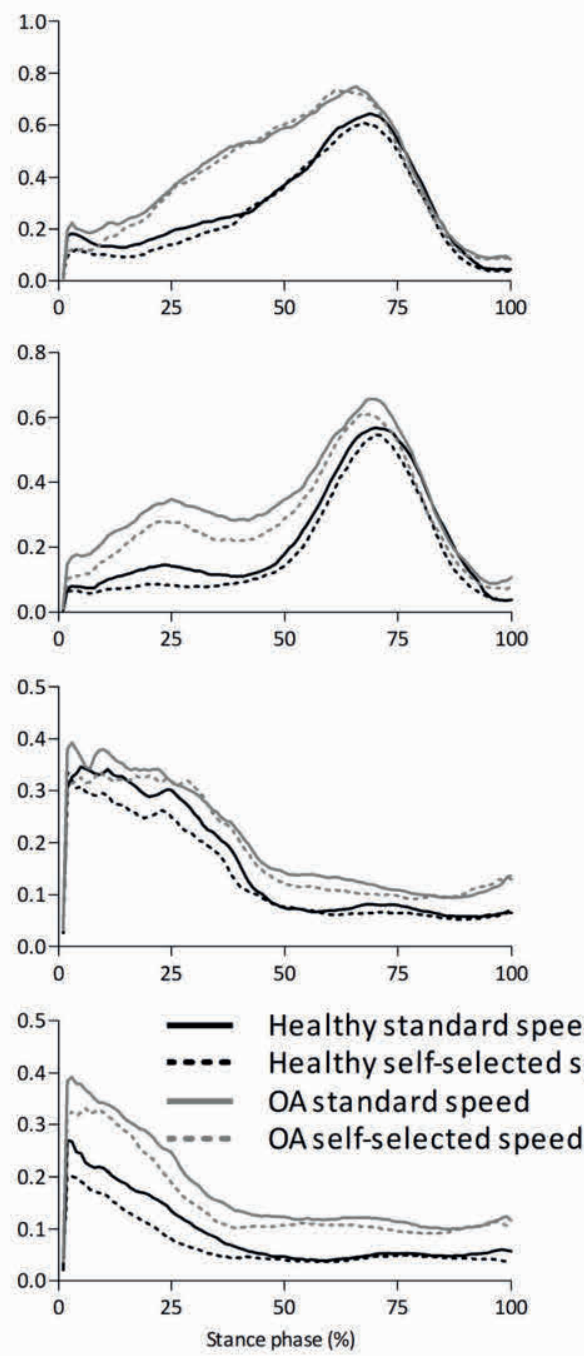


\section{Chapter 3}

For the interpretations of the results of this study we acknowledge the multiple comparisons problem, which might introduce type 1 errors. However, no correction for multiple testing was performed, since this study was explorative for the different components of internal loading and we only used a small amount of planned comparisons.

Several determinants should be taken into account considering the EKAM results. The first determinant is the severity of OA, which was shown to be positively related with EKAM ${ }^{6}$. Therefore, this study included a homogeneous group of mildly severe knee OA patients. Varus alignment has been positively associated with EKAM. ${ }^{28}$ In our study, we found significantly more varus alignment in the OA group, which might explain the higher EKAM in this group. Furthermore, we included a homogeneous group of patients with only medial knee OA, since patients with lateral knee OA have a reversed mechanical cause and correspond with decreased EKAM. ${ }^{22}$ Therefore, our results cannot necessarily be extrapolated to patients with lateral knee OA.

Shear forces on the cartilage tissue are suggested to be important in the development and progression of knee OA. ${ }^{16,29}$ An increase of shear stress may disrupt cartilage homeostasis and induce cartilage break down. ${ }^{17}$ The mediolateral component of internal knee force predicted by the current model is an approximation of the shear force in mediolateral direction at the cartilage surface. For a better understanding on how these forces relate to cartilage damage, more detailed knee models including the contact forces and loaded areas are required. ${ }^{30}$ In addition, advances in musculoskeletal modelling might increase the accuracy of model outcomes; for example personalisation and adding multiple degrees of freedom in the knee joint. ${ }^{31,32}$

We need to take into account that the knee joint was modelled as a typical hinge joint in the musculoskeletal model. This disregards translational and rotational movements in the frontal and axial plane during dynamic activities, which resulted in possibly inaccurate outcomes. Therefore, muscles in the model did not respond to an increased knee adduction moment, while some studies report increased co-contraction of muscles in order to increase joint stability in OA patients. ${ }^{33}$ This might explain the respectively similar muscle activities in the model between both groups, while EMG activity is different between $\mathrm{OA}$ patients and healthy volunteers (Figure 3.2). A recent study by $\mathrm{Xu}$ et al. described a multiple degrees of freedom knee joint in OpenSim, ${ }^{31}$ which possibly improves musculoskeletal models and aid in more realistic model outcomes.

A final point of concern is the difference between measured EMG and simulated muscle activations. In other words, poorly simulated muscle activation patterns will give inaccurate results on the loading of the knee. However, the relationship between muscle 
force and surface EMG is still poorly understood. Most studies assume a non-linear relationship of EMG with increasing muscle force contraction. ${ }^{34,35}$ Furthermore, surface EMG is limited to superficially located muscle tissue, therefore incapable to detect signal of the entire muscle volume. ${ }^{36}$ An additional problem is that pain and muscle weakness in OA patients may influence the EMG values. ${ }^{37}$

In-vivo measurements in the literature provided evidence that the magnitude of the proximodistal component of internal knee forces in our study are within acceptable ranges. ${ }^{5}$ More research on the mediolateral component of joint reaction force is necessary in order to show normal ranges and provide evidence of the importance of this parameter in knee OA gait. For example, gait adaptations that alter the mediolateral component of the joint reaction force can possibly aid in decreasing the progression of knee OA. In addition, the effect of walking pole, walking speed, trunk sway and toe angle on the mediolateral component of knee force can add valuable information to EKAM. ${ }^{26,38}$

In conclusion, this study shows differences in knee loading between OA patients and healthy volunteers. In addition, our simulations reveal increased internal knee forces in mediolateral direction in patients with knee OA. In contrast to EKAM, we found statistical differences in internal knee force in mediolateral direction between patients with knee OA and healthy controls at both self-selected (slow) speeds and standard (fast) speed. EKAM correlated with the mediolateral component of internal knee forces in OA patients only, therefore, EKAM is probably a less useful parameter to quantify joint loading than the mediolateral component of internal knee forces in healthy volunteers. Advances in musculoskeletal modelling may eventually result in even more accurate estimations of internal forces. For example, current techniques to personalize joint kinematics, bone geometry and muscle strength could be improved for a better understanding of pathological mechanics of knee OA. 


\section{References}

1. Jordan KM, Arden NK, Doherty M, et al. 2003. EULAR Recommendations 2003: an evidence based approach to the management of knee osteoarthritis: Report of a Task Force of the Standing Committee for International Clinical Studies Including Therapeutic Trials (ESCISIT). Ann Rheum Dis 62:1145-55.

2. van Saase JL, van Romunde LK, Cats A, et al. 1989. Epidemiology of osteoarthritis: Zoetermeer survey. Comparison of radiological osteoarthritis in a Dutch population with that in 10 other populations. Ann Rheum Dis 48:271-80.

3. Andriacchi TP, Mundermann A. 2006. The role of ambulatory mechanics in the initiation and progression of knee osteoarthritis. Curr Opin Rheumatol 18:514-8.

4. Schipplein OD, Andriacchi TP. 1991. Interaction between active and passive knee stabilizers during level walking. J Orthop Res 9:113-9.

5. Meyer AJ, D'Lima DD, Besier TF, et al. 2013. Are external knee load and EMG measures accurate indicators of internal knee contact forces during gait? J Orthop Res 31:921-9.

6. Mundermann A, Dyrby CO, Andriacchi TP. 2005. Secondary gait changes in patients with medial compartment knee osteoarthritis: increased load at the ankle, knee, and hip during walking. Arthritis Rheum 52:2835-44.

7. Walter JP, D'Lima DD, Colwell CW, Jr., Fregly BJ. 2010. Decreased knee adduction moment does not guarantee decreased medial contact force during gait. J Orthop Res 28:1348-54.

8. Andriacchi TP, Koo S, Scanlan SF. 2009. Gait mechanics influence healthy cartilage morphology and osteoarthritis of the knee. J Bone Joint Surg Am 91 Suppl 1:95-101.

9. Kutzner I, Trepczynski A, Heller MO, Bergmann G. 2013. Knee adduction moment and medial contact force--facts about their correlation during gait. PLoS One 8:e81036.

10. Fregly BJ, Besier TF, Lloyd DG, et al. 2012. Grand challenge competition to predict in vivo knee loads. J Orthop Res 30:503-13.

11. Kinney AL, Besier TF, D'Lima DD, Fregly BJ. 2013. Update on grand challenge competition to predict in vivo knee loads. J Biomech Eng 135:021012.

12. Ogaya S, Naito H, Iwata A, et al. 2014. Knee adduction moment and medial knee contact force during gait in older people. Gait Posture 40:341-5.

13. Kumar D, Manal KT, Rudolph KS. 2013. Knee joint loading during gait in healthy controls and individuals with knee osteoarthritis. Osteoarthritis Cartilage 21:298305.

14. Meireles S, De Groote F, Reeves ND, et al. 2016. Knee contact forces are not altered in early knee osteoarthritis. Gait Posture 45:115-20.

15. Sritharan P, Lin YC, Richardson SE, et al. 2017. Musculoskeletal loading in the symptomatic and asymptomatic knees of middle-aged osteoarthritis patients. J Orthop Res 35:321-30.

16. Lynn SK, Reid SM, Costigan PA. 2007. The influence of gait pattern on signs of knee osteoarthritis in older adults over a 5-11 year follow-up period: a case study analysis. Knee 14:22-8. 
17. Smith RL, Donlon BS, Gupta MK, et al. 1995. Effects of fluid-induced shear on articular chondrocyte morphology and metabolism in vitro. J Orthop Res 13:824-31.

18. Kellgren JH, Lawrence JS. 1957. Radiological assessment of osteo-arthrosis. Ann Rheum Dis 16:494-502.

19. Hermens HJ, Merletti R, Freriks B. SENIAM European recommendations for surface electromyography. Enschede, The Netherlands: Roessingh Research and Development; 1999.

20. Rasmussen J, de Zee M, Damsgaard M, et al, editors. A General Method for Scaling Musculo-Skeletal Models. International Symposium on Computer Simulation in Biomechanics; 2005; Ohio, USA.

21. Crowninshield RD, Brand RA. 1981. A physiologically based criterion of muscle force prediction in locomotion. J Biomech 14:793-801.

22. Butler RJ, Barrios JA, Royer T, Davis IS. 2011. Frontal-plane gait mechanics in people with medial knee osteoarthritis are different from those in people with lateral knee osteoarthritis. Phys Ther 91:1235-43.

23. Landry SC, McKean KA, Hubley-Kozey CL, et al. 2007. Knee biomechanics of moderate $\mathrm{OA}$ patients measured during gait at a self-selected and fast walking speed. J Biomech 40:1754-61.

24. Gok H, Ergin S, Yavuzer G. 2002. Kinetic and kinematic characteristics of gait in patients with medial knee arthrosis. Acta Orthop Scand 73:647-52.

25. Kim WY, Richards J, Jones RK, Hegab A. 2004. A new biomechanical model for the functional assessment of knee osteoarthritis. Knee 11:225-31.

26. van den Noort JC, Schaffers I, Snijders J, Harlaar J. 2013. The effectiveness of voluntary modifications of gait pattern to reduce the knee adduction moment. Hum Mov Sci 32:412-24.

27. Robbins SM, Maly MR. 2009. The effect of gait speed on the knee adduction moment depends on waveform summary measures. Gait Posture 30:543-6.

28. Stief F, Bohm H, Schwirtz A, et al. 2011. Dynamic loading of the knee and hip joint and compensatory strategies in children and adolescents with varus malalignment. Gait Posture 33:490-5.

29. Nishino K, Omori G, Koga Y, et al. 2015. Three-dimensional dynamic analysis of knee joint during gait in medial knee osteoarthritis using loading axis of knee. Gait Posture 42:127-32.

30. Marra MA, Vanheule V, Fluit R, et al. 2015. A subject-specific musculoskeletal modeling framework to predict in vivo mechanics of total knee arthroplasty. J Biomech Eng 137:020904.

31. Xu H, Bloswick D, Merryweather A. 2015. An improved OpenSim gait model with multiple degrees of freedom knee joint and knee ligaments. Comput Methods Biomech Biomed Engin 18:1217-24.

32. Fregly BJ, Boninger ML, Reinkensmeyer DJ. 2012. Personalized neuromusculoskeletal modeling to improve treatment of mobility impairments: a perspective from European research sites. J Neuroeng Rehabil 9:18.

33. Schmitt LC, Rudolph KS. 2008. Muscle stabilization strategies in people with medial knee osteoarthritis: the effect of instability. J Orthop Res 26:1180-5. 
34. Madeleine P, Bajaj P, Sogaard K, Arendt-Nielsen L. 2001. Mechanomyography and electromyography force relationships during concentric, isometric and eccentric contractions. J Electromyogr Kinesiol 11:113-21.

35. Solomonow M, Baratta R, Shoji H, D'Ambrosia R. 1990. The EMG-force relationships of skeletal muscle; dependence on contraction rate, and motor units control strategy. Electromyogr Clin Neurophysiol 30:141-52.

36. de Luca CJ. 1997. The Use of Surface Electromyography in Biomechanics. J Appl Biomech 13:135-63.

37. Kumar D, Swanik CB, Reisman DS, Rudolph KS. 2014. Individuals with medial knee osteoarthritis show neuromuscular adaptation when perturbed during walking despite functional and structural impairments. J Appl Physiol (1985) 116:13-23.

38. Mundermann A, Dyrby CO, Hurwitz DE, et al. 2004. Potential strategies to reduce medial compartment loading in patients with knee osteoarthritis of varying severity: reduced walking speed. Arthritis Rheum 50:1172-8. 


\section{Development and validation of a rule-based strength scaling method for musculoskeletal modelling}

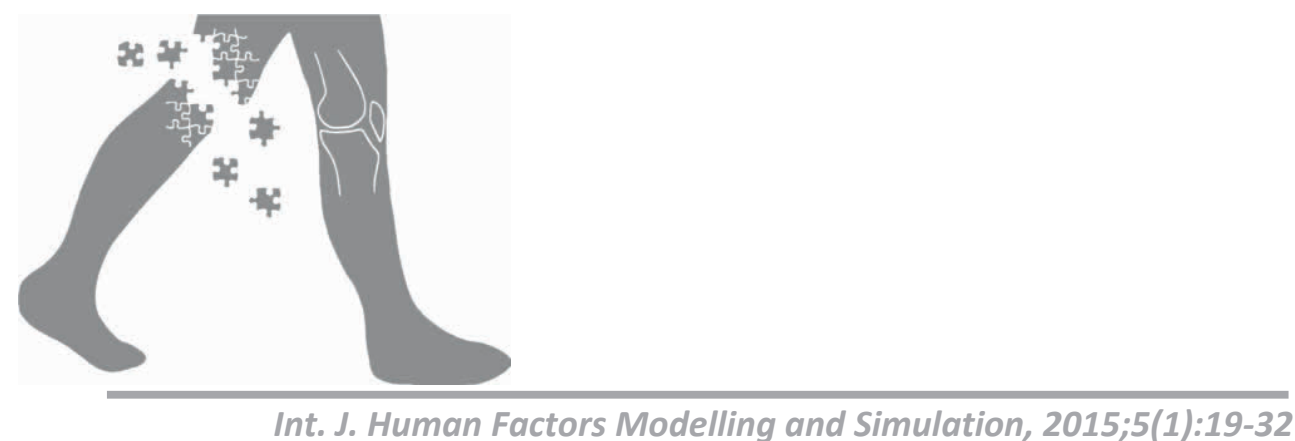

Copyright (c) 2015 Inderscience Enterprises Ltd.

Pieter Oomen, Janneke Annegarn, John Rasmussen, Jessica Rausch, Karl Siebertz, Lex Verdijk, Maarten Drost, Kenneth Meijer 


\section{Abstract}

Background Rule-based strength scaling is an easy, cheap and relatively accurate technique to personalise musculoskeletal models. This paper presents a new strength scaling approach for musculoskeletal models and validates it by maximal voluntary contractions.

Methods A heterogeneous group of 63 healthy subjects performed maximal isometric knee extensions. A multiple linear regression analysis resulted in a best-fit rule-based strength scaling equation, with age, mass, height, gender, segment masses and segment lengths as predictors. A second strength scaling equation was obtained through multiple linear regression using backwards elimination, resulting in an equation consisting of only the significant predictors: age, body mass and gender. For validation purposes, 20 newly included healthy subjects performed a maximal isometric leg-press.

Results The newly developed strength scaling technique taking all predictors into account resulted in the most accurate predictions of muscle activities compared to alternative strength scaling methods.

Conclusion These techniques personalise musculoskeletal models to a larger extend. However, some applications that require more detailed personalised models, imaging might be necessary to obtain more specific individual muscle characteristics. 


\section{Introduction}

Simulation of human activities by digital modelling is a valuable instrument for the purpose of ergonomic evaluation. Besides, multi-body simulation of human activities enables researchers to perform virtual experiments that are impossible, too difficult, costly or dangerous to perform in real life. ${ }^{1,2}$ In addition, musculoskeletal models are useful to reveal general principles of human movement. ${ }^{4,5}$ However, musculoskeletal dimensions have a major impact on bodily functions. ${ }^{6}$ Therefore, the inclusion of subjectspecific data can improve the accuracy of model predictions. ${ }^{7,8}$ For instance, research has shown that model predictions are very sensitive to assumptions on muscle attachment sites, which are used to calculate muscle moment arms and muscle tendon lengths. ${ }^{6,9-11}$ Moreover, subject-specific joint geometry has been shown of importance to find reliable musculoskeletal model outcomes. ${ }^{12}$ Blemker et al. emphasised the importance of realistic estimates of muscle strength within a musculoskeletal model. ${ }^{13}$

Muscle strength mainly depends on physiological cross-sectional area, which might be derived from musculoskeletal imaging. ${ }^{14}$ Unfortunately, application of imaging techniques is still expensive and time consuming, which limits application in musculoskeletal modelling. In this paper, rule-based strength scaling (RBSS) is considered as a simpler, cheaper and more straightforward alternative that is based on easily accessible body parameters. Current musculoskeletal models incorporate fairly general scaling rules, for example geometric similarity, which assumes that muscle strength is proportional to muscle mass to the power $2 / 3 .{ }^{15}$ The approach of strength scaling using mass with a certain power-law works well for comparing strength between differently sized species; however, its application on a class of similar sized animals is questionable. ${ }^{16,17}$ In humans, strength is known to vary with body size and body composition. ${ }^{18,19}$ Moreover, mass gain does not automatically mean more force-producing muscle tissue, but can also be caused by an increased fat mass, particularly in our modern society. Therefore, a strength scaling method was developed that accounts for geometrical variations as well as differences in body composition. ${ }^{15}$ Body composition (i.e., fat percentage) could be either calculated ${ }^{20}$ or measured directly. However, both approaches are questionable, since these techniques are rather expensive or inaccurate. ${ }^{21}$

To our knowledge, these RBSS methods have not been rigorously tested within musculoskeletal models. Besides, these models generally do not include moderating factors like age and gender, which have been shown to influence strength independently. ${ }^{22-26}$ Recently, D'Souza et al. developed a strength scaling equation, including age, segment mass and gender. ${ }^{27}$ In their study, they focused on a relative homogeneous group of elderly subjects. These elderly subjects might be prone to 
incomplete voluntary activation, ${ }^{28}$ besides a small variation in age might result in incorrect generalisability to other age groups. Another drawback of the study from D'Souza et al. is that an independent validation was lacking. ${ }^{27}$ Furthermore, they did not test the application of the derived equation in a musculoskeletal model.

The purpose of this study was to develop a new RBSS method for the leg muscles, including age, gender, segment lengths and masses in a heterogeneous population. Subsequently, we will try to simplify this model by removing all non-significant contributors. This results in a second RBSS method. Our second goal was to validate these two RBSS methods and two currently used strength scaling methods in a separate group of subjects who performed a multi-joint task. Therefore, this study consists of two parts:

1 the development of a new RBSS method (calibration study)

2 validation of the strength scaling method based on new experimental data (validation study).

\section{Methods}

For the development of the new scaling method we used maximal isometric leg extension measurements and anthropometrics for multiple linear regression (MLR) (Figure 4.1). For the validation study we collected a new dataset containing maximal multi-joint contractions using an isometric leg-press, within newly included volunteers (Figure 4.1). Before participation volunteers provided informed consent. This study was accepted by the local medical ethics committee.

\section{Experimental procedures: calibration study}

For the development of a new RBSS method we established a dataset containing maximal isometric knee extensions from a heterogeneous population $(N=63)$. Experimental data $(N=48)$ from Verdijk et al. were used, ${ }^{3}$ and additional data $(N=15)$ were collected within this study. All data included peak isometric torques during knee extension of the right leg, gender, age, body mass, body height, right leg segment volumes and right leg segment lengths (Table 4.1). In order to keep the method simple and widely applicable, leg volumes were estimated using leg length and circumferences according to the truncated cones method first described by Jones and Pearson. ${ }^{29}$ Masses were subsequently calculated assuming densities of $1,060 \mathrm{~kg} / \mathrm{m}^{3}$. Static knee extension strength was measured with a Cybex-II dynamometer (sampling rate $1 \mathrm{kHz}, 12$ bit ADC) with subjects in a seated position. 
Knee extension torque was measured with hip joint angle at 80 의 flexion. The lateral femoral epicondyle was aligned with the axis of rotation of the dynamometer and the upper leg and pelvis were stabilised with Velcro straps to restrict compensatory movement. The lever arm was attached five centimetres proximal to the ankle joint. Because optimal joint angle can differ between subjects, ${ }^{30,31}$ isometric contractions were performed at both 80 and $90^{\circ}$ included knee angles. Three contractions in each angle were performed in random order. Subjects were encouraged to perform maximal voluntary contractions (MVCs) for 2-3 seconds. All trials were separated by 2 min of rest to minimise fatigue. Only the maximal knee extension torque, corrected for the gravitational force was used for further evaluation.

Calibration study:

Validation study:

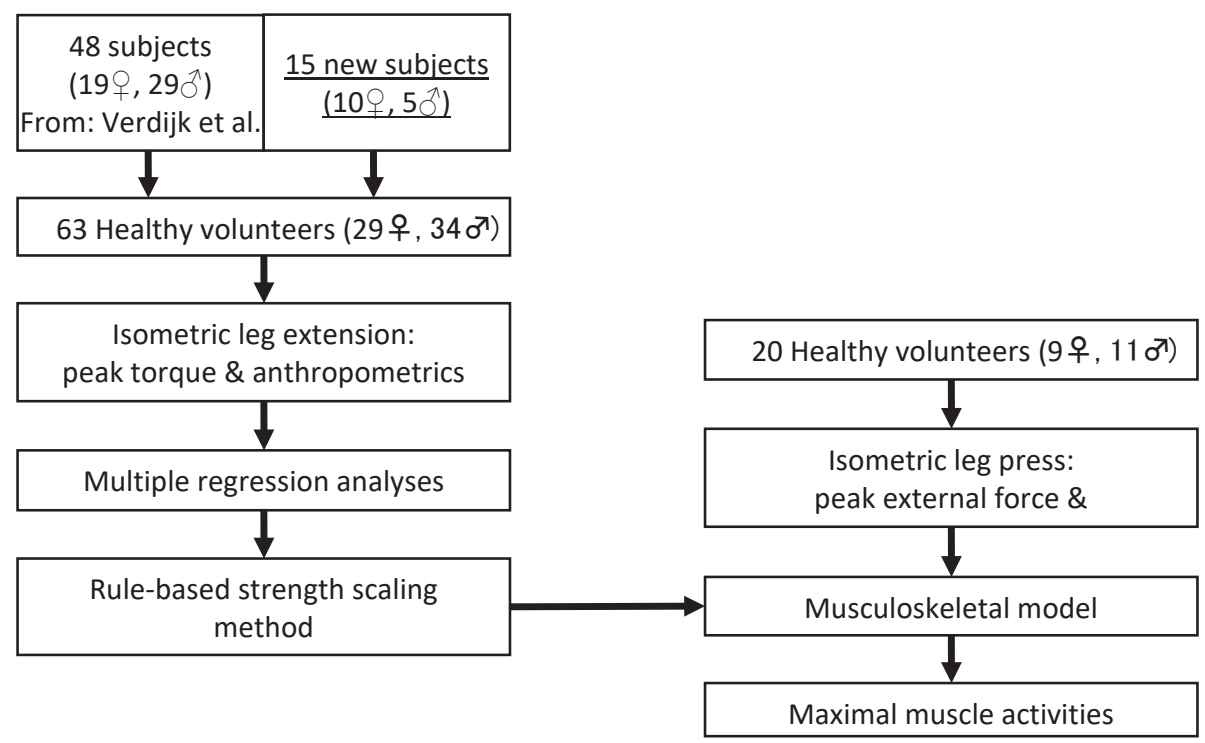

Figure 4.1 A flow diagram of the study design. We used experimental data of isometric peak torque knee extensions to develop a new rule-based empirical strength scaling method. A new dataset of peak isometric leg press measurements was collected to validate the newly developed strength scaling method. 
Table 4.1 Results of the calibration study, data presented as mean ( $\pm S D)$.

\begin{tabular}{|c|c|c|c|c|c|c|c|}
\hline & \multirow{2}{*}{$\begin{array}{l}\text { Variable } \\
\text { Age (y) }\end{array}$} & \multicolumn{2}{|c|}{ Total $(n=63)$} & \multicolumn{2}{|c|}{ Men $(n=34)$} & \multicolumn{2}{|c|}{ Women $(n=29)$} \\
\hline \multirow{9}{*}{ 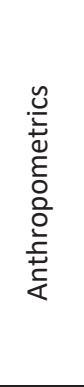 } & & 41.3 & $( \pm 20.2)$ & 45.0 & $( \pm 21.5)$ & 37.0 & $( \pm 18.0)$ \\
\hline & Mass (kg) & 72.5 & $( \pm 10.3)$ & 77.8 & $( \pm 7.9)$ & 66.2 & $( \pm 9.3) *$ \\
\hline & Height (m) & 1.74 & $( \pm 0.10)$ & 1.79 & $( \pm 0.09)$ & 1.68 & $( \pm 0.07)^{*}$ \\
\hline & BMI $\left(\mathrm{kg} / \mathrm{m}^{2}\right)$ & 24.0 & $( \pm 3.5)$ & 24.4 & $( \pm 3.6)$ & 23.4 & $( \pm 3.3)$ \\
\hline & Fat $(\%)^{\#}$ & 24.9 & $( \pm 8.3)$ & 20.1 & $( \pm 6.9)$ & 30.6 & $( \pm 6.0) *$ \\
\hline & Shank mass (kg) & 3.3 & $( \pm 0.4)$ & 3.4 & $( \pm 0.3)$ & 3.1 & $( \pm 0.5) *$ \\
\hline & Thigh mass (kg) & 6.0 & $( \pm 0.9)$ & 6.2 & $( \pm 0.9)$ & 5.8 & $( \pm 1.0)$ \\
\hline & Shank length (m) & 0.42 & $( \pm 0.04)$ & 0.44 & $( \pm 0.03)$ & 0.41 & $( \pm 0.03) *$ \\
\hline & Thigh length (m) & 0.37 & $( \pm 0.03)$ & 0.38 & $( \pm 0.02)$ & 0.35 & $( \pm 0.03)^{*}$ \\
\hline 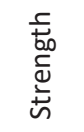 & MVC Torque (Nm) & 166.5 & $( \pm 50.4)$ & 186.1 & $( \pm 48.0)$ & 143.5 & $( \pm 43.5)^{*}$ \\
\hline \multirow{2}{*}{ 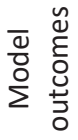 } & $\mathrm{SSF}_{\mathrm{RBSS}, \mathrm{F}}$ & 0.91 & $( \pm 0.17)$ & 0.99 & $( \pm 0.14)$ & 0.81 & $( \pm 0.15) *$ \\
\hline & $\mathrm{SSF}_{\mathrm{RBSS}, \mathrm{S}}$ & 0.91 & $( \pm 0.17)$ & 0.99 & $( \pm 0.13)$ & 0.81 & $( \pm 0.15)^{*}$ \\
\hline
\end{tabular}

* Significant difference between male and female $(p<0.05)$ acquired by one-way ANOVA,

\# Calculated by method of Gallagher et al (2000). MVC = maximal voluntary contraction. SSF = strength scaling factor obtained by rule-based strength scaling $(F=$ full model, $S=$ only significant variables included).

\section{Experimental procedures: validation study}

For validation purposes, 20 young healthy subjects participated in the second part of this study. Anthropometrical data were obtained (Table 4.2) using the same procedures employed in the calibration study.

Before conducting the MVCs, subjects performed a warm-up on a cycle ergometer at $75 \mathrm{~W}$ for five minutes. A commercial leg press setup (Technogym, Rotterdam, the Netherlands) was modified to conduct single leg isometric leg press experiments. A steel frame was constructed to support a pressure plate (Emed system novel-AT, Germany) at the footrest in front of the right foot. The data from the pressure plate were used for determining the maximal external force and centre of pressure. A 2D-camera was placed perpendicular to the subject and registered the joint angles during the MVC (approximately 85o hip angle and 50 o knee angle). For this purpose, reflective markers were attached at the medial malleolus, femoral condyle, greater trochanter and acromion. The subject performed three MVCs with three minutes rest in between the different trials. Consistent encouragement was given in all subjects and trials. 
Table 4.2 Results of the validation study, data presented as mean ( \pm SD)

\begin{tabular}{|c|c|c|c|c|c|c|c|}
\hline & Variable & \multicolumn{2}{|c|}{ Total $(n=20)$} & \multicolumn{2}{|c|}{ Men $(n=11)$} & \multicolumn{2}{|c|}{ Women $(n=9)$} \\
\hline \multirow{9}{*}{ 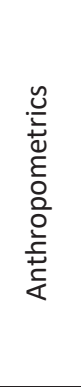 } & Age (y) & 22.4 & $( \pm 2.5)$ & 22.2 & $( \pm 2.4)$ & 22.6 & $( \pm 2.8)$ \\
\hline & Mass (kg) & 71.8 & $( \pm 12.0)$ & 77.9 & $( \pm 12.3)$ & 64.4 & $( \pm 6.4)^{*}$ \\
\hline & Height (m) & 1.79 & $( \pm 0.10)$ & 1.84 & $( \pm 0.09)$ & 1.72 & $( \pm 0.07) *$ \\
\hline & BMI $\left(\mathrm{kg} / \mathrm{m}^{2}\right)$ & 22.4 & $( \pm 2.5)$ & 23.0 & $( \pm 3.0)$ & 21.7 & $( \pm 1.5)$ \\
\hline & Fat $(\%)^{\#}$ & 20.6 & $( \pm 7.2)$ & 15.2 & $( \pm 4.8)$ & 27.1 & $( \pm 2.9)^{*}$ \\
\hline & Shank mass (kg) & 3.7 & $( \pm 0.6)$ & 3.9 & $( \pm 0.6)$ & 3.5 & $( \pm 0.5)$ \\
\hline & Thigh mass (kg) & 5.5 & $( \pm 1.0)$ & 5.8 & $( \pm 1.0)$ & 5.2 & $( \pm 0.8)$ \\
\hline & Shank length (m) & 0.43 & $( \pm 0.04)$ & 0.45 & $( \pm 0.03)$ & 0.40 & $( \pm 0.04) *$ \\
\hline & Thigh length (m) & 0.46 & $( \pm 0.04)$ & 0.47 & $( \pm 0.04)$ & 0.45 & $( \pm 0.03)$ \\
\hline 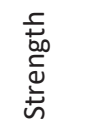 & MVC Force $(\mathrm{N})$ & 1923 & $( \pm 557)$ & 2180 & $( \pm 592)$ & 1608 & $( \pm 310) *$ \\
\hline & $\mathrm{MMA}_{\text {TLEM }}(\%)$ & 95 & $( \pm 24)$ & 105 & $( \pm 19)$ & 82 & $( \pm 24) *$ \\
\hline$\overline{\frac{D}{0}}$ & $\mathrm{MMA}_{\mathrm{LMF}}(\%)$ & 123 & $( \pm 34)$ & 113 & $( \pm 21)$ & 134 & $( \pm 44)$ \\
\hline$\sum \stackrel{0}{J}$ & $\mathrm{MMA}_{\mathrm{RBSS}, \mathrm{F}}(\%)$ & 103 & $( \pm 24)$ & 102 & $( \pm 21)$ & 104 & $( \pm 29)$ \\
\hline & $\mathrm{MMA}_{\mathrm{RBSS}, \mathrm{S}}(\%)$ & 91 & $( \pm 19)$ & 91 & $( \pm 17)$ & 90 & $( \pm 23)$ \\
\hline
\end{tabular}

* Significant difference between male and female $(p<0.05)$ acquired by one-way ANOVA,

\# Calculated by method of Gallagher et al (2000) MVC = maximal voluntary contraction, SSF = strength scaling factor, MMA = maximal muscle activity, LMF = length-fat-mass scaling, RBSS = rulebased strength scaling ( $\mathrm{F}=$ Full model, $\mathrm{S}=$ only Significant variables included), TLEM = Twente lower extremity model muscle strength.

\section{Modelling: validation of scaling methods}

In this study, we used the Twente lower extremity model (TLEM) implemented in the AnyBody Modelling System (version 5.0). To date, TLEM is the most advanced lower extremity model and consists of a complete anatomic dataset from a human cadaveric specimen, including joint orientations, muscle and geometrical parameters. ${ }^{32}$ The model uses a three-element Hill type muscle model. The configuration of the joint angles in the AnyBody model was arranged per subject to match the experimental condition. The $\mathrm{min} / \mathrm{max}$ muscle recruitment criterion was selected, accordingly predicted joint strength is not limited by load-limiting constraints, i.e., all muscles that can contribute will be activated. $^{33}$

It should be noted that joint torque depends on muscle strength as well as geometrical properties, i.e., muscle moment arms. In order to calculate muscle moment arms from each subject, segment lengths and segment masses were measured. Using the AnyBody Modelling System, the muscles' origin and insertion points were personalised by scaling 
the subject's bone geometry. ${ }^{15}$ Validation was achieved by comparing the predicted maximal muscle activations (MMAs) during a maximal isometric leg press for different strength scaling methods.

Default TLEM strength: The first series of simulations served as controls in which strength of the muscles was not scaled. Hence, standard muscle strengths were used as described in the TLEM model. ${ }^{32}$

Length-mass-fat scaling: With only external subject-specific dimensions available, the current most advanced strength scaling method available in the AnyBody modelling software is the length-mass-fat (LMF) scaling method. This scaling method was developed and implemented by Rasmussen et al. and accounts for segment mass, segment length and body composition, ${ }^{15}$ as shown in the following equation:

$S S F_{L M F}=\frac{K_{m}}{K_{l}} \frac{R_{\text {muscle }, 1}}{R_{\text {muscle }, 0}}=\frac{K_{m}}{K_{l}} \frac{1-R_{\text {other }}-R_{\text {fat }, 1}}{1-R_{\text {other }}-R_{\text {fat }, 0}}$

Personalising muscle strength was achieved by multiplying the default TLEM muscle strength by the dimensionless strength scaling factor (SSF). Muscle mass percentage $\left(R_{\text {muscle }}\right)$ was calculated as percentage of total body mass, subtracting fat percentage $\left(R_{\text {fat }}\right)$ and the percentage corresponding to the other tissue in the body like blood, organs and bone $\left(R_{\text {other }}\right)$. $R_{\text {fat }}$ was calculated based on the equation from Gallagher et al.. ${ }^{34}$ Unfortunately, such an equation could not be found for $R_{\text {other }}$. In order to keep the method simple and in line with the AnyBody recommendation, $R_{\text {other }}$ was assumed to be a constant percentage of $50 \%$ in all individuals. ${ }^{15}$ The segment cross-sectional area was estimated by dividing the mass ratio $K_{m}$ by the length ratio $K_{l}$ (calculated by dividing the mass or length of the segment that needs to be scaled by the reference segment length in AnyBody). Subscripts 1 and 0 represent the subject in question and the reference model, respectively.

Rule-based strength scaling: The RBSS method is a newly developed strength scaling method obtained from the maximal isometric knee extension experiments as described in the calibration part of this paper. The SSF was obtained empirically by MLR including the parameters: age, total body mass, total body height, gender, mass upper leg, length upper leg, mass lower leg, length lower leg. MLR with backwards elimination was used to exclude all nonsignificant parameters. Both the full model containing all parameters and the model containing only significant parameters were used for comparison. 


\section{Data analysis}

The primary outcome variable is MMA; it shows the response of the model regarding all muscles given the maximal torque, geometrical scaling and SSF. 100\% MMA indicates a maximal experimental torque that is in accordance with the predicted torque based on the personalised strength scaling. Note that if the model-predicted strength is too low (i.e., SSF is underestimated), strength scaling is not sufficient for the exerted forces and the model will respond with muscle activations exceeding $100 \%$ accordingly. Consequently, a decreased SSF will increase the MMA and an increased SSF will decrease MMA.

A mixed model two-way ANOVA with the factors strength scaling model outcomes (MMA) and gender was used to locate differences between models. Hereafter, one-sampled Ttests were performed to test statistical significance from 100\% MMA. Besides, one-way ANOVA was used to test for gender differences in anthropometrics, strength and MMA. ANOVA and MLR were performed using the SPSS statistical package (V 21.0.0.1). Statistical significance was set at $p<0.05$.

\section{Results}

\section{Calibration study}

The experimental data of the maximal isometric knee extension were used to develop the RBSS method (Table 4.1). MLR taking all variables (age, height, mass, gender, segment masses and segment lengths) into account resulted in the following equation:

$\mathrm{SSF}_{\mathrm{RBSS}, \text { Full }}=0.006$ (age) +0.009 (body mass) -0.105 (gender) -0.111 (shank mass)

+0.998 (shank length) +0.029 (thigh mass) -0.748 (thigh length) +0.281 (body height)

The units of age is years; body mass, mass of the shank and thigh is kg; body height, length of the shank and thigh is $\mathrm{m}$; Gender $=1$ for men, Gender $=2$ for women. $\mathrm{R}^{2}=0.459$.

The MLR with backwards elimination resulted in the following equation:

$\mathrm{SSF}_{\mathrm{RBSS}, \text { Significant }}=0.704-0.007$ (age) +0.010 (body mass) -0.127 (gender)

The units of age is years; body mass is $\mathrm{kg}$; Gender $=1$ for men, Gender $=2$ for women, $\mathrm{R}^{2}=$ 0.439 . 


\section{Validation study}

Strength scaling methods were found to differ significantly in model outcomes $(p<0.001)$ and a significant interaction between strength scaling method and gender $(p<0.001)$ was found using two-way ANOVA. LMF strength scaling resulted in significant underestimation of muscle strength, indicated by an elevated MMA (123\%, p = 0.007) (Table 4.2 and Figure 4.3). In contrary, RBSS,S resulted in significant overestimation of muscle strength, indicated by a decreased MMA (91\%, $p=0.046)$. The closest predictions to $100 \% \mathrm{MMA}$ were found using the RBSS method including all variables (MMA:SSF ${ }_{\mathrm{RBSS}, \mathrm{F}}: 103 \%$, MMA:SSF TLEM: 95\%). The default muscle strength of the TLEM resulted in better predictions for men (MMA: 105\%) compared to women (MMA: 82\%). Individual results show larger variation within the LMF scaling method (range: $84 \%$ to $210 \%$ ) compared to RBSS,F (range: $68 \%$ to $158 \%$ ) in MMA (Figure 4.2 ).

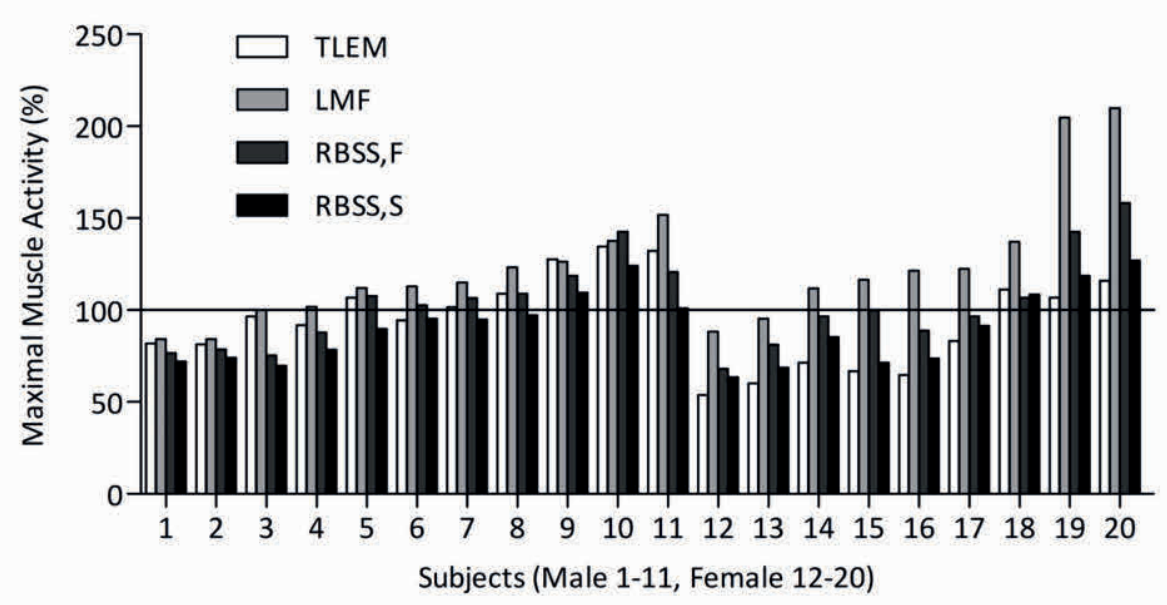

Figure 4.2 Individual results of maximal muscle activity using three scaling methods. 1) TLEM strength: SSF equals $1 ; 2$ ) LMF scaling: SSF dependent of three variables (length, mass, fat percentage); 3) RBSS,F: SSF dependent of the full model including eight variables (length, mass, age, gender, mass and length of lower and upper leg) RBSS,S: SSF dependent of only significantly variables (age, gender, mass). 


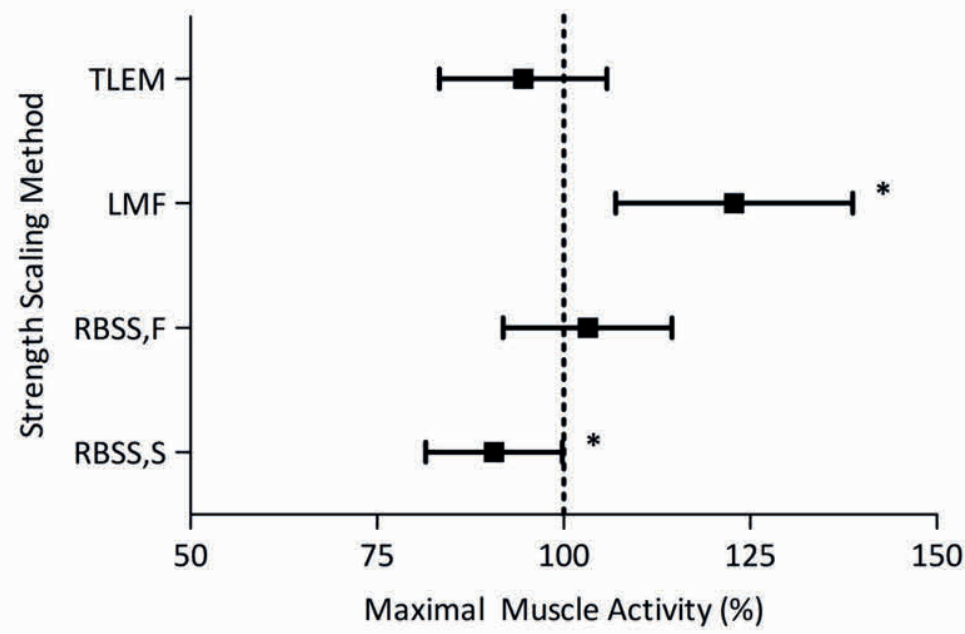

Figure 4.3 The maximal muscle activity of the strength scaling methods used in this study. Data displayed as mean and 95\% confidence interval. 1) TLEM strength: SSF equals 1; 2) LMF scaling: SSF dependent of three variables (length, mass, fat percentage); 3) RBSS,F: SSF dependent of a full model including eight variables (length, mass, age, gender, mass and length of lower and upper leg) RBSS,S: SSF dependent of only significant variables (age, gender, mass). *Significant different from $100 \%$ maximal muscle activity ( $p$ $<0.05)$.

\section{Discussion}

This study presented a new RBSS method that was validated using a separate dataset according to the recommendations of Lund et al.. ${ }^{35}$ This empirical strength scaling method used age, gender, segment length and mass as predictors. It improved prediction accuracy compared to the current LMF strength scaling method. MMA of both the RBSS,F and the LMF strength scaling method exceeded $100 \%$ indicating an overall underestimation of muscle strength, though the new RBSS method was much closer to the expected $100 \%$ MMA (SSF ${ }_{\text {RBSS }}$ : 103\%, SSF LMF $_{12}$ 123\%). Three female subjects showed on average $83 \%$ underestimation of muscle strength using the LMF method (Figure 4.2). These subjects had relatively high thigh masses ( $0.8 \mathrm{~kg}$ above mean female thigh mass), and fat percentage may not have been correctly calculated or was unevenly distributed in various body parts in these cases. The results emphasise that scaling of musculoskeletal models needs to account for age, gender and segment properties. In addition, the RBSS,S accounting only for age, mass and gender resulted in less accurate model predictions (MMA: 91\%). 
Default TLEM muscle strength was used as control muscle strength to test whether strength scaling resulted in better predictions compared to the standard model. TLEM was based on a male embalmed specimen (age 77y, height $1.74 \mathrm{~m}$, mass $105 \mathrm{~kg}$ ), selected with a high muscle mass and high fat percentage. ${ }^{32}$ Interestingly, the default TLEM muscle strength showed better results compared to the LMF scaling, especially for male subjects. Female muscle strengths were mostly overestimated, which can be explained by the fact TLEM muscle geometry is based on a single male cadaver very different from the female subjects.

In a study by D'Souza et al., ${ }^{27}$ they found similar results in the MLR with backwards elimination. The only difference was found in the predictor thigh mass, which was replaced in our study with total body mass. Moreover, they proposed from a practical point of view that body mass is a more assessable predictor compared to thigh mass and was considered as an acceptable replacement.

The range in predicted MMA was relatively large (68\% to 158\%) and therefore these scaling methods should be considered with care before applying them for subject-specific purposes. A possible explanation for the deviation within RBSS presented in this study is that it did not cover all subject-specific variations. For example, maybe some variables did not fulfil all assumptions of MLR, i.e., strength does not scale linearly with the variable age. ${ }^{25}$ A nonlinear relationship would lead to errors in the prediction of the MLR method. Therefore, RBSS using a nonlinear approach may improve predictions, ${ }^{36}$ but generally requires a larger dataset and lacks reliability in extrapolations. A second explanation for individual variations is that strength is influenced by muscle moment arms. Subjectspecific moment arms depend on both anatomically correct reference models and bone geometry scaling. Anatomically correct models are still under development and validation still needs to be done. ${ }^{37}$ Quantitative scaling relationships between muscle moment arms and anthropometric dimensions are currently not available. Murray et al. showed in human cadavers that bone size is a good measure for the prediction of muscle moment arms. $^{38}$ Therefore, we applied bone geometry scaling implemented in AnyBody and muscle moment arms were adjusted accordingly.

With respect to the measurements of maximal strength in the calibration study, inaccuracies can be caused by the non-rigidity of the dynamometer-leg system, which could lead to differences between the resultant moment at the knee joint and the measured moment. ${ }^{39}$ Another limitation is the fact that it is not certain that maximal strength was obtained during the experiments. Incomplete muscle activation can influence both the calibration and validation part of this study. Therefore the results of 
this study need to be considered in the light of the fundamental problems associated with the determination of maximal strength. Furthermore, the extrapolation of these results to the upper extremities should be done with caution, since males differ considerably in upper body strength. From prior work, RBSS equations are already available for the upper

extremities. ${ }^{27}$ A possibility for both the upper and lower extremity is to use distinct scaling methods for males and females. In future research it might be worthwhile to investigate the use of distinct scaling methods for different genders and age groups, rather than include them as a term in MLR. In this study, fat percentage was not included in the MLR model, since only advanced methods are accurate and reliable to determine body composition. Moreover, the RBSS method only included easily accessible and reliable body parameters.

A strength of this study was the use of an independent sample with a distinct protocol for external validation of the strength scaling method; i.e., a maximal leg press instead of a leg extension. A valid strength scaling method tested within a multi-joint situation will support the new strength scaling method, with possible future use for multiple other functional movement simulations.

\section{Conclusion}

This study provided new insights and suggestions to improve strength scaling for the leg muscles in human simulation systems. The results of this study show that the current LMF scaling method might be insufficient for an adequate model of muscle strength prediction. RBSS accounting for body composition, age and gender is recommended for more realistic strength prediction. However, for subject-specific modelling we found both scaling methods less satisfactory; substantial deviation from $100 \%$ muscle activation indicated large differences between measured and predicted strength in individuals. Strength scaling methods might not be sufficient to accurately predict individual differences. Therefore, more elaborate techniques, such as magnetic resonance imaging (MRI) are recommended. ${ }^{37}$ 


\section{References}

1. Goldberg EJ, Neptune RR. 2007. Compensatory strategies during normal walking in response to muscle weakness and increased hip joint stiffness. Gait Posture 25:360-7.

2. Hutchinson JR. 2004. Biomechanical modeling and sensitivity analysis of bipedal running ability. I. Extant taxa. J Morphol 262:421-40.

3. Verdijk LB, van Loon L, Meijer K, Savelberg HH. 2009. One-repetition maximum strength test represents a valid means to assess leg strength in vivo in humans. J Sports Sci 27:59-68.

4. Bobbert MF, Huijing PA, van Ingen Schenau GJ. 1986. A model of the human triceps surae muscle-tendon complex applied to jumping. J Biomech 19:887-98.

5. Zajac FE, Gordon ME. 1989. Determining muscle's force and action in multiarticular movement. Exerc Sport Sci Rev 17:187-230.

6. Duda GN, Brand D, Freitag S, et al. 1996. Variability of femoral muscle attachments. J Biomech 29:1185-90.

7. Delp SL, Hess WE, Hungerford DS, Jones LC. 1999. Variation of rotation moment arms with hip flexion. J Biomech 32:493-501.

8. Neptune RR. 2000. Computer modeling and simulation of human movement. Applications in sport and rehabilitation. Phys Med Rehabil Clin N Am 11:417-34, viii.

9. Bolsterlee B, Zadpoor AA. 2014. Transformation methods for estimation of subject-specific scapular muscle attachment sites. Comput Methods Biomech Biomed Eng 17:1492-501.

10. Carbone V, van der Krogt MM, Koopman HF, Verdonschot N. 2012. Sensitivity of subject-specific models to errors in musculo-skeletal geometry. J Biomech 45:2476-80.

11. Scheys L, Desloovere K, Suetens P, Jonkers I. 2011. Level of subject-specific detail in musculoskeletal models affects hip moment arm length calculation during gait in pediatric subjects with increased femoral anteversion. J Biomech 44:1346-53.

12. Gerus P, Sartori M, Besier TF, et al. 2013. Subject-specific knee joint geometry improves predictions of medial tibiofemoral contact forces. J Biomech 46:277886.

13. Blemker SS, Asakawa DS, Gold GE, Delp SL. 2007. Image-based musculoskeletal modeling: applications, advances, and future opportunities. J Magn Reson Imaging 25:441-51.

14. Fernandez JW, Pandy MG. 2006. Integrating modelling and experiments to assess dynamic musculoskeletal function in humans. Exp Physiol 91:371-82.

15. Rasmussen J, de Zee M, Damsgaard M, et al, editors. A General Method for Scaling Musculo-Skeletal Models. International Symposium on Computer Simulation in Biomechanics; 2005; Ohio, USA.

16. Feldman HA. 1995. On the allometric mass exponent, when it exists. J Theor Biol 172:187-97.

17. Jaric S. 2002. Muscle strength testing: use of normalisation for body size. Sports Med 32:615-31. 
18. Folland JP, Mc Cauley TM, Williams AG. 2008. Allometric scaling of strength measurements to body size. Eur J Appl Physiol 102:739-45.

19. Nevill AM, Bate S, Holder RL. 2005. Modeling physiological and anthropometric variables known to vary with body size and other confounding variables. Am J Phys Anthropol Suppl 41:141-53.

20. Frankenfield DC, Rowe WA, Cooney RN, et al. 2001. Limits of body mass index to detect obesity and predict body composition. Nutrition 17:26-30.

21. Chambers AJ, Parise E, McCrory JL, Cham R. 2014. A comparison of prediction equations for the estimation of body fat percentage in non-obese and obese older Caucasian adults in the United States. J Nutr Health Aging 18:586-90.

22. Amara CE, Rice CL, Koval JJ, et al. 2003. Allometric scaling of strength in an independently living population age 55-86 years. Am J Hum Biol 15:48-60.

23. Delbaere K, Bourgois J, Witvrouw EE, et al. 2003. Age-related changes in concentric and eccentric muscle strength in the lower and upper extremity: A cross-sectional study. Isokinet Exerc Sci 11:145-51.

24. Jubrias SA, Odderson IR, Esselman PC, Conley KE. 1997. Decline in isokinetic force with age: muscle cross-sectional area and specific force. Pflugers Arch 434:24653.

25. Lindle RS, Metter EJ, Lynch NA, et al. 1997. Age and gender comparisons of muscle strength in 654 women and men aged 20-93 yr. J Appl Physiol (1985) 83:1581-7.

26. Lynch NA, Metter EJ, Lindle RS, et al. 1999. Muscle quality. I. Age-associated differences between arm and leg muscle groups. J Appl Physiol (1985) 86:188-94.

27. D'Souza S, Rasmussen J, Schwirtz A. 2012. Multiple linear regression to develop strength scaled equations for knee and elbow joints based on age, gender and segment mass. International Journal of Human Factors Modelling and Simulation 3:32-47.

28. Morse Cl, Thom JM, Birch KM, Narici MV. 2005. Changes in triceps surae muscle architecture with sarcopenia. Acta Physiol Scand 183:291-8.

29. Jones PR, Pearson J. 1969. Anthropometric determination of leg fat and muscle plus bone volumes in young male and female adults. J Physiol 204:63P-6P.

30. Rassier DE, Maclntosh BR, Herzog W. 1999. Length dependence of active force production in skeletal muscle. J Appl Physiol (1985) 86:1445-57.

31. Savelberg HH, Meijer K. 2004. The effect of age and joint angle on the proportionality of extensor and flexor strength at the knee joint. J Gerontol A Biol Sci Med Sci 59:1120-8.

32. Klein Horsman MD, Koopman HF, van der Helm FC, et al. 2007. Morphological muscle and joint parameters for musculoskeletal modelling of the lower extremity. Clin Biomech (Bristol, Avon) 22:239-47.

33. Rasmussen J, Damsgaard M, Voigt M. 2001. Muscle recruitment by the $\mathrm{min} / \mathrm{max}$ criterion -- a comparative numerical study. J Biomech 34:409-15.

34. Gallagher D, Heymsfield SB, Heo M, et al. 2000. Healthy percentage body fat ranges: an approach for developing guidelines based on body mass index. Am J Clin Nutr 72:694-701. 
35. Lund ME, de Zee M, Andersen MS, Rasmussen J. 2012. On validation of multibody musculoskeletal models. Proc Inst Mech Eng H 226:82-94.

36. Rasmussen J. 1998. Nonlinear programming by cumulative approximation refinement. Structural Optimization 15:1-7.

37. Erdemir A, McLean S, Herzog W, van den Bogert AJ. 2007. Model-based estimation of muscle forces exerted during movements. Clin Biomech (Bristol, Avon) 22:131-54.

38. Murray WM, Buchanan TS, Delp SL. 2002. Scaling of peak moment arms of elbow muscles with upper extremity bone dimensions. J Biomech 35:19-26.

39. Arampatzis A, Karamanidis K, De Monte G, et al. 2004. Differences between measured and resultant joint moments during voluntary and artificially elicited isometric knee extension contractions. Clin Biomech (Bristol, Avon) 19:277-83. 
CHAPTER

\section{Comparison of in vivo muscle volumes of the lower extremity to cadaveric data sets}

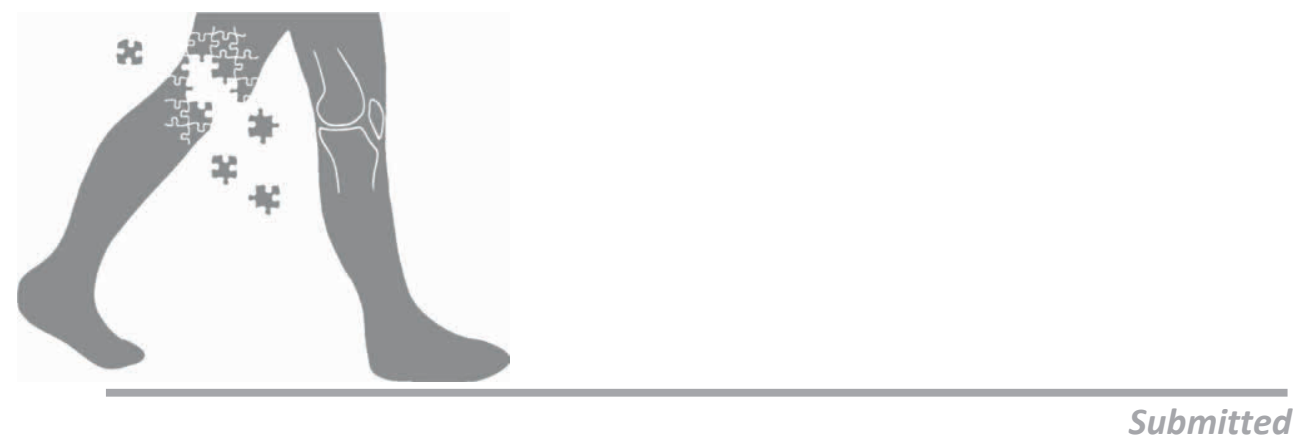

Pieter Oomen, Kenneth Meijer, Maarten Drost 


\section{Abstract}

Background Current musculoskeletal models are based upon cadaveric data sets. These data sets are not representative for modelling young adults. Moreover, personalized modelling requires complete and accurate anatomical data from the concerning subject. Therefore, the purpose of this study is to determine individual muscle volumes of the lower extremity in vivo by MRI.

Methods This study used T1-weighted magnetic resonance images to create a complete in vivo data set of lower extremity muscle volumes from a healthy 23 year old male volunteer. A total of 34 muscles were manually segmented from a single leg.

Results The combined muscle volume of hamstrings and quadriceps was up to 6.8 times higher compared to literature values. After normalizing for thigh muscle volume the apparent differences in muscle volume distribution disappeared, minor differences are most likely explained by individual variation.

Conclusion Aging was found to decrease absolute muscle volumes. It appeared that distribution of relative volumes remained constant, however, muscles consisting mostly of slow twitch muscle fibres (e.g. m. soleus) appeared to be preserved. Imaging can be a useful tool to find individual variations and consequently increase accuracy of personalized modelling. 


\section{Introduction}

Musculoskeletal models have been developed to gain insight in the principles of human movement. Anatomical data from the human body are required for accurate musculoskeletal models. ${ }^{1}$ To date, most musculoskeletal models are based on cadaveric data sets containing muscle parameters derived from careful dissection, e.g. attachment sites, PCSA, muscle volumes and pennation angles. ${ }^{1-5}$ Obviously, cadaveric specimens are not representative to model a healthy adult, given the advanced age of cadaver specimens. Since sarcopenia due to aging contributes to significant changes in muscle volume compared to healthy young subjects. ${ }^{6}$ In addition, aging might lead to degeneration of especially fast twitch fibres ${ }^{7}$ which are not equally present in various muscles. ${ }^{8}$ Therefore scaling muscle size from a cadaveric data set might introduce errors in personalising the musculoskeletal model.

Alternatively, imaging muscle characteristics is becoming more feasible for personalising musculoskeletal models, because it is supposed to increase accuracy of musculoskeletal models and it has become more easily available. ${ }^{9}$ Holzbaur et al. used MRI measurements to determine muscle volumes of upper limb segments. ${ }^{10}$ Accordingly, they conclude that muscle volume is the major predictor of strength. ${ }^{11}$ Therefore, realistic subject-specific muscle volumes can increase the accuracy of personalized models. However, a complete in vivo dataset of the lower extremities is lacking for the application in a personalized lower limb model. Thus, the purpose of this study is to determine individual muscle volumes of the lower extremity in vivo by MRI.

\section{Methods}

Muscle volumes of the complete lower limb were obtained from one healthy adult male ( 23 years, $81 \mathrm{~kg}, 1.88 \mathrm{~m}$ ). The subject had an office job for 40 hours a week and was active in recreational sports for about 5-7 hours a week. MRI measurements were conducted using a 3T Philips Intera scanner (Philips Medical Systems, Best, The Netherlands). The sense-xl-torso coil for signal reception was placed around the concerned segment, i.e. lower leg, upper leg, hip or lower torso. T1-weighted imaging was performed using a Turbo Spin Echo, with the following parameters: field of view $=400 \times 400 \mathrm{~mm}^{2}$, matrix size $=480 \times 480$, slice thickness $=5 \mathrm{~mm}$, slice gap $=0 \mathrm{~mm}$, number of slices $=80$ slices for lower leg, upper leg and hip region, 40 slices for lower torso, slices overlay $=5$ slices, repetition time $=600 \mathrm{~ms}$ and echo time $=10 \mathrm{~ms}$. 
Segmentation of the individual muscles was conducted manually in every slice using the delineation software Volumetool (version 1.3.0, UMC Utrecht, Utrecht, the Netherlands). ${ }^{12}$ Connective and adipose tissues were excluded when located on the outside of the muscle; only contractive muscle tissue and tissue surrounded by muscle tissue (e.g. internal tendons) were included during the segmentation; The Volume plugin was used to calculate volume sizes for each segment. The volumes of muscles that spanned more than one segment were combined, accounting for overlay.

To compare muscle volumes to that in literature, we used the most complete lower limb cadaveric data sets reported by Friederich and Brand, Klein Horsman et al., Ward et al. and Wickiewicz et al.. ${ }^{1-4}$ Individual muscle volumes were normalized to the combined hamstring and quadriceps volume using the following equation:

$$
\text { Relative muscle volume }(\%)=\frac{\text { muscle volume }(\mathrm{ml})}{\sum \text { muscle volume quadriceps, hamstrings }(\mathrm{ml})} \times 100 \%
$$

Muscle masses from literature were calculated to volumes assuming a muscle density of $1.056 \mathrm{~g} / \mathrm{cm}^{3}{ }^{13}$

\section{Results}

Individual muscle volumes segmented from MR images acquired in this study are shown in Table 5.1. Muscle volumes ranged from $1191.4 \mathrm{ml}$ for the gluteus maximus to $24.6 \mathrm{ml}$ for the popliteus. Almost all lower limb muscles could be segmented individually except for two muscle groups, the extensor digitorum and hallucis longus muscle group and the peroneus muscle group. Therefore, these muscles were combined during segmentation. In vivo muscle volumes of the quadriceps and hamstrings combined were 1.3 up to 6.8 times larger compared to volumes reported in literature (Table 5.1). Relative muscle volumes showed consistency compared to literature. For example, the distribution of relative muscle volume of the rectus femoris ranged from 8.5 to $10.4 \%$ of total hamstrings and quadriceps muscle volume (in vivo: 9.4\%). However, some muscles showed a larger difference in muscle volumes, i.e. the gluteus medius $10.4 \%$ in vivo versus $14.7-23.3 \%$ in cadaver studies. 
Table 5.1 In vivo measured muscle volumes compared to cadaveric datasets. Relative muscle volumes were calculated as a percentage of the combined hamstrings and quadriceps muscle volume. Note that individual results from other papers were shown if available. Friederich, ${ }^{4}$ Klein $\mathrm{H}^{1}{ }^{1}$ Ward, ${ }^{2}$ Wickiewicz. ${ }^{3}(-)$ reference lacked information on this parameter; (\{) combined muscle volume

\begin{tabular}{|c|c|c|c|c|c|c|c|c|c|}
\hline \multirow{2}{*}{ Subjects (n) } & \multicolumn{2}{|c|}{ This study } & \multicolumn{2}{|c|}{ Friederich } & \multirow{2}{*}{$\begin{array}{c}\text { Klein } \mathbf{H} \\
1\end{array}$} & \multirow{2}{*}{$\begin{array}{c}\text { Ward } \\
n=16-21\end{array}$} & \multicolumn{3}{|c|}{ Wickiewicz } \\
\hline & \multicolumn{2}{|c|}{1} & $1\left[1^{\mathrm{st}}\right]$ & $1\left[2^{\text {nd }}\right]$ & & & $1\left[1^{\text {st }}\right]$ & $1\left[2^{\text {nd }}\right]$ & $1\left[3^{\text {rd }}\right]$ \\
\hline Age (y) & \multicolumn{2}{|c|}{23} & 37 & 63 & 77 & $83 \pm 9$ & - & - & - \\
\hline Length $(\mathrm{cm})$ & \multicolumn{2}{|c|}{188} & 183 & 168 & 174 & $168 \pm 9$ & - & - & - \\
\hline Mass (kg) & \multicolumn{2}{|c|}{81} & 91 & 69 & 105 & $83 \pm 15$ & - & - & - \\
\hline Volume & \multirow{2}{*}{\multicolumn{2}{|c|}{3575.3}} & & & & & & & \\
\hline $\begin{array}{l}\text { Hamstrings \& } \\
\text { Quadriceps (ml) }\end{array}$ & & & 2789.0 & 683.0 & 2262.3 & 1235.8 & 1125.9 & 980.3 & 523.5 \\
\hline Muscle & (ml) & (rel\%) & (rel\%) & (rel\%) & (rel\%) & (rel\%) & (rel\%) & (rel\%) & (rel\%) \\
\hline Iliacus & 277.7 & 7.8 & 8.4 & 12.4 & 9.0 & 8.7 & - & - & - \\
\hline Glut max & 1191.4 & 33.3 & 31.0 & 47.9 & 41.4 & 41.9 & - & - & - \\
\hline Glut med & 372.2 & 10.4 & 14.7 & 23.3 & 18.4 & 21.0 & - & - & - \\
\hline Glut min & 178.3 & 5.0 & 4.9 & 10.5 & 3.7 & - & - & - & - \\
\hline Piriformus & 50.6 & 1.4 & 1.9 & 5.6 & 1.4 & - & - & - & - \\
\hline Obt ext & 107.8 & 3.0 & 0.3 & 3.5 & 4.7 & - & - & - & - \\
\hline Obt int & 72.2 & 2.0 & 1.5 & 4.7 & 2.3 & - & - & - & - \\
\hline Quad fem & 50.6 & 1.4 & 4.1 & - & 2.2 & - & - & - & - \\
\hline Pectineus & 65.3 & 1.8 & 2.3 & 1.9 & 3.4 & - & 2.4 & 3.5 & 2.8 \\
\hline Add brev & 178.7 & 5.0 & 4.4 & 6.7 & 4.8 & 4.2 & 4.0 & 5.4 & 5.1 \\
\hline Add long & 210.3 & 5.9 & 6.7 & 15.1 & 7.1 & 5.7 & 5.4 & 8.7 & 6.5 \\
\hline Add mag & 656.5 & 18.4 & 23.9 & 36.9 & 25.2 & 24.9 & 22.9 & 24.0 & 30.2 \\
\hline Gracilis & 164.4 & 4.6 & 3.2 & 2.9 & 3.9 & 4.0 & 2.6 & 4.8 & 4.5 \\
\hline Sartorius & 232.9 & 6.5 & 5.0 & 15.4 & 18.2 & 6.0 & 6.3 & 7.4 & 6.0 \\
\hline Rectus fem & 335.7 & 9.4 & 8.5 & 8.8 & 10.0 & 8.5 & 8.7 & 8.9 & 10.4 \\
\hline Vastus inter & 816.4 & 22.8 & 21.7 & 19.8 & 12.9 & 13.2 & 23.4 & 9.0 & 19.5 \\
\hline Vastus lat & 798.3 & 22.3 & 18.4 & 19.5 & 25.8 & 28.8 & 17.5 & 31.1 & 23.2 \\
\hline Vastus med & 556.8 & 15.6 & 19.9 & 18.0 & 20.9 & 18.3 & 18.8 & 20.3 & 16.9 \\
\hline Bic fem long & 250.2 & 7.0 & 7.8 & 8.8 & 10.3 & 8.7 & & & \\
\hline Bic fem short & 166.6 & 4.7 & 3.6 & 7.6 & 4.8 & 4.6 & 13.4 & \} 14.8 & \} 13.1 \\
\hline Semimembr & 348.4 & 9.7 & 12.4 & 11.0 & 6.1 & 10.3 & 11.1 & 9.3 & 17.0 \\
\hline Semitend & 303.0 & 8.5 & 7.6 & 6.6 & 9.2 & 7.6 & 7.1 & 6.7 & - \\
\hline Tens fasc lat & 111.6 & 3.1 & 2.7 & 3.7 & 3.7 & - & - & - & - \\
\hline Tibialis ant & 151.7 & 4.2 & 4.7 & 8.5 & 5.4 & 6.1 & 6.6 & 7.0 & 8.2 \\
\hline Ext dig long & & & 2.3 & 4.4 & 1.4 & 3.1 & 2.9 & 4.0 & 5.3 \\
\hline Ext hal long & \} 140.9 & 3.9 & 1.1 & 2.6 & 1.6 & 1.6 & 1.2 & 1.4 & 1.8 \\
\hline Peroneus I & & & 3.8 & 5.1 & 3.6 & 4.4 & 3.9 & 5.1 & 4.5 \\
\hline Peroneus $\mathrm{b}$ & \} 125.9 & \} 3.5 & 2.5 & 3.4 & 2.3 & 1.9 & 1.4 & 2.1 & 2.4 \\
\hline Gastroc lat & 153.7 & 4.3 & 7.6 & 8.9 & 6.0 & 4.8 & & & \\
\hline Gastroc med & 307.3 & 8.6 & 3.9 & 5.6 & 11.6 & 8.7 & \} 13.2 & \} 16.4 & \} 22.2 \\
\hline Soleus & 543.1 & 15.2 & 20.6 & 25.2 & 20.0 & 21.1 & 18.1 & - & - \\
\hline Plantaris & 29.3 & 0.8 & - & - & 0.5 & - & 0.5 & 0.7 & 0.3 \\
\hline Popliteus & 24.6 & 0.7 & - & - & 1.1 & - & 1.9 & 1.7 & - \\
\hline Flex dig long & 37.7 & 1.1 & 1.1 & 2.5 & 1.1 & 1.6 & 1.6 & 1.9 & 1.9 \\
\hline Flex hal long & 157.7 & 4.4 & 3.3 & 4.5 & 3.5 & 3.0 & 2.0 & 2.5 & 2.7 \\
\hline Tibialis post & 117.2 & 3.3 & 3.3 & 6.0 & 4.7 & 4.5 & 5.6 & 5.1 & 7.4 \\
\hline
\end{tabular}




\section{Discussion}

The present study generated a complete data set of in vivo measured muscle volumes of the lower extremity from one subject. It was found that relative muscle volumes were in agreement with literature. Minor differences could arise by interchanging muscle volumes between similar muscle groups. Although muscles can be reliably determined by $\mathrm{MRI}^{14}$ some boundaries between muscles were hard to distinguish, for example in the proximal part of the vasti group. As a result several millilitres could have been interchanged between these muscles. This might not be a major problem in musculoskeletal modelling, since these muscles have similar functions. For some muscles we were unable to differentiate muscle contours, hence we combined these muscle groups i.e. peroneus muscle group and an extensor digitorum and hallucis longus muscle group. Finally, a possible factor influencing relative muscle volumes were interindividual variations. Consequently, scaling muscle volumes could result in erroneous predictions of muscle volumes and accordingly in inaccurate subject specific models. Therefore, in vivo imaging by MRI might become an important tool to personalize musculoskeletal models. Moreover, some relative muscles volumes were found to be systematically smaller in our data set compared to data sets from old cadaveric subjects. A possible explanation is that age related atrophy affects mostly Type II muscle fibres. ${ }^{7}$ Previous work from Johnson et al. showed fibre type distributions from the major muscle groups in the lower extremity within six young subjects; the gastrocnemii, gluteus maximus, adductor magnus, vastus medialis, peroneus longus, biceps femoris, tibialis anterior and soleus to contain more than 50\% Type I muscle fibres. ${ }^{15}$ Indeed, relative muscles volumes of these muscles are consequently increased in the datasets from older specimens (Table 5.1).

It should be noted that cadaveric data sets from Wickiewicz et al. lacked data on subject characteristics and important hip muscles, besides some muscle heads were combined to one entire muscle. ${ }^{3}$ Furthermore, the third specimen from Wickiewicz et al. lacked data on the semitendinosus muscle, which influenced relative muscle volumes. ${ }^{3}$ Our in vivo data set was complete up to the proximal part of ilium, which resulted in a partly missing psoas major which originates from the vertebral bodies of T12 and L1-L5. Therefore, the psoas major was not listed in Table 5.1.

A recent paper from Handsfield et al. showed that imaging techniques are becoming more and more available for the application on a large dataset $(n=24)$ of lower limb muscles ( $n$ $=35) \cdot{ }^{16}$ For the implementation in personalized modelling, subject specific characteristics are needed to drive these musculoskeletal models. Future applications in musculoskeletal modelling might involve more specific architectural parameters. First of all, subject specific bone geometries and tendon attachments can be morphed from CT or MR 
images. ${ }^{17}$ Furthermore, diffusion weighted MRI might increase knowledge on in vivo muscle architecture, i.e. muscle fibre length, pennation angle and physiological crosssectional area. ${ }^{18,19}$ Further research might incorporate these and possibly other detailed characteristics of subject specific anatomical data in a musculoskeletal model.

\section{Conclusion}

This data set gives the opportunity for more accurate musculoskeletal models targeting young and healthy adults. To date musculoskeletal models are using scaled cadaveric data sets from mostly older and sometimes fragile subjects. Integration of subject-specific data can increase accuracy and utility of these models in a clinical context. ${ }^{9}$ 


\section{References}

1. Klein Horsman MD, Koopman HF, van der Helm FC, et al. 2007. Morphological muscle and joint parameters for musculoskeletal modelling of the lower extremity. Clin Biomech (Bristol, Avon) 22:239-47.

2. Ward SR, Eng CM, Smallwood LH, Lieber RL. 2009. Are current measurements of lower extremity muscle architecture accurate? Clin Orthop Relat Res 467:107482.

3. Wickiewicz TL, Roy RR, Powell PL, Edgerton VR. 1983. Muscle architecture of the human lower limb. Clin Orthop Relat Res 179:275-83.

4. Friederich JA, Brand RA. 1990. Muscle fiber architecture in the human lower limb. J Biomech 23:91-5.

5. Yamaguchi GT, Sawa AGU, Moran DW, et al. A Survey of Human Musculotendon Actuator Parameters. In: Winter JM, Woo SLY, editors. Multiple Muscle Systems: Biomechanics and Movement Organization. Berlin: Springer; 1990. p. 717-73.

6. Narici MV, Maganaris CN. 2006. Adaptability of elderly human muscles and tendons to increased loading. J Anat 208:433-43.

7. Larsson L, Sjodin B, Karlsson J. 1978. Histochemical and biochemical changes in human skeletal muscle with age in sedentary males, age $22--65$ years. Acta Physiol Scand 103:31-9.

8. Edgerton VR, Smith JL, Simpson DR. 1975. Muscle fibre type populations of human leg muscles. Histochem J 7:259-66.

9. Blemker SS, Asakawa DS, Gold GE, Delp SL. 2007. Image-based musculoskeletal modeling: applications, advances, and future opportunities. J Magn Reson Imaging 25:441-51.

10. Holzbaur KR, Murray WM, Gold GE, Delp SL. 2007. Upper limb muscle volumes in adult subjects. J Biomech 40:742-9.

11. Holzbaur KR, Delp SL, Gold GE, Murray WM. 2007. Moment-generating capacity of upper limb muscles in healthy adults. J Biomech 40:2442-9.

12. Bol GH, Kotte AN, van der Heide UA, Lagendijk JJ. 2009. Simultaneous multimodality ROI delineation in clinical practice. Comput Methods Programs Biomed 96:133-40.

13. Ward SR, Lieber RL. 2005. Density and hydration of fresh and fixed human skeletal muscle. J Biomech 38:2317-20.

14. Tingart MJ, Apreleva M, Lehtinen JT, et al. 2003. Magnetic resonance imaging in quantitative analysis of rotator cuff muscle volume. Clin Orthop Relat Res 104-10.

15. Johnson MA, Polgar J, Weightman D, Appleton D. 1973. Data on the distribution of fibre types in thirty-six human muscles. An autopsy study. J Neurol Sci 18:11129.

16. Handsfield GG, Meyer CH, Hart JM, et al. 2014. Relationships of 35 lower limb muscles to height and body mass quantified using MRI. J Biomech 47:631-8.

17. Fernandez JW, Mithraratne P, Thrupp SF, et al. 2004. Anatomically based geometric modelling of the musculo-skeletal system and other organs. Biomech Model Mechanobiol 2:139-55. 
18. Heemskerk AM, Strijkers GJ, Vilanova A, et al. 2005. Determination of mouse skeletal muscle architecture using three-dimensional diffusion tensor imaging. Magn Reson Med 53:1333-40.

19. Lansdown DA, Ding Z, Wadington M, et al. 2007. Quantitative diffusion tensor MRI-based fiber tracking of human skeletal muscle. J Appl Physiol (1985) 103:67381. 


\section{Personalised muscle strength for musculoskeletal modelling of locomotion, a proof of concept study}

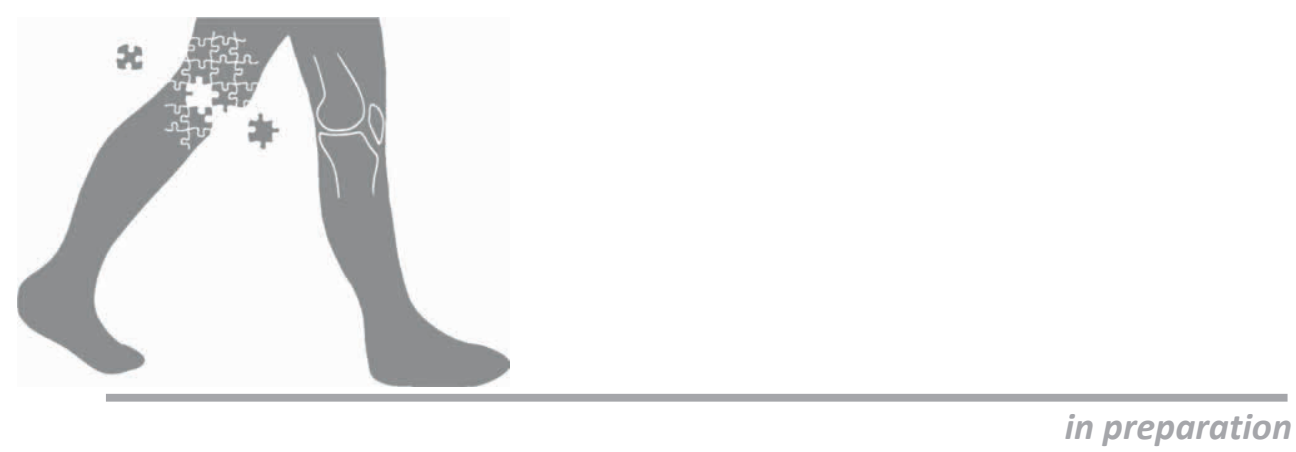

Pieter Oomen, Kenneth Meijer, Maarten Drost 


\begin{abstract}
Background Uniform strength scaling is an easy to use method to personalise musculoskeletal models, however, these rescaled generic musculoskeletal models might be less subject-specific and precise compared to models based on musculoskeletal imaging. This study provides a proof of concept that evaluates the impact of different approaches to personalise muscle strength on estimated muscle activities and joint loading in musculoskeletal modelling.
\end{abstract}

Methods A healthy female volunteer participated in this proof of concept study. Individual muscle volumes of the lower extremities were obtained by T1 weighted MRI; and motion capture was performed at different walking speeds. Model simulations of gait were performed using different muscle strength optimizations: two methods employed uniform strength scaling, one method used MRI derived muscle volumes, and as a control the model was run without personalising muscle strength.

Results The two scaling methods scaled the muscle strength 17 - 33\% smaller compared to the control model, resulting in higher muscle activations (6-55\%), while internal joint forces remained unaltered. The method using MRI derived muscle volumes showed that muscles were individually changed in volume relative to the control model (range: $-75 \%$, $+56 \%$ compared to the control model), resulting in different muscle activations (range: $40 \%,+97 \%$ compared to control model). Furthermore, the method using MRI muscle volumes showed that joint loading was maximally decreased by $16 \%$ in mediolateral direction compared to the control model.

Conclusion This proof of concept study shows that subject specific data from imaging can alter muscle activities more than uniform strength scaling techniques; whilst internal joint reaction forces were almost unaltered. Future studies could elaborate on this proof of concept study to evaluate these effects in a larger dataset. 


\section{Introduction}

Musculoskeletal modelling is an important tool to understand determinants of pathological gait in a variety of musculoskeletal disorders. ${ }^{1,2}$ These models allow us to identify the affected parameters in pathological gait that are difficult or rather impossible to measure in real life, such as muscle activity in the smaller or deeper located muscles and joint loading. ${ }^{3,4}$

To date the input parameters of musculoskeletal models are mostly based upon data derived from cadaveric experiments. ${ }^{5,6}$ It is most likely that differences between the cadaver specimens and the individual to be investigated result in erroneous model predictions. It has been proposed that musculoskeletal models need to be personalised to obtain more accurate model outcomes. ${ }^{7,8}$ Two possible strategies are available to make musculoskeletal models subject specific: i) rescaling generic models and ii) the use of medical imaging. Imaging might result in better personalisation, but it is more costly and time-consuming compared to rescaled generic models. Moissenet et al. concluded that sufficient personalisation could be acquired by uncomplicated rescaling methods, furthermore, they questioned if imaging was necessary as input for musculoskeletal models in order to estimate joint contact forces. ${ }^{9}$

Sensitivity analyses are useful to explore the impact of input parameters. For example, Carbone et al., (2012) showed that insertion points of muscles have a major impact on muscle force predictions. ${ }^{10}$ Furthermore, the tibiofemoral alignment and contact locations in musculoskeletal models were found to have a significant impact on the accuracy of knee contact forces. ${ }^{11}$ A sensitivity analysis of Navacchia et al. showed that maximal muscle force is one of the input characteristics that has the largest impact on compressive loads at the knee during gait. ${ }^{12}$ Maximal muscle force is dependent on its physiological cross-sectional area, pennation angle and maximal muscle stress. The physiological crosssectional area (PCSA) is defined as the sum of areas of all perpendicular cross-sections of each muscle fibre. ${ }^{13}$ Moreover, PCSA can be calculated by dividing muscle volume by optimal muscle fibre length. ${ }^{14}$ Maximal muscle stress (or specific tension) is considered as the amount of force per unit of PCSA; however, the magnitude and constancy of this parameter is still under debate. ${ }^{15,16}$

It remains unclear whether the PCSA can be accurately determined by rescaled generic models or that imaging is required. Previous studies have already shown that scaling muscle strength alters the prediction of maximal muscle strength significantly. ${ }^{17,18}$ However, these rule-based strength scaling routines were found to have limited accuracy to individuals. Alternatively, imaging might be a powerful tool to personalise muscle 
strength of individual muscles. ${ }^{19}$ In a study of Bolsterlee et al. the impact of personalisation of muscle volume was examined in the upper extremities. ${ }^{20}$ Their results showed almost no differences between MRI measured muscle volumes and those resulting from a uniform strength scaling routine. In contrast to the upper extremities; aging, sedentary behaviour and training have been shown to result in very specific alterations in individual muscles of the lower extremities. ${ }^{21}$ Therefore, the results of Bolsterlee et al. might not be generalizable to the lower extremity; hence, imaging might significantly contribute to more accurate musculoskeletal models of the lower extremities. $^{20}$

The aim of this study is to evaluate different personalisation strategies for muscle strength within a single subject in order to provide a proof of concept. Our hypothesis is that personalisation of muscle strength using MRI derived muscle volumes has a substantial impact on predicted muscle activities and joint contact forces compared to generic strength scaling methods.

\section{Methods}

\section{Anthropometrics}

A healthy female volunteer $(23 \mathrm{y}, 1.75 \mathrm{~m}$, and $63.9 \mathrm{~kg})$ participated in this study. Anthropometrics were obtained in order to personalise the models. Fat percentage was measured by a four sites skinfold measurement (calliper: Harpenden); segment lengths and masses of the upper and lower leg were determined (densities were assumed to be $1.0078 \mathrm{~g} / \mathrm{ml}$ and $1.0279 \mathrm{~g} / \mathrm{ml}$ for respectively the thigh and the shank). ${ }^{22,23}$

\section{Experimental procedures}

Imaging; An MRI scan of the lower extremities was conducted using a 3T Philips Achieva Scanner (Philips Medical Systems, Best, the Netherlands). For signal reception a sense-xltorso coil was placed around the lower extremities of the subject. T1-weighted images were obtained using Turbo Spin Echo: field of view $=400 \times 400 \mathrm{~mm}^{2}$, matrix size $=480 \times$ 480 , slice thickness $=4 \mathrm{~mm}$, slice gap $=0 \mathrm{~mm}$, number of slices $=9$ times 40 slices (three separate regions consisting of three stacks each, overlay $=5$ slices), repetition time $=763$ $\mathrm{ms}$ and echo time $=16 \mathrm{~ms}$. Segmentation of the main muscles at the right leg was conducted manually using the delineation software Volumetool (version 1.3.0, UMC Utrecht, the Netherlands). ${ }^{24}$ The volumes were calculated using a custom made 
Mathematica program (Version 9.0.1.0, Wolfram research, Champaign, USA) accounting for overlay.

The model was calibrated for maximal muscle stress using a separate experimental dataset of maximal voluntary contractions (MVCs). In order to get an individualized assessment of muscle stress and optimal length of the knee extensors, the subject performed MVCs at five different knee angles using the Biodex system 3 with knee attachment. A quadratic polynomial was fitted through the data points to obtain the maximum joint moment and optimal knee angle. In addition, a five-camera setup for motion capture (VICON, $200 \mathrm{~Hz}$, Oxford Metrics Ltd., Oxford, UK) was used to determine actual knee angles and alignment with the Biodex rotation centre during the contractions. Misalignment between the knee and Biodex rotational centre was corrected according the method of Arampatzis et al.. ${ }^{25}$ The model was calibrated by using the maximal knee extension torque to adjust maximal stress for all muscles in the model; whilst, the optimal knee extension angle was used for calibrating muscle characteristics at optimal knee joint.

Gait analysis was performed using an eight-camera motion capture system (VICON, 200 $\mathrm{Hz}$, Oxford Metrics Ltd., Oxford, UK), with two AMTI force plates (1000Hz, Advanced Mechanical Technology, Watertown, USA). The subject was equipped with 16 retroreflective markers positioned on the lower extremities as defined by the plug-in-gait marker placement manual. Delsys TrignoTM (1000Hz, Delsys Inc., Boston, USA) wireless surface electromyography (EMG) electrodes were placed according to the Seniam procedures $^{26}$ on the following 10 muscles on the right leg, gluteus maximus, rectus femoris, medial and lateral vastus, biceps femoris long head, semitendinosus, soleus, tibialis anterior, medial and lateral gastrocnemius. In order to normalize EMG data maximum peak activation levels during various maximum contractions were obtained. After the subject was accustomed in the setup, the subject performed 7 correct preferred walking speed (PWS) trials. Subsequently, the subject walked 7 fast trials at approximately $120 \%$ and 7 slow trials at approximately $80 \%$ of PWS. From each trial one gait cycle from the right leg was analysed from heel strike until the next heel strike, including the stance phase on the force platform.

\section{Modelling procedures}

The AnyBody modelling system (AnyBody version 6.0, AnyBody Technology, DK), with the AnyBody managed Model Repository version 1.6.3 was used for musculoskeletal modelling the gait trials. A three-element Hill type muscle model enabled both active and passive components in the muscle model. 
For calibration purpose, the maximal joint torque and optimal knee angle were simulated in the musculoskeletal model. Min/max muscle recruitment was used to exclude loadlimiting constraints. ${ }^{27}$ Furthermore, we used the MRI derived muscle volumes in order to personalize muscle strength. Consequently, the maximal joint torque was applied at the specific knee angle. The model was calibrated by manipulating maximal muscle stress in order to obtain $100 \%$ maximal muscle activation. Accordingly, this maximal muscle stress was used for all muscles during the simulations of the gait trials.

For the gait trials we used a third order polynomial muscle recruitment algorithm to solve the redundant distribution problem physiologically for locomotion. ${ }^{28}$ The gait trials were simulated using the standard model strengths derived from the Twente Lower Extremity model (TLEM) ${ }^{5}$ as control model and three experimental methods for personalisation muscle strength of increasingly personalisation: 1) the Length-Mass-Fat strength scaling as implemented in the AnyBody software; ${ }^{29}$ 2) a rule-based strength scaling routine accounting for age, gender, segment masses and lengths; ${ }^{18} 3$ ) muscle volumetric data as derived from MRI (abbreviated 1:LMF, 2:RBSS, 3:MRI). In addition, all other muscle parameters (e.g. muscle recruitment algorithm, pennation angle, optimal fibre angle, insertion points) were unaltered between personalisation methods.

\section{Data analysis}

Muscle activities and internal knee forces were exported from AnyBody and the magnitude of the peak values were calculated using Matlab (version 7.14 the Mathworks, Inc, USA). Since muscles in AnyBody are divided in multiple elements, muscle activations were calculated taking into account the physiological cross-sectional area of each muscle element as a weighting factor. The EMG measurements were used to verify model derived muscle activations. EMG for both the MVC and the gait trials were band-pass filtered (10$250 \mathrm{~Hz}$ ) with a fourth order Butterworth filter, subsequently, the moving average (100 samples/second) was calculated from the rectified signal. The EMG for the gait trials was normalized accordingly to the MVC trials. Finally, a mean signal during a rest trial was used as cut-off point for muscle activation. 


\section{Results}

\section{Anthropometrics}

The anthropometrical characteristics of the subject were as follows: fat percentage: 22.5\%; thigh mass: $4.7 \mathrm{~kg}$; shank mass: $3.0 \mathrm{~kg}$; thigh length: $0.44 \mathrm{~m}$ (from top of trochanter to lateral epicondylus); shank length $0.42 \mathrm{~m}$ (from medial condyles to medial malleolus).

\section{Determination of optimal knee angle and maximal muscle stress}

Maximal voluntary contractions of the knee extensors resulted in a maximum value of $192.0 \mathrm{Nm}$ at 60 degrees knee flexion. Therefore, the optimal knee angle for knee extensor strength was set at 60 degrees and specific tension of muscles (maximum muscle stress) was set at $30.4 \mathrm{~N} / \mathrm{cm}^{2}$ to match $100 \%$ muscle activation at 60 degrees.

\section{Muscle sizes between personalisation techniques}

In order to compare muscle strength across personalisation techniques PCSA per muscle was calculated (Table 6.1). Muscle strength of the LMF personalisation technique was scaled by a factor 0.8 and 0.67 for the upper and lower leg respectively compared to TLEM muscle size. The RBSS personalisation method scaled both upper and lower leg muscles with a factor 0.83. Finally the method using MRI derived muscle volumes showed that most muscles were smaller compared to TLEM; for example the PCSA of Sartorius was decreased by $75 \%$, only the semimembranosus, vastus intermedius and rectus femoris had higher PCSAs compared to TLEM (resp. $+56 \%$; +22\%; +4\%).

\section{Subject specific muscle activation}

The personalised models showed increased muscle activation compared to the control model for most muscles (Figure 6.1, Table 6.2). In addition, the LMF and RBSS methods resulted in increased muscle activation peaks in all muscles. At preferred walking speed the LMF personalisation technique compared to TLEM showed up to $55 \%$ increased muscle activation in the lower leg muscles and up to $26 \%$ in upper leg muscles. The RBSS method resulted in about $20 \%$ increased muscle activations compared to TLEM at all walking conditions. The personalised muscle strength technique using MRI derived muscle volumes resulted in some muscles becoming more active and others that were less activated compared to the TLEM (range: $-40 \%$ for sartorius; $+100 \%$ for lateral gastrocnemius). 
Table 6.1 Muscle characteristics as input for the musculoskeletal models. Optimal fibre length and pennation angle remained unaltered between the personalisation procedures, PCSAs were calculated from muscle volumes (TLEM and MRI) or strength scaling (LMF and RBSS). Total muscle volume and PCSA are displayed, whilst some muscles are divided in multiple elements in TLEM.

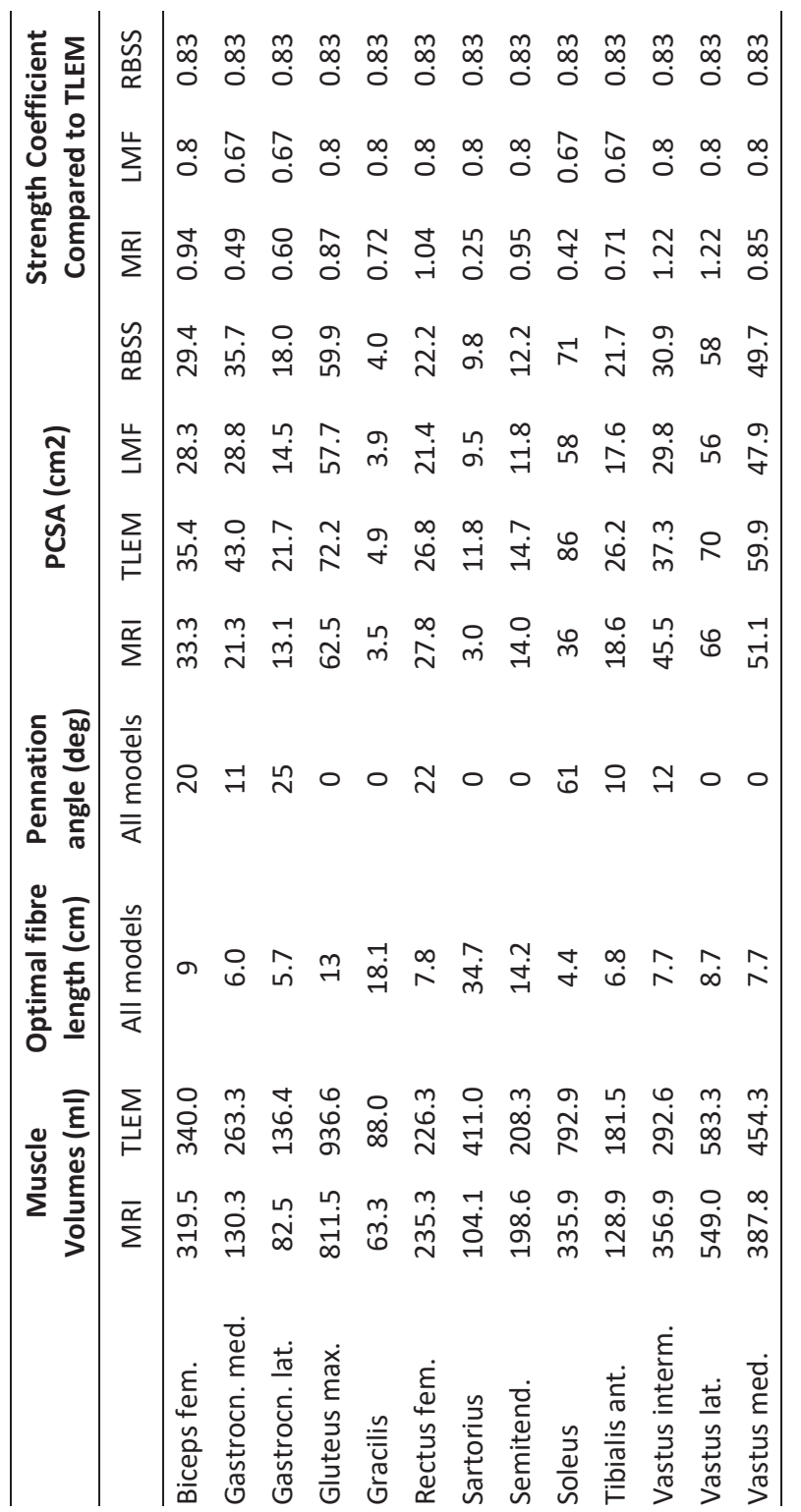



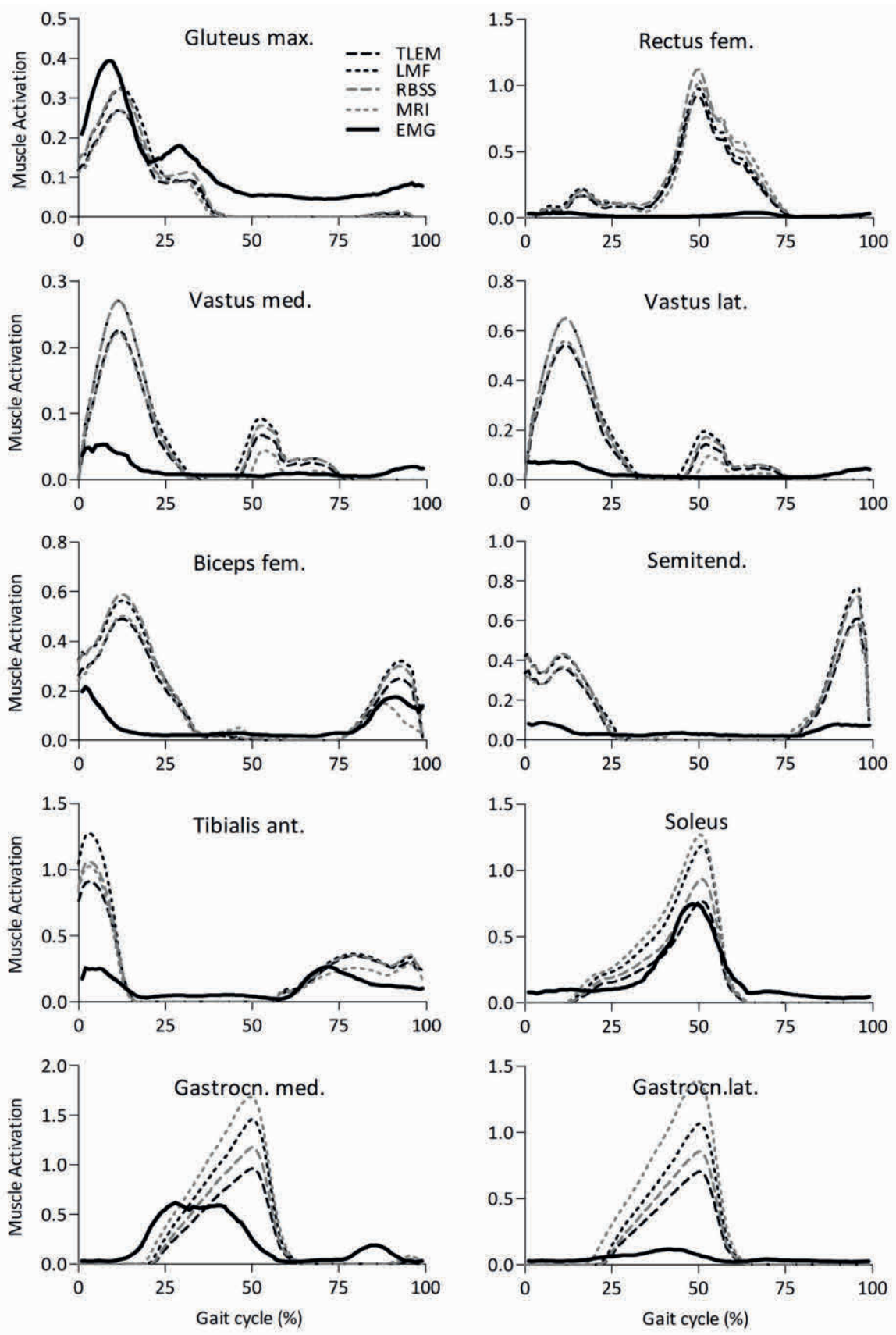

Figure 6.1 Muscle activations patterns during a full gait cycle $(0 \%$ and $100 \%=$ heel strike) at self-selected walking speed. Muscle activations as factor of maximal muscle activation are shown for the different personalisation methods, the control model and electromyography. 


\section{Subject specific joint contact forces}

Internal knee forces were almost unaltered using LMF or RBSS compared to the standard TLEM at self-selected walking speed (Figure 6.2, Table 6.3). Only personalisation using MRI derived muscle volumes showed differences in knee joint forces compared to TLEM; at late stance the mediolateral peak was decreased by $16 \%$ and proximodistal peak by $9 \%$.

\section{Effect of walking speed}

The effect of walking at a slower pace $(1.13 \mathrm{~m} / \mathrm{s})$ resulted in mostly lower muscle activations (peak simulated muscle activities: $-6 \%$ until $-21 \%$ ) compared to PWS (1.36 $\mathrm{m} / \mathrm{s}$ ). Only triceps surae muscles showed similar muscle activations during slow walking (peak simulated muscle activities: $-2 \%$ until $+3 \%$ ). Knee internal forces showed similar internal peak knee forces; however, the area under the curve was larger (10-18\%) compared to PWS (Figure 6.3).

Fast walking resulted in higher muscle activities and higher peak internal forces (resp. about $+20 \%$ and $+5 \%$ ), while the area under the curve of knee forces remained similar.

\section{Discussion}

This study evaluated the effect of personalisation of muscle strength on model output parameters. Three methods of personalisation were compared to a control model without personalisation. The control model used data from TLEM as described in Klein Horsman et al.. ${ }^{5}$ Personalisation by two uniform strength scaling methods (LMF and RBSS) resulted in overall decreased muscle strength in the model, whilst they increased muscle activations. In addition, the uniform strength scaling methods required similar absolute muscle forces, which resulted in similar internal joint forces. The third personalisation technique used subject specific muscle volumes derived from MRI, in order to further personalise the musculoskeletal model. This non-uniform strength personalisation method resulted in altered muscle recruitment, since muscles were unevenly activated compared to the TLEM control model (Table 6.2). Furthermore, joint forces adapted accordingly (differences up to $16 \%)$.

MRI showed large non-uniform differences in muscle volumes (range between $-75 \%$ and $+56 \%$ ) compared to TLEM. TLEM is an often used dataset in musculoskeletal models. ${ }^{5,30,31}$ Bolsterlee et al. showed small differences in personalised muscle volumes compared to uniform scaling. ${ }^{20}$ This discrepancy might be explained by fibre type distribution between muscles and their age related atrophy. ${ }^{32,33}$ In the light of this proof of concept study we 
Table 6.2 Maximum muscle activation of the personalisation methods compared to TLEM during a full gait cycle at self-selected speed.

\begin{tabular}{lccc}
\hline & LMF vs TLEM & RBSS vs TLEM & MRI vs TLEM \\
\hline Biceps fem. & +15.5 & +20.2 & +2.8 \\
Gastrocn. med. & +50.8 & +21.6 & +74.0 \\
Gastrocn. lat. & +51.3 & +21.6 & +97.3 \\
Gluteus max. & +20.6 & +20.1 & -0.1 \\
Gracilis & +26.1 & +17.6 & -7.3 \\
Rectus fem. & +6.0 & +21.8 & +13.0 \\
Sartorius & +6.2 & +21.9 & -39.7 \\
Semitend. & +24.9 & +18.2 & -4.6 \\
Soleus & +54.1 & +21.7 & +64.9 \\
Tibialis ant. & +39.8 & +16.2 & +12.5 \\
Vastus interm. & +19.8 & +20.2 & +17.5 \\
Vastus lat. & +19.8 & +20.2 & +3.2 \\
Vastus med. & +20.1 & +20.2 & -1.6 \\
\hline
\end{tabular}

Table 6.3 Internal knee forces in the frontal plane during gait at self-selected speed. Mean \pm standard deviation is shown for the control model and three personalised muscle strength methods.

\begin{tabular}{|c|c|c|c|c|}
\hline & TLEM & LMF & RBSS & MRI \\
\hline Mediolateral $1^{\text {st }}$ peak (N/kg) & $0.19 \pm 0.02$ & $0.19 \pm 0.02$ & $0.19 \pm 0.02$ & $0.19 \pm 0.02$ \\
\hline Mediolateral $2^{\text {nd }}$ peak (N/kg) & $0.29 \pm 0.01$ & $0.28 \pm 0.01$ & $0.29 \pm 0.01$ & $0.24 \pm 0.01$ \\
\hline Mediolateral area (N/kg*s) & $0.11 \pm 0.00$ & $0.11 \pm 0.00$ & $0.11 \pm 0.00$ & $0.09 \pm 0.00$ \\
\hline Proximodistal $1^{\text {st }}$ peak (N/kg) & $2.81 \pm 0.20$ & $2.72 \pm 0.20$ & $2.79 \pm 0.20$ & $2.83 \pm 0.20$ \\
\hline Proximodistal $2^{\text {nd }}$ peak (N/kg) & $3.41 \pm 0.13$ & $3.24 \pm 0.06$ & $3.41 \pm 0.13$ & $3.11 \pm 0.07$ \\
\hline Proximodistal area (N/kg*s) & $1.60 \pm 0.04$ & $1.55 \pm 0.04$ & $1.60 \pm 0.04$ & $1.50 \pm 0.04$ \\
\hline
\end{tabular}

Figure 6.2 Internal knee joint forces in the frontal plane during a full gait cycle $(0 \%$ and $100 \%=$ heel strike) at self-selected walking speed. Joint forces were derived from the musculoskeletal model using different personalisation methods and the control model.
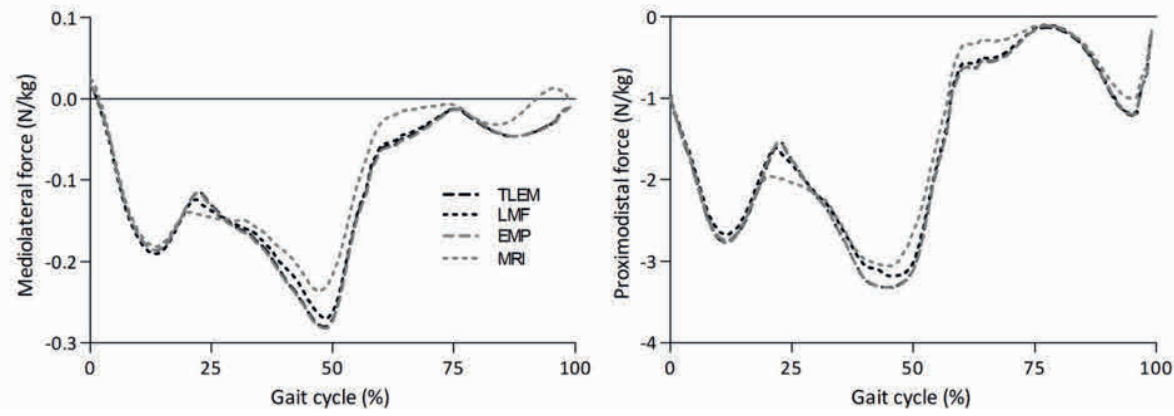

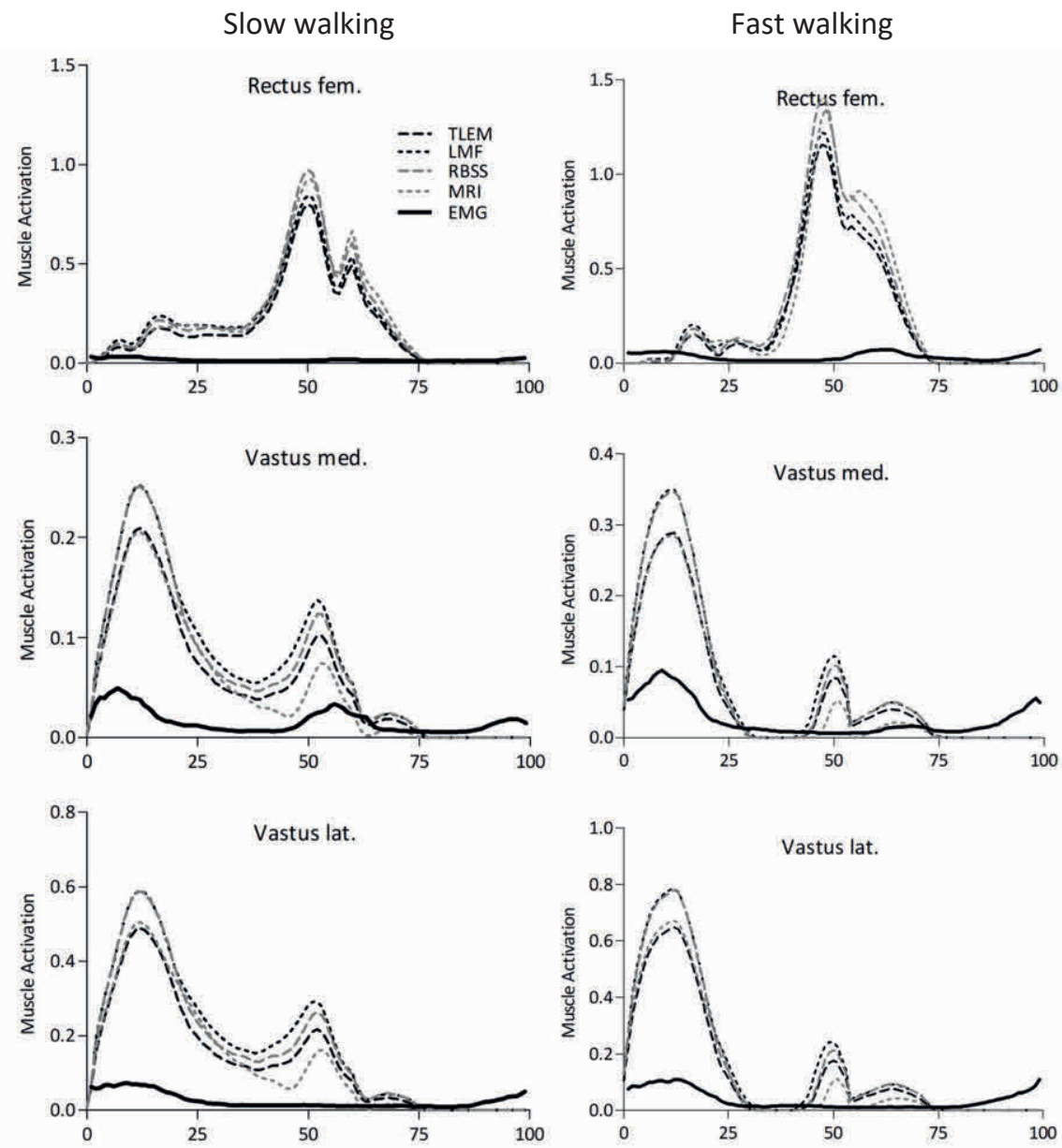

Figure 6.3 Activation patterns of the quadriceps muscles during a full gait cycle during slow and fast walking. Normalized data are shown $(0 \%$ and $100 \%=$ heel strike $)$ during slow walking in the left row ( $80 \%$ of self selected) and during fast walking right row $(120 \%$ of self selected). Muscle activations as factor of maximal muscle activation are shown for the different personalisation methods, the control model and electromyography.

included a subject that deviated considerably from the standard model. The standard model used TLEM muscle volumes from a $105 \mathrm{~kg}$, 77 year old male. ${ }^{5}$

This large non-uniform difference shown by MRI would suggest that personalisation by means of imaging is required for accurate muscle strength parameters. In accordance with literature muscle strength has a substantial effect on simulated internal forces. ${ }^{12}$ On the other hand, imaging involves costly resources, post-processing and segmentation, which 
can be time-consuming. Therefore, researchers should carefully consider alternative approaches that might suffice their specific objective. For example, if researchers are interesting in comparing model outcomes in large groups, personalisation on this level might not be necessary and other techniques could be advised. However, in other cases (e.g. small groups, or subjects suffering from selective muscle atrophy) personalisation by means of MRI derived muscle volumes might be necessary. ${ }^{34}$

Although the manual segmentation process is still time-consuming ( 1 up to 4 hours per muscle), alternative methods might facilitate in this laborious process. For example, semiautomatic procedures using advanced post-processing software can aid in fast segmentation. $^{35}$ Moreover, hybrid methods using specific imaged-based data and morphing techniques can result in accurate models that do not require traditional image processing. $^{36}$

Some limitations should be taken into account considering the results of this study. Our first concern is that our results showed muscle activations above $100 \%$, which can be explained by an insufficient maximum muscle stress. We used a maximal knee extension test in the calibration study for determining the maximal muscle stress. However, the magnitude and constancy of maximum muscle stress across muscles is still under debate. ${ }^{14-16}$ Second, we disregarded muscle volumes of the smaller muscles in the lower extremities. In order to further improve the personalisation in muscle strength, the input of these muscle volumes and other muscle architectural parameters might be necessary. ${ }^{37}$ Our final concern is that the model produced muscle activations did not correspond with electromyography; the level of activation and sometimes timing differed from electromyography. Discomfort during the MVC tests, skin movement and noise might introduce errors in the EMG signal. ${ }^{38,39}$

\section{Conclusion}

In conclusion, this study demonstrated a proof of concept regarding the effect of personalisation of muscle strength on model outcomes. A model personalised using imaging was found to have substantial effects on muscle recruitment and minor effects on joint loading. In addition, generic scaling resulted in even alterations in muscle sizes, which had only effect on muscle activation level and not on internal joint and muscle forces. This study provides insights in the added value of personalised muscle strength in musculoskeletal models; especially in subject specific models imaging might be considered for personalising muscle strength. 


\section{References}

1. Arnold AS, Delp SL. 2005. Computer modeling of gait abnormalities in cerebral palsy: application to treatment planning. Theor Issues Ergonomics Sci 6:305-12.

2. Piazza SJ, Delp SL. 2001. Three-dimensional dynamic simulation of total knee replacement motion during a step-up task. J Biomech Eng 123:599-606.

3. Correa TA, Baker R, Graham HK, Pandy MG. 2011. Accuracy of generic musculoskeletal models in predicting the functional roles of muscles in human gait. J Biomech 44:2096-105.

4. Chen YJ, Scher I, Powers CM. 2010. Quantification of patellofemoral joint reaction forces during functional activities using a subject-specific three-dimensional model. J Appl Biomech 26:415-23.

5. Klein Horsman MD, Koopman HF, van der Helm FC, et al. 2007. Morphological muscle and joint parameters for musculoskeletal modelling of the lower extremity. Clin Biomech (Bristol, Avon) 22:239-47.

6. Veeger HE, Yu B, An KN, Rozendal RH. 1997. Parameters for modeling the upper extremity. J Biomech 30:647-52.

7. Scheys L, Van Campenhout A, Spaepen A, et al. 2008. Personalized MR-based musculoskeletal models compared to rescaled generic models in the presence of increased femoral anteversion: effect on hip moment arm lengths. Gait Posture 28:358-65.

8. Bonnefoy A, Doriot N, Senk M, et al. 2007. A non-invasive protocol to determine the personalized moment arms of knee and ankle muscles. J Biomech 40:1776-85.

9. Moissenet F, Modenese L, Dumas R. 2017. Alterations of musculoskeletal models for a more accurate estimation of lower limb joint contact forces during normal gait: A systematic review. J Biomech 63:8-20.

10. Carbone V, van der Krogt MM, Koopman HF, Verdonschot N. 2012. Sensitivity of subject-specific models to errors in musculo-skeletal geometry. J Biomech 45:2476-80.

11. Lerner ZF, DeMers MS, Delp SL, Browning RC. 2015. How tibiofemoral alignment and contact locations affect predictions of medial and lateral tibiofemoral contact forces. J Biomech 48:644-50.

12. Navacchia A, Myers CA, Rullkoetter PJ, Shelburne KB. 2016. Prediction of In Vivo Knee Joint Loads Using a Global Probabilistic Analysis. J Biomech Eng 138:4032379.

13. Lieber RL. Skeletal muscle structure and function: implications for physical therapy and sports medicine. . Wilkins W, editor. Baltimore1992.

14. Narici M. 1999. Human skeletal muscle architecture studied in vivo by noninvasive imaging techniques: functional significance and applications. J Electromyogr Kinesiol 9:97-103.

15. Buchanan TS. 1995. Evidence that maximum muscle stress is not a constant: differences in specific tension in elbow flexors and extensors. Med Eng Phys 17:529-36.

16. O'Brien TD, Reeves ND, Baltzopoulos V, et al. 2010. In vivo measurements of muscle specific tension in adults and children. Exp Physiol 95:202-10. 
17. D'Souza S, Rasmussen J, Schwirtz A. 2012. Multiple linear regression to develop strength scaled equations for knee and elbow joints based on age, gender and segment mass. International Journal of Human Factors Modelling and Simulation 3:32-47.

18. Oomen P, Annegarn J, Rasmussen J, et al. 2015. Development and validation of a rule-based strength scaling method for musculoskeletal modelling. Int J Human Factors Modelling and Simulation, 5:19-32.

19. Handsfield GG, Meyer CH, Hart JM, et al. 2014. Relationships of 35 lower limb muscles to height and body mass quantified using MRI. J Biomech 47:631-8.

20. Bolsterlee B, Vardy AN, van der Helm FC, Veeger HE. 2015. The effect of scaling physiological cross-sectional area on musculoskeletal model predictions. J Biomech 48:1760-8.

21. Abe T, Loenneke JP, Thiebaud RS, Fukunaga T. 2014. Age-related site-specific muscle wasting of upper and lower extremities and trunk in Japanese men and women. Age (Dordr) 36:813-21.

22. Jones PR, Pearson J. 1969. Anthropometric determination of leg fat and muscle plus bone volumes in young male and female adults. J Physiol 204:63P-6P.

23. Wicke J, Dumas GA. 2014. A new geometric-based model to accurately estimate arm and leg inertial estimates. J Biomech 47:1869-75.

24. Bol GH, Kotte AN, van der Heide UA, Lagendijk JJ. 2009. Simultaneous multimodality ROI delineation in clinical practice. Comput Methods Programs Biomed 96:133-40.

25. Arampatzis A, Karamanidis K, De Monte G, et al. 2004. Differences between measured and resultant joint moments during voluntary and artificially elicited isometric knee extension contractions. Clin Biomech (Bristol, Avon) 19:277-83.

26. Hermens HJ, Freriks B, Merletti R, et al. European Recomendations for Surface Electromyography: Roessingh Research and Development b.v.; 1999

27. Rasmussen J, Damsgaard M, Voigt M. 2001. Muscle recruitment by the $\mathrm{min} / \mathrm{max}$ criterion -- a comparative numerical study. J Biomech 34:409-15.

28. Crowninshield RD, Brand RA. 1981. A physiologically based criterion of muscle force prediction in locomotion. J Biomech 14:793-801.

29. Rasmussen J, de Zee M, Damsgaard M, et al, editors. A General Method for Scaling Musculo-Skeletal Models. International Symposium on Computer Simulation in Biomechanics; 2005; Ohio, USA.

30. Kolk S, Fluit R, Luijten J, et al. 2015. Gait and lower limb muscle strength in women after triple innominate osteotomy. BMC Musculoskelet Disord 16:68.

31. van Arkel RJ, Modenese L, Phillips AT, Jeffers JR. 2013. Hip abduction can prevent posterior edge loading of hip replacements. J Orthop Res 31:1172-9.

32. Johnson MA, Polgar J, Weightman D, Appleton D. 1973. Data on the distribution of fibre types in thirty-six human muscles. An autopsy study. J Neurol Sci 18:11129.

33. Larsson L, Sjodin B, Karlsson J. 1978. Histochemical and biochemical changes in human skeletal muscle with age in sedentary males, age 22--65 years. Acta Physiol Scand 103:31-9. 
34. Hu X, Blemker SS. 2015. Musculoskeletal simulation can help explain selective muscle degeneration in Duchenne muscular dystrophy. Muscle Nerve 52:174-82.

35. Carbone V, Fluit R, Pellikaan P, et al. 2015. TLEM 2.0 - a comprehensive musculoskeletal geometry dataset for subject-specific modeling of lower extremity. J Biomech 48:734-41.

36. Salo Z, Beek M, Wright D, Whyne CM. 2015. Computed tomography landmarkbased semi-automated mesh morphing and mapping techniques: generation of patient specific models of the human pelvis without segmentation. J Biomech 48:1125-32.

37. Blemker SS, Asakawa DS, Gold GE, Delp SL. 2007. Image-based musculoskeletal modeling: applications, advances, and future opportunities. J Magn Reson Imaging 25:441-51.

38. Keller A, Johansen JG, Hellesnes J, Brox JI. 1999. Predictors of isokinetic back muscle strength in patients with low back pain. Spine (Phila Pa 1976) 24:275-80.

39. De Luca CJ, Gilmore LD, Kuznetsov M, Roy SH. 2010. Filtering the surface EMG signal: Movement artifact and baseline noise contamination. J Biomech 43:15739. 
$a$ 


\section{Overview}

Knee osteoarthritis (OA) is the main cause of pain and disability in elderly. ${ }^{1,2}$ An estimated $10 \%$ of people older than 55 years have disabling knee symptoms. ${ }^{3}$ Normal activities of daily living, such as walking, stair ambulation and standing up from a chair become painful or rather impossible in patients with knee OA. Understanding the initiation and progression of knee $O A$ is essential to find strategies for patients to cope with pain and discomfort. ${ }^{4}$ Motion capture and musculoskeletal models have the possibility to detect early changes in gait patterns. ${ }^{5}$ Moreover, they can evaluate possible strategies to prevent further cartilage damage. ${ }^{6,7}$ Musculoskeletal models have the potential to simulate knee loading non-invasively. ${ }^{8}$ However, these generic musculoskeletal models should include personalisation to acquire accurate outcomes. ${ }^{9}$

The purpose of this thesis was to evaluate kinematic and kinetic gait changes in patients with knee OA using traditional gait analysis and musculoskeletal models. Furthermore, the additional value of personalised muscle strength was investigated for these models.

In this chapter, the main findings of this thesis will be considered in a broader perspective. First, the most important results of the previous chapters will be summarized and placed in the context of literature. Second, future perspectives will be described, with an important role for imaging. Finally, towards the end of this chapter, conclusions of this dissertation will be presented. 


\section{Key Findings}

Knee $\mathrm{OA}$ is initiated when the balance between mechanical loading and cartilage biology of the structure is disrupted. ${ }^{4}$ An injury, an increase of lateral laxity or varus alignment can shift load completely to medial regions of the knee cartilage that are not adapted to such ambulatory loading. ${ }^{10,11}$ Moreover, high shear and compression forces at the knee during daily activity tasks can increase the rate of progression of knee OA. ${ }^{12}$ The external knee adduction moment (EKAM) can be obtained by gait analysis and has been suggested to be strongly related to internal medial loading. ${ }^{13}$ In chapter $\mathbf{2}$, we were able to detect higher EKAM magnitudes in obese knee OA patients compared to lean patients and healthy controls. However, minor changes in EKAM were found in the lean OA group compared to weight matched healthy controls. These results suggest that the combination of a high body mass and the presence of knee OA are associated with high EKAM, whilst knee OA pathology alone has not a major impact on EKAM. Moreover, differences in EKAM between obese and lean OA patients remained significant after normalizing EKAM for body weight. Furthermore, a standardized higher walking speed increased EKAM significantly. Several studies did indeed describe a relation between high EKAM and the onset and progression of knee OA. ${ }^{14-16}$ However, some limitations should be taken into account considering these studies. For example, Miyazaki et al. found increased EKAM in patients with disease progression; however, they implemented self-selected walking speed only. ${ }^{14}$ Walking speed is an important determinant of EKAM, which could explain differences between groups. ${ }^{6,17}$ Furthermore, the studies of Mundermann et al. and Thorp et al. included patients with higher body mass indexes in the more severe knee OA groups; $;^{15,16}$ a higher body mass could have contributed to higher EKAM. Previous literature confirms that EKAM magnitude is higher in subjects with higher body mass. ${ }^{18}$ Weight reduction is therefore an important recommendation in obese patients that reduces joint loads, inflammation and pain, and improves knee function. ${ }^{19,20}$

Although EKAM has been associated with knee OA, Meyer et al. concluded that external measures (e.g. EKAM) are weak indicators of internal contact forces. ${ }^{21}$ Especially internal shear forces are linked to cartilage breakdown. ${ }^{12,22}$ Therefore, we investigated a subset of the aforementioned dataset (chapter 2), in order to evaluate internal loading by means of musculoskeletal modelling. Hence, chapter $\mathbf{3}$ showed increased mediolateral knee forces, estimated by musculoskeletal modelling, in patients with knee OA compared to weight matched volunteers. In addition, by analysing the mediolateral force we were able to find differences between mild knee OA patients and healthy volunteers at a slow walking speed, whilst the groups showed similar magnitudes of EKAM. It has been postulated that advances in personalisation of musculoskeletal modelling can aid in more accurate 
estimations of in vivo contact forces. ${ }^{21}$ External forces are balanced internally by knee joint contact forces and muscle forces. ${ }^{21}$ In other words, muscle forces are important determinants of internal knee contact forces in musculoskeletal modelling. Therefore, the input of muscle architectural parameters is essential to give accurate outcomes of muscle forces. ${ }^{23,24}$ To date, most of these input parameters are based upon data derived from cadaveric experiments. ${ }^{25,26}$ It is most likely that differences between the cadaver specimens and the individual to be investigated result in erroneous model predictions. Personalisation of these muscle parameters offers the possibility to increase the accuracy of musculoskeletal models. ${ }^{27,28}$ Muscle' physiological cross sectional area (PCSA) is the main muscle architectural parameter involved in muscle strength. ${ }^{23}$ Personalisation of muscle' PCSA is therefore a promising tool to improve musculoskeletal models. Two main approaches in personalising muscle PCSA were investigated in this dissertation: uniform strength scaling and MRI-based personalisation.

Uniform strength scaling can be characterized as an uncomplicated and easy to use method to personalise all muscles at once. Different forms of uniform strength scaling were evaluated in chapter 4 . Furthermore, a new strength scaling routine was presented. This new empiric strength scaling routine included age, gender, fat percentage and easy to obtain segment properties that contributed to muscle strength. ${ }^{29-32}$ Therefore, we were able to predict maximal strength more accurately than current methods (i.e. implemented by Rasmussen et al.). ${ }^{33}$ However, the individual results showed that the most accurate strength scaling technique resulted in some cases in $30 \%$ over or under prediction of muscle strength. Therefore, strength scaling might not be sufficient to accurately predict subject-specific muscle strength and more elaborate techniques are recommended. ${ }^{9}$

Imaging of muscle characteristics is becoming more feasible for personalising musculoskeletal models. ${ }^{25}$ Previous literature imaged musculoskeletal parameters in large datasets, ${ }^{34}$ which enables its use for personalisation in musculoskeletal models. In chapter 5 we used imaging to obtain subject-specific muscle volume and compared these with cadaveric datasets. ${ }^{26,35-37}$ These cadaveric datasets are often used in musculoskeletal models, but deviated considerably from our dataset. The results in chapter 5 showed larger muscle volumes compared to literature, which could be explained by age related hypotrophy. However, after correction using total quadriceps and hamstring muscle volume, results showed only minor non-uniform differences compared to literature. Therefore, this study agrees with Handsfield et al. that uniform strength scaling, should be able to correct for most changes. ${ }^{34}$ On the other hand, imaging is able to detect small nonuniform differences in order to personalise musculoskeletal models to a higher level. 
The impact of different muscle strength personalisation techniques on musculoskeletal modelling were evaluated in chapter 6 . Muscle strength was personalised by strength scaling or imaging and model outcomes (i.e. muscle activation and joint loading) were compared. In this chapter a proof of concept study demonstrated that imaging might be a necessary tool to acquire subject-specific muscle strength characteristics (i.e. muscle volumes), since major differences in muscle activations were found. However, the effect of personalising muscle volumes had minor effects on model joint forces.

The findings of chapter 2 and 3 might contribute to a better understanding of the pathomechanics of knee OA during gait. Body mass was found to be the most important determinant of external joint loading (EKAM). Therefore, interventions targeting body weight reductions in obese knee OA patients should be advised. Furthermore, a minor increased EKAM was found in lean patients compared to healthy volunteers. However this small effect on EKAM contributed significantly to internal loading as predicted by musculoskeletal modelling. Therefore, researchers should take into account that metrics for external loading do not automatically reflect internal loading.

Musculoskeletal models are becoming increasingly relevant for clinical application, e.g. for the estimation of internal loading. However, valid musculoskeletal models depend on accurate input parameters. Scaling is a straightforward method to personalise musculoskeletal models and can be easily implemented in a clinical setting. On the other hand, imaging might be more accurate for obtaining muscle strength parameters; however, extensive clinical application is not realistic in the near future. Advances in imaging can contribute to better approximation of these input parameters. However, for clinical application of imaged based models effort should be made in fast and easy post processing. Furthermore, sensitivity analyses are needed to unravel the effect of inaccuracies of input parameters.

\section{Future Perspectives}

\section{Imaging in musculoskeletal models}

Musculoskeletal models are able to estimate internal forces that differ between normal and pathologic human movement. Furthermore, they have been used in multiple orthopaedic procedures, in order to simulate post-operative outcomes. However, accurate model outcomes require hard to obtain subject-specific parameters. ${ }^{27,38}$ Blemker et al. discussed that imaging will have a major impact in the use of musculoskeletal models 
in clinical applications. ${ }^{9}$ In addition, dynamic imaging offers the possibility to evaluate the mechanics of the musculoskeletal system. ${ }^{39}$ In the following section four topics are described in which imaging could have an important role in musculoskeletal modelling: bone geometry, joint kinematics, muscle paths and muscle architecture.

\section{Bone geometry}

Bone surface geometries can be segmented with great precision from CT or MR images, because it has relatively high image contrast with the surrounding tissue. ${ }^{40}$ Furthermore, commercially available software (e.g. Mimics, Materialise N.V., Leuven, Belgium) can aid in semiautomatic segmentation. Moreover, new techniques using bone morphing can aid in fast personalisation of musculoskeletal models without the use of time-consuming segmentation. ${ }^{41}$ The next step for implementing bone parameters in musculoskeletal models is to acquire full automatic segmentation and integration within the musculoskeletal models. This should include automatic post-processing, such as hole filling and smoothing. When these steps are becoming easily applicable or can be processed automatically, clinical application of personalised bone geometries in musculoskeletal models might be possible in the near feature.

\section{Joint kinematics}

Joint motion in musculoskeletal models is often simplified in order to make these models practically useful. For example, the foot is often referred to as a single segment, which does not reflect the foot kinematics properly. ${ }^{42}$ Furthermore, the knee is repeatedly modelled as a hinge joint, disregarding translational and rotational movements, which might decrease accuracy of model predictions. ${ }^{43}$ Cine phase-contrast MRI has been shown to be a promising tool for characterizing personalised joint kinematics. ${ }^{44}$ Although recent studies have reduced scan time and increased accuracy. ${ }^{45,46}$ musculoskeletal models have not widely implemented cine phase-contrast MRI. Extensive validation on other joints and complex movements are needed for more applications of cine phase-contrast MRI on musculoskeletal models.

\section{Muscle paths}

Sensitivity analyses have shown that accurate origin and insertion points of muscles contribute significantly to reliable model outcomes. ${ }^{47}$ Moreover, the attachment sites of muscles influence muscle moment $\mathrm{arms}^{48}{ }^{48}$ which contribute to accurate prediction of joint and muscle forces for musculoskeletal modelling. ${ }^{49} \mathrm{MRI}$ provides possibilities in accurately 
determine muscle tendon lengths and moment arms in vivo. ${ }^{50}$ However, since most muscle paths have curved lines of action, quantification based on MRI remains difficult. ${ }^{51}$

\section{Muscle architecture}

Muscle architecture is the main determinant of muscle function and is defined as the arrangement of muscle fibres relative to the axis of force generation. ${ }^{52}$ In this dissertation we evaluated the effect of personalising muscle volume on musculoskeletal models (chapter 6). Although this is an important step for personalised muscle strength in musculoskeletal models, this does not account for variation in physiological crosssectional area, optimal fibre length or pennation angle. Therefore, more sophisticated MRI techniques are needed, such as diffusion weighted MRI, in order to obtain these complex muscle architectural parameters. ${ }^{53}$ The following paragraph ("Muscle architecture by DTI: a pilot study") elaborates on diffusion weighted imaging for the determination of muscle architecture for musculoskeletal models.

Imaging has been suggested to be an important tool for acquiring subject-specific data. However, most parameters require more validation. Furthermore, the implementation of some of these parameters in musculoskeletal models is difficult or musculoskeletal models should be adapted before implementation is eventually possible. In addition, automatic procedures that derive musculoskeletal parameters from imaging and/or an easy implementation of these parameters to musculoskeletal models can contribute to wider implementation.

\section{Muscle architecture by DTI: a pilot study}

Muscle architecture has been shown to be an important determinant of joint loading; therefore, it is a main element that needs personalisation in musculoskeletal models. ${ }^{9,23}$ One potential strategy to obtain image-based muscle architecture is by means of diffusion weighted imaging. ${ }^{9}$ Froeling et al. presented a diffusion tensor imaging (DTI) acquisition protocol suitable for in vivo human purposes. ${ }^{53}$ They showed convincing visual muscle fibre trajectories in the human forearm compared to dissections on a cadaver specimen. The validation by means of visual comparison is limited to subjective assessments. Moreover, the comparison of cadaver tissues together with in vivo DTI might involve inaccuracies. Therefore we tested a different approach to make an objective comparison and quantify the accuracy of tractography from diffusion weighted images.

In a pilot study we used a fixed human cadaver to investigate muscle architecture of the medial gastrocnemius muscle both in a MRI scanner (3-T Achieva, Philips Healthcare, Best, 
the Netherlands) and after dissection. In order to diminish movement between MRI and dissection, the leg was secured in an MRI conceivable construction. A suitable MRI protocol was selected for fixed cadaver material we adjusted the scan parameters taking into account the decreased diffusion in fixed cadaver material (Table 7.1). Segmentations of muscles were performed using $\mathrm{T} 1$ and $\mathrm{T} 2$ weighted scans using the delineation program Volumetool (Version 1.3.0 described in Bol et al.). ${ }^{54}$ Post processing of the MRI data was performed in Mathematica (Version 9.0.1.0, Wolfram research, Champaign, USA). In this program background noise was removed and diffusion tensor values were corrected for field inhomogeneity. Segmentations of the muscles were used as constraints for diffusion values in order to limit fibre tracking beyond muscle volumes. Fibre tracking (Figure 7.1B) was performed in the open source tool vISTe (Eindhoven University of Technology, Eindhoven, the Netherlands). The anatomical dissection was performed systematically. Muscle fibres were selected evenly over the surface and marked with a felt tipped pen. A four camera VICON motion capture system (Oxford Metrics Ltd., Oxford, UK) combined with a marker equipped pointing stick were used to digitize the muscle fibres. Four 3D coordinates of each muscle fibre were measured as follows: the proximal attachment to the tendon, two coordinates along the muscle fibre, the distal attachment to the tendon. When superficial muscle fibres were measured a small layer of muscle tissue was dissected in order to measure deeper located muscle fibres. This process continued until the complete muscle was digitized.

Table 7.1 Scan parameters for the cadaver lower leg using a 3-T Philips Achieva scanner.

\begin{tabular}{|c|c|c|c|}
\hline & $\mathrm{T} 1$ & $\mathrm{~T} 2$ & DTI \\
\hline Sequence & $\mathrm{T}_{1} \mathrm{w}$ SPIR & $\mathrm{T}_{2} \mathrm{w}$ SPAIR & Dw SE \\
\hline Slice thickness (mm) & 3 & 3 & 3 \\
\hline Number of slices & 77 & 77 & 77 \\
\hline Repetition time (s) & 0.6 & 12.4 & 7.4 \\
\hline Echo time (ms) & 20 & 62 & 66 \\
\hline Scan time (h:min:s) & $00: 21: 45$ & $00: 17: 18$ & $11: 44: 16$ \\
\hline Reconstructed matrix & $672 \times 672$ & $672 \times 672$ & $112 \times 112$ \\
\hline Field of view $\left(\mathrm{cm}^{2}\right)$ & $200 \times 200$ & $200 \times 200$ & $200 \times 200$ \\
\hline Echo train length & 7 & 13 & 7 \\
\hline Number of signal averages & 2 & 2 & 12 \\
\hline $\mathrm{b}$-value $\left(\mathrm{s} / \mathrm{mm}^{2}\right)$ & - & - & 800 \\
\hline Diffusion directions & - & - & 34 \\
\hline Voxel dimensions $\left(\mathrm{mm}^{3}\right)$ & $0.30 \times 0.30 \times 3$ & $0.30 \times 0.30 \times 3$ & $1.79 \times 1.79 \times 3$ \\
\hline
\end{tabular}


The digitized anatomical muscle fibres were matched with the nearest DTI trajectories. An example of an anatomic fibre and matched DTI trajectory is shown in Figure 7.1B. A spline was fitted through each trajectory and anatomic fibre; and 100 three-dimensional data points were evenly divided over the spline. Consequently, the two closest data points on each line were determined and the vectors of the splines were obtained. Finally, the angle between both vectors was calculated and was defined as the error angle. The error angle showed differences in alignment between anatomically measured muscle fibres and DTI trajectories. Results showed an error angle between 0 degrees (perfectly aligned) up to 60 degrees for the medial head of gastrocnemius. The error angle (mean: $25.4 \pm 14.0$ degrees) indicates non-systematic errors in DTI trajectories in the medial gastrocnemius.

This pilot study showed visual comparable data for DTI trajectories and manually measured muscle fibres. In accordance to Froeling et al. DTI showed high potential obtaining muscle architecture in vivo. ${ }^{53}$ However, the error angles showed not negligible objective differences between DTI trajectories and anatomically measured muscle fibres. A possible explanation for the poor results in this pilot study is that the scan parameters were insufficient in human fixated tissues. ${ }^{55,56}$ Furthermore a contributing factor that might introduce error is manual inaccuracies in measuring the muscle fibres; though, errors up to 60 degrees are unlikely. This study does not answer the question that in vivo measurements are prone to similar errors. However, objective quantitative studies are needed to ensure validity of DTI trajectories in order to quantify muscle architectural parameters. $^{57}$

When validity of these muscle trajectories can be guaranteed, the next step is to quantify muscle architectural parameters in vivo. Diffusion weighted MRI has the potential to access muscle fibre length, ${ }^{58}$ pennation angle ${ }^{59}$ and physiological cross-sectional area in order to further personalise musculoskeletal models. ${ }^{9}$ In addition, the optimum length on the length-tendon relationship is a crucial determinant that could possibly be obtained by in vivo measurements. ${ }^{59,60}$ 

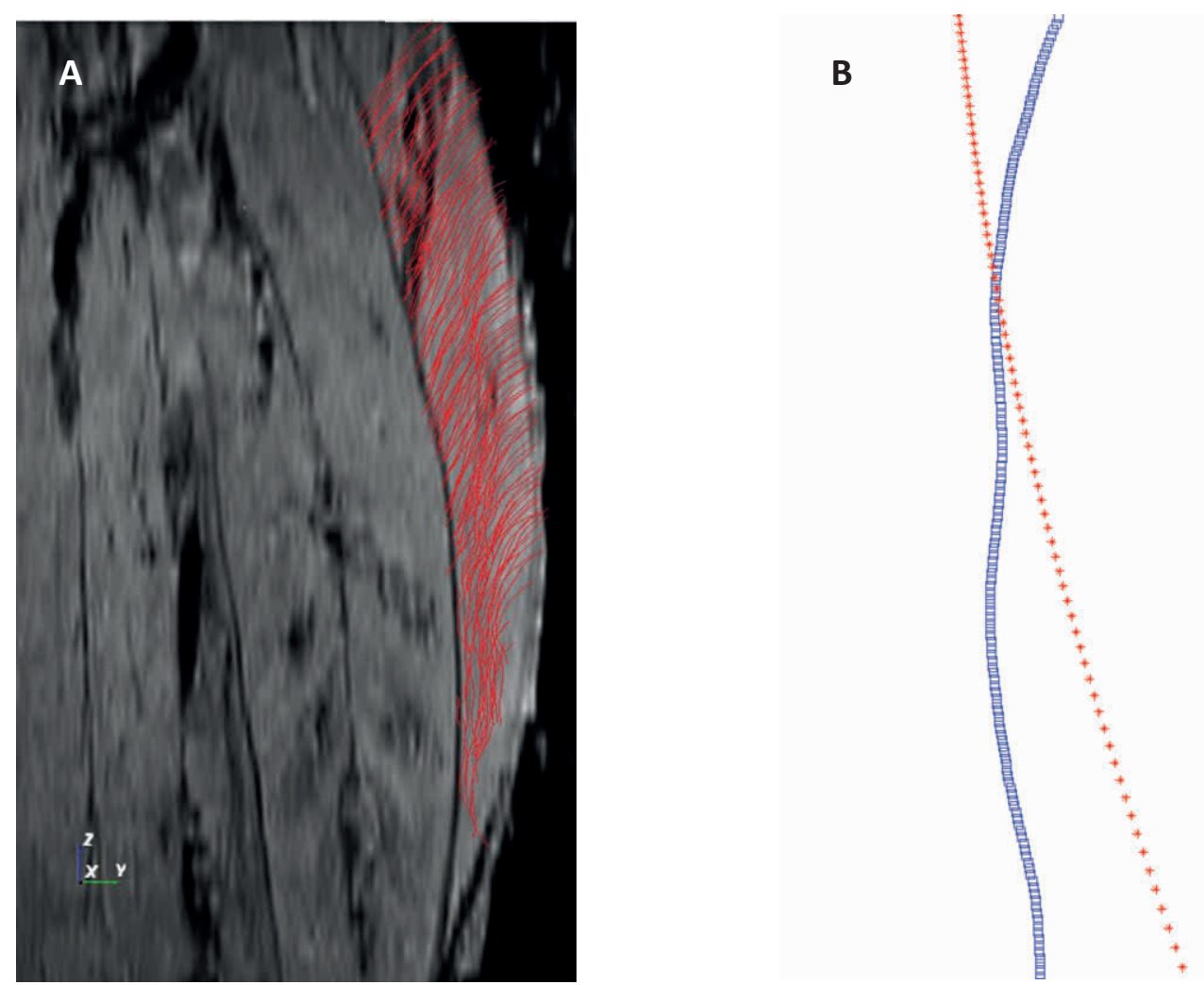

Figure 7.1 Process of matching anatomic measured muscle fibres with DTI trajectories. A) Visualisation of muscle trajectories derived from diffusion weighted MRI of the cadaver medial gastrocnemius muscle. B) An example of an individual muscle fibre derived from anatomic dissection (red) and best match trajectory from DTI (blue).

\section{Validation of musculoskeletal models}

The use of musculoskeletal models for clinical applications indicates the necessity that these models give accurate representations of the reality. Therefore, validation and verification is essential for application and credibility of musculoskeletal models. ${ }^{61,62}$ There are several methods to evaluate if musculoskeletal models give realistic outcomes. Electromyography and Instrumented prostheses are used in order to check internal forces. However, their limitations should be taken into account.

Electromyography (EMG) is an often used instrument to validate muscle activation patterns from inverse dynamic models. ${ }^{63}$ However, surface EMG is limited for superficial muscles only, and is affected by both electrode placement and skin movement. ${ }^{64,65}$ Furthermore, the relationship between muscle force and surface EMG is still poorly 
understood. Moreover, pain, muscle weakness and discomfort could potentially influence normalization of EMG signal. ${ }^{8,66}$ Therefore, evaluation of model muscle activation by using EMG is limited, and their relation should be addressed in further research.

An instrumented prosthesis is a valuable tool to evaluate models and have led to important improvements in musculoskeletal models. ${ }^{67}$ However, they are limited in their application in patients only; so far only small sample sizes used instrumented prostheses. ${ }^{68}$ A final point of concern in the use of instrumented prostheses is that knee arthroplasty influences natural walking behaviour, which affects external validity to subjects without prostheses. $^{69}$ Moreover, prostheses influence joint kinematics, which makes generalisability to healthy subjects rather difficult or impossible.

In conclusion, quality of the validation of musculoskeletal models is closely related to advances in musculoskeletal models. ${ }^{61}$ Although, good evaluation methods of musculoskeletal model are limited, validated models are essential for clinical application.

\section{Considering personalisation of musculoskeletal models}

Personalised models are considered more accurate and representative for individual patients compared to generic models. Recent advances in musculoskeletal imaging provided the opportunity to incorporate detailed subject-specific data in modelling systems. ${ }^{9}$ Personalised musculoskeletal models for clinical applications are therefore within reach. However, it should be noted that imaging requires considerable resources and is highly time-consuming compared to generic models. Therefore, researchers should carefully consider the needed accuracy for it specific purpose. Sensitivity analyses are useful to evaluate the impact of inaccuracies of musculoskeletal parameters (e.g. in Carbone et al.). ${ }^{47}$ These sensitivity analyses might help researchers or clinicians choose the approach (e.g. uniform scaling or imaging) that suffices their specific requirements.

\section{Conclusion}

Gait analysis showed that obese knee OA patients have a significant increased knee adduction moment compared to lean patients. However, knee OA pathology alone showed no convincing increase in knee adduction moment. Recent advances in musculoskeletal models offer the opportunity to better understand the mechanisms of musculoskeletal diseases. These models are able to simulate internal loading taking into account the complex biomechanics of the human body. This dissertation showed that musculoskeletal models were able to show significant increased internal knee loading in 


\section{Chapter 7}

lean knee OA patients compared to healthy volunteers. Moreover, musculoskeletal models could detect changes that were not observed using traditional gait analysis between lean OA patients and weight matched subjects.

The accuracy of musculoskeletal modelling outcomes is limited to the input of subjectspecific parameters. In other words, if the internal knee loading of a specific patient is required, a personalised model is needed to obtain accurate predictions. Personalised muscle strength is one of many parameters in a musculoskeletal model that contribute to subject-specific models. Muscle strength can be estimated by uniform scaling or can be derived directly from imaging. Strength scaling was generally able to approximate subject muscle strength; however, non-uniform muscle changes could only be addressed using imaging. Researchers should carefully consider which level of personalisation is required for its specific purpose, taking into account the accuracy that is needed versus the given effort. 


\section{References}

1. Jordan KM, Arden NK, Doherty M, et al. 2003. EULAR Recommendations 2003: an evidence based approach to the management of knee osteoarthritis: Report of a Task Force of the Standing Committee for International Clinical Studies Including Therapeutic Trials (ESCISIT). Ann Rheum Dis 62:1145-55.

2. Volksgezondheidenzorg.info. $2016 . \quad$ Available from: https://www.volksgezondheidenzorg.info/onderwerp/artrose/cijferscontext/huidige-situatie\#node-prevalentie-en-aantal-nieuwe-gevallen-vanartrose.

3. Peat G, McCarney R, Croft P. 2001. Knee pain and osteoarthritis in older adults: a review of community burden and current use of primary health care. Ann Rheum Dis 60:91-7.

4. Andriacchi TP, Koo S, Scanlan SF. 2009. Gait mechanics influence healthy cartilage morphology and osteoarthritis of the knee. J Bone Joint Surg Am 91 Suppl 1:95101.

5. Astephen JL, Deluzio KJ, Caldwell GE, Dunbar MJ. 2008. Biomechanical changes at the hip, knee, and ankle joints during gait are associated with knee osteoarthritis severity. J Orthop Res 26:332-41.

6. Mundermann A, Dyrby CO, Hurwitz DE, et al. 2004. Potential strategies to reduce medial compartment loading in patients with knee osteoarthritis of varying severity: reduced walking speed. Arthritis Rheum 50:1172-8.

7. Simic M, Wrigley TV, Hinman RS, et al. 2013. Altering foot progression angle in people with medial knee osteoarthritis: the effects of varying toe-in and toe-out angles are mediated by pain and malalignment. Osteoarthritis Cartilage 21:127280.

8. Kumar D, Manal KT, Rudolph KS. 2013. Knee joint loading during gait in healthy controls and individuals with knee osteoarthritis. Osteoarthritis Cartilage 21:298305.

9. Blemker SS, Asakawa DS, Gold GE, Delp SL. 2007. Image-based musculoskeletal modeling: applications, advances, and future opportunities. J Magn Reson Imaging 25:441-51.

10. Sharma L, Lou C, Felson DT, et al. 1999. Laxity in healthy and osteoarthritic knees. Arthritis Rheum 42:861-70.

11. Sharma L, Song J, Dunlop D, et al. 2010. Varus and valgus alignment and incident and progressive knee osteoarthritis. Ann Rheum Dis 69:1940-5.

12. Andriacchi TP, Mundermann A, Smith RL, et al. 2004. A framework for the in vivo pathomechanics of osteoarthritis at the knee. Ann Biomed Eng 32:447-57.

13. Schipplein OD, Andriacchi TP. 1991. Interaction between active and passive knee stabilizers during level walking. J Orthop Res 9:113-9.

14. Miyazaki T, Wada M, Kawahara H, et al. 2002. Dynamic load at baseline can predict radiographic disease progression in medial compartment knee osteoarthritis. Ann Rheum Dis 61:617-22. 
15. Mundermann A, Dyrby CO, Andriacchi TP. 2005. Secondary gait changes in patients with medial compartment knee osteoarthritis: increased load at the ankle, knee, and hip during walking. Arthritis Rheum 52:2835-44.

16. Thorp LE, Sumner DR, Block JA, et al. 2006. Knee joint loading differs in individuals with mild compared with moderate medial knee osteoarthritis. Arthritis Rheum 54:3842-9.

17. Landry SC, McKean KA, Hubley-Kozey CL, et al. 2007. Knee biomechanics of moderate $\mathrm{OA}$ patients measured during gait at a self-selected and fast walking speed. J Biomech 40:1754-61.

18. Browning RC, Kram R. 2007. Effects of obesity on the biomechanics of walking at different speeds. Med Sci Sports Exerc 39:1632-41.

19. Zhang W, Nuki G, Moskowitz RW, et al. 2010. OARSI recommendations for the management of hip and knee osteoarthritis: part III: Changes in evidence following systematic cumulative update of research published through January 2009. Osteoarthritis Cartilage 18:476-99.

20. Messier SP, Gutekunst DJ, Davis C, DeVita P. 2005. Weight loss reduces knee-joint loads in overweight and obese older adults with knee osteoarthritis. Arthritis Rheum 52:2026-32.

21. Meyer AJ, D'Lima DD, Besier TF, et al. 2013. Are external knee load and EMG measures accurate indicators of internal knee contact forces during gait? J Orthop Res 31:921-9.

22. Smith RL, Donlon BS, Gupta MK, et al. 1995. Effects of fluid-induced shear on articular chondrocyte morphology and metabolism in vitro. J Orthop Res 13:82431.

23. Navacchia A, Myers CA, Rullkoetter PJ, Shelburne KB. 2016. Prediction of In Vivo Knee Joint Loads Using a Global Probabilistic Analysis. J Biomech Eng 138:4032379.

24. Rasmussen J, Damsgaard M, Voigt M. 2001. Muscle recruitment by the $\mathrm{min} / \mathrm{max}$ criterion -- a comparative numerical study. J Biomech 34:409-15.

25. Carbone V, Fluit R, Pellikaan P, et al. 2015. TLEM 2.0 - a comprehensive musculoskeletal geometry dataset for subject-specific modeling of lower extremity. J Biomech 48:734-41.

26. Klein Horsman MD, Koopman HF, van der Helm FC, et al. 2007. Morphological muscle and joint parameters for musculoskeletal modelling of the lower extremity. Clin Biomech (Bristol, Avon) 22:239-47.

27. Bonnefoy A, Doriot N, Senk M, et al. 2007. A non-invasive protocol to determine the personalised moment arms of knee and ankle muscles. J Biomech 40:1776-85.

28. Scheys L, Spaepen A, Suetens P, Jonkers I. 2008. Calculated moment-arm and muscle-tendon lengths during gait differ substantially using MR based versus rescaled generic lower-limb musculoskeletal models. Gait Posture 28:640-8.

29. Delbaere K, Bourgois J, Witvrouw EE, et al. 2003. Age-related changes in concentric and eccentric muscle strength in the lower and upper extremity: A cross-sectional study. Isokinet Exerc Sci 11:145-51. 
30. Lindle RS, Metter EJ, Lynch NA, et al. 1997. Age and gender comparisons of muscle strength in 654 women and men aged 20-93 yr. J Appl Physiol (1985) 83:1581-7.

31. Lynch NA, Metter EJ, Lindle RS, et al. 1999. Muscle quality. I. Age-associated differences between arm and leg muscle groups. J Appl Physiol (1985) 86:188-94.

32. D'Souza S, Rasmussen J, Schwirtz A. 2012. Multiple linear regression to develop strength scaled equations for knee and elbow joints based on age, gender and segment mass. International Journal of Human Factors Modelling and Simulation 3:32-47.

33. Rasmussen J, de Zee $M$, Damsgaard $M$, et al, editors. A General Method for Scaling Musculo-Skeletal Models. International Symposium on Computer Simulation in Biomechanics; 2005; Ohio, USA.

34. Handsfield GG, Meyer CH, Hart JM, et al. 2014. Relationships of 35 lower limb muscles to height and body mass quantified using MRI. J Biomech 47:631-8.

35. Wickiewicz TL, Roy RR, Powell PL, Edgerton VR. 1983. Muscle architecture of the human lower limb. Clin Orthop Relat Res 179:275-83.

36. Ward SR, Eng CM, Smallwood LH, Lieber RL. 2009. Are current measurements of lower extremity muscle architecture accurate? Clin Orthop Relat Res 467:107482.

37. Friederich JA, Brand RA. 1990. Muscle fiber architecture in the human lower limb. J Biomech 23:91-5.

38. Scheys L, Van Campenhout A, Spaepen A, et al. 2008. Personalised MR-based musculoskeletal models compared to rescaled generic models in the presence of increased femoral anteversion: effect on hip moment arm lengths. Gait Posture 28:358-65.

39. Borotikar B, Lempereur $M$, Lelievre $M$, et al. 2017. Dynamic MRI to quantify musculoskeletal motion: A systematic review of concurrent validity and reliability, and perspectives for evaluation of musculoskeletal disorders. PLoS One 12:e0189587.

40. Gelaude F, Vander Sloten J, Lauwers B. 2008. Accuracy assessment of CT-based outer surface femur meshes. Comput Aided Surg 13:188-99.

41. Salo Z, Beek M, Wright D, Whyne CM. 2015. Computed tomography landmarkbased semi-automated mesh morphing and mapping techniques: generation of patient specific models of the human pelvis without segmentation. J Biomech 48:1125-32.

42. Oosterwaal M, Carbes S, Telfer S, et al. 2016. The Glasgow-Maastricht foot model, evaluation of a 26 segment kinematic model of the foot. J Foot Ankle Res 9:19.

43. Xu H, Bloswick D, Merryweather A. 2015. An improved OpenSim gait model with multiple degrees of freedom knee joint and knee ligaments. Comput Methods Biomech Biomed Engin 18:1217-24.

44. Sheehan FT, Zajac FE, Drace JE. 1998. Using cine phase contrast magnetic resonance imaging to non-invasively study in vivo knee dynamics. J Biomech 31:21-6.

45. Rebmann AJ, Sheehan FT. 2003. Precise 3D skeletal kinematics using fast phase contrast magnetic resonance imaging. J Magn Reson Imaging 17:206-13. 
46. Behnam AJ, Herzka DA, Sheehan FT. 2011. Assessing the accuracy and precision of musculoskeletal motion tracking using cine-PC MRI on a 3.0T platform. J Biomech 44:193-7.

47. Carbone V, van der Krogt MM, Koopman HF, Verdonschot N. 2012. Sensitivity of subject-specific models to errors in musculo-skeletal geometry. J Biomech 45:2476-80.

48. Pal S, Langenderfer JE, Stowe JQ, et al. 2007. Probabilistic modeling of knee muscle moment arms: effects of methods, origin-insertion, and kinematic variability. Ann Biomed Eng 35:1632-42.

49. Murray WM, Delp SL, Buchanan TS. 1995. Variation of muscle moment arms with elbow and forearm position. J Biomech 28:513-25.

50. Arnold AS, Salinas S, Asakawa DJ, Delp SL. 2000. Accuracy of muscle moment arms estimated from MRI-based musculoskeletal models of the lower extremity. Comput Aided Surg 5:108-19.

51. Suderman BL, Vasavada AN. 2017. Neck Muscle Moment Arms Obtained In-Vivo from MRI: Effect of Curved and Straight Modeled Paths. Ann Biomed Eng 45:2009-24.

52. Lieber RL. Skeletal muscle structure and function: implications for physical therapy and sports medicine. . Wilkins W, editor. Baltimore1992.

53. Froeling M, Nederveen AJ, Heijtel DF, et al. 2012. Diffusion-tensor MRI reveals the complex muscle architecture of the human forearm. J Magn Reson Imaging 36:237-48.

54. Bol GH, Kotte AN, van der Heide UA, Lagendijk JJ. 2009. Simultaneous multimodality ROI delineation in clinical practice. Comput Methods Programs Biomed 96:133-40.

55. Kim TH, Zollinger L, Shi XF, et al. 2009. Diffusion tensor imaging of ex vivo cervical spinal cord specimens: the immediate and long-term effects of fixation on diffusivity. Anat Rec (Hoboken) 292:234-41.

56. Sun SW, Liang HF, Xie M, et al. 2009. Fixation, not death, reduces sensitivity of DTI in detecting optic nerve damage. Neuroimage 44:611-9.

57. Heemskerk AM, Strijkers GJ, Vilanova A, et al. 2005. Determination of mouse skeletal muscle architecture using three-dimensional diffusion tensor imaging. Magn Reson Med 53:1333-40.

58. Oudeman J, Mazzoli V, Marra MA, et al. 2016. A novel diffusion-tensor MRI approach for skeletal muscle fascicle length measurements. Physiol Rep 4:

59. Bolsterlee B, Finni T, D'Souza A, et al. 2018. Three-dimensional architecture of the whole human soleus muscle in vivo. PeerJ 6:e4610.

60. Chang YW, Su FC, Wu HW, An KN. 1999. Optimum length of muscle contraction. Clin Biomech (Bristol, Avon) 14:537-42.

61. Lund ME, de Zee M, Andersen MS, Rasmussen J. 2012. On validation of multibody musculoskeletal models. Proc Inst Mech Eng H 226:82-94.

62. Hicks JL, Uchida TK, Seth A, et al. 2015. Is my model good enough? Best practices for verification and validation of musculoskeletal models and simulations of movement. J Biomech Eng 137:020905. 
63. Erdemir A, McLean S, Herzog W, van den Bogert AJ. 2007. Model-based estimation of muscle forces exerted during movements. Clin Biomech (Bristol, Avon) 22:131-54.

64. de Luca CJ. 1997. The Use of Surface Electromyography in Biomechanics. J Appl Biomech 13:135-63.

65. De Luca CJ, Gilmore LD, Kuznetsov M, Roy SH. 2010. Filtering the surface EMG signal: Movement artifact and baseline noise contamination. J Biomech 43:15739.

66. Keller A, Johansen JG, Hellesnes J, Brox JI. 1999. Predictors of isokinetic back muscle strength in patients with low back pain. Spine (Phila Pa 1976) 24:275-80.

67. Fregly BJ, Besier TF, Lloyd DG, et al. 2012. Grand challenge competition to predict in vivo knee loads. J Orthop Res 30:503-13.

68. Torrao JN, Dos Santos MP, Ferreira JA. 2015. Instrumented knee joint implants: innovations and promising concepts. Expert Rev Med Devices 12:571-84.

69. Hatfield GL, Hubley-Kozey CL, Astephen Wilson JL, Dunbar MJ. 2011. The effect of total knee arthroplasty on knee joint kinematics and kinetics during gait. J Arthroplasty 26:309-18. 
Samenvatting

Summary

Valorisation

Dankwoord

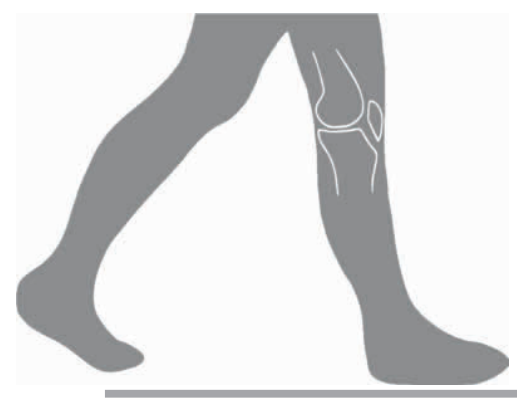

About the author

List of publications 


\section{Samenvatting}

Knieartrose is een aandoening waarbij het kraakbeen in de knie wordt aangetast. Ruim één op de tien mensen boven de leeftijd van 55 jaar heeft klachten aan de knie die veroorzaakt worden door knieartrose. De klachten die patiënten ervaren zijn pijn bij het uitvoeren van dagelijkse taken, zoals opstaan, lopen en traplopen. Het risico op het ontwikkelen van knieartrose wordt verhoogd door een hoog lichaamsgewicht, het vrouwelijk geslacht, een hogere leeftijd en met name boven de 50 jaar, een eerder trauma aan de knie of een afwijkende stand (varus) van de knie.

In het ontstaan en de verergering van knieartrose spelen biomechanische componenten een belangrijke rol. Gewrichtskrachten en -momenten kunnen worden bepaald door middel van gangbeeldanalyse. Bij het ontstaan en verergeren van knieartrose wordt in de literatuur het knie adductiemoment als een belangrijke maatstaf genoemd. Bij een hoog knie adductiemoment neemt de belasting aan de binnenkant van de knie toe. In een vroeg stadium van knieartrose kan al een hoger knie adductiemoment in de knie worden ontdekt. Met behulp van bewegingsanalyse zou men ook strategieën kunnen toetsen die de belasting in de knie trachten te reduceren.

Voor de daadwerkelijke belasting op het gewricht is echter ook informatie nodig van interne spier- en ligamentskrachten, welke niet worden meegenomen in gangbeeldanalyse. Computermodellen hebben wel de potentie om de functie van het complexe bewegingsapparaat te simuleren, waardoor de belasting op interne structuren kan worden onderzocht. Daarnaast zijn computermodellen in staat om "wat als" vragen te beantwoorden. Met andere woorden, computermodellen kunnen virtuele experimenten uitvoeren die moeilijk, onethisch of te duur zijn om in de realiteit uit te voeren.

Deze computersimulaties zijn afhankelijk van de gegeven input parameters, zoals bot geometrie, spiervolume, spiervezellengte, peeslengte en spieraanhechtingen. Tot op heden worden veel van deze input parameters uit kadavermetingen gehaald. Vervolgens wordt het model specifiek gemaakt door antropometrische persoonskenmerken, zoals lengte en gewicht, toe te voegen of een schalingsfactor toe te passen. Een andere mogelijkheid om het model persoonsspecifiek te maken is door beeldvormende technieken zoals MRI te gebruiken.

Het doel van dit proefschrift is om meer inzicht te krijgen in de belasting van het kniegewricht tijdens lopen bij patiënten met knieartrose, en om kniebelasting beter te voorspellen met behulp van persoonsspecifieke computermodellen. 
In hoofdstuk 2 werd onderzocht in welke mate de knie wordt belast bij mensen met beginnende knieartrose en welke rol een hoog lichaamsgewicht heeft in deze kniebelasting. Hiervoor werd traditionele gangbeeldanalyse gebruikt om kniebelasting te meten tijdens het lopen. Drie groepen werden vergeleken: patiënten met knieartrose en ernstig overgewicht, patiënten met een gezond gewicht en gezonde vrijwilligers met een gezond gewicht. Hieruit bleek dat voornamelijk de combinatie van ernstig overgewicht en de aanwezigheid van knieartrose een verhoging van het knie adductiemoment veroorzaakte. Bij de slanke knieartrose patiënten was het knie adductiemoment vrijwel gelijk aan de gezonde vrijwilligers.

Hoofdstuk 3 beschreef dat een computermodel additionele informatie kon geven over de kniebelasting ten opzichte van gangbeeldanalyse. De resultaten uit dit hoofdstuk lieten zien dat de medio-laterale gewrichtskracht bij patiënten met knieartrose en een gezond gewicht hoger was dan bij gezonde vrijwilligers, terwijl het externe knie adductiemoment gelijk was tussen deze groepen.

Voor het personaliseren van computermodellen werd in hoofdstuk 4 een nieuwe methode van krachtschaling gepresenteerd en geëvalueerd. Door middel van krachtschaling worden meerdere spieren met eenzelfde factor vermenigvuldigd om het model persoonsspecifiek te maken. Onafhankelijk van lengte, gewicht en vetpercentage bleken onder andere leeftijd en geslacht een belangrijke determinant van maximale kracht. Door deze nieuwe krachtschalingsmethode kon op eenvoudige wijze het computermodel persoonsspecifieker gemaakt worden.

In hoofdstuk 5 werd onderzocht in hoeverre individuele spiervolumes bepaald kunnen worden door middel van beeldvormende technieken en in welke mate deze afwijken van datasets in de literatuur. Door gebruik te maken van beeldvorming met magnetische resonantie waren we in staat om bij één individu de meeste spieren te onderscheiden. De gemeten spiervolumes resulteerden in grotere waarden dan in de literatuur werden vermeld, wat verklaard kon worden doordat datasets in de literatuur gebruik maakten van oudere personen, bij wie sprake kan zijn van afname van spiervolume. Voor een betere vergelijking hebben we daarnaast de relatieve spiergrootten uitgerekend ten opzicht van de som van de quadriceps en hamstring spiervolumes. Na deze correctie bleek de relatieve spiergrootte vrijwel gelijk aan andere datasets uit de literatuur.

In hoofdstuk 6 werd onderzocht welk effect het personaliseren van spierkracht heeft op de voorspelling van het computermodel tijdens lopen. In deze explorerende studie hebben we verschillende soorten personalisatiemethoden toegepast en werden modeluitkomsten vergeleken. De resultaten lieten grote verschillen zien in spiervolumes 
tussen de verschillende personalisatiemethoden. Echter, ondanks deze grote verschillen in individuele spiervolumes resulteerden de verschillende methoden in ongeveer dezelfde gewrichtskrachten. Een mogelijke verklaring hiervoor is dat de aanpassing in spiervolume werd gecompenseerd door een hogere activiteit van dezelfde spier, waardoor de absolute spierkrachten en daardoor ook de gewrichtskrachten gelijk bleven.

In hoofdstuk 7 zijn de belangrijkste bevindingen van dit proefschrift beschreven en in de context geplaatst van de huidige literatuur. Daarnaast werden in dit hoofdstuk perspectieven gepresenteerd voor toekomstig onderzoek.

De resultaten in dit proefschrift beschreven dat patiënten met knieartrose in combinatie met ernstig overgewicht een groter knie adductiemoment hadden tijdens lopen dan patiënten met een gezond gewicht. Hierdoor nam de belasting aan de binnenkant van de knie bij deze patiënten toe. Interventies die zich richten op gewichtsverlies in de patiënt met ernstig overgewicht zouden daarom een belangrijke bijdrage kunnen leveren aan een afname van de gewrichtsbelasting. Patiënten met een gezond gewicht hadden een vergelijkbaar knie adductiemoment in vergelijking met gezonde vrijwilligers. De interne belasting, zoals werd voorspeld met computersimulaties, lieten echter een verschil zien tussen deze groepen. Het is daarom belangrijk dat men rekening houdt dat de belasting, zoals bepaald wordt met bewegingsanalyse, niet altijd overeenkomt met de interne gewrichtskrachten.

Het persoonsspecifiek maken van de maximale spierkracht droeg bij aan een accurater computermodel. Zowel het gebruik van een uniforme schaal als beeldvormende technieken konden hiertoe bijdragen. Een schaalfactor is eenvoudig in het gebruik, waardoor deze techniek direct klinisch toepasbaar is. Echter, beeldvormende technieken zijn nauwkeuriger. De keuze van personalisatietechniek binnen computermodellen is dus afhankelijk van de mate van accuraatheid die benodigd is. 


\section{Summary}

Knee osteoarthritis is the main cause of disability in elderly and is characterized by degeneration of knee cartilage. Ten percent of elderly above 55 years have disabling symptoms, for example, pain during daily activities as walking, rising from a chair and stair ambulation. A complex combination of risk factors is associated with knee osteoarthritis; they include a high body mass, the female gender, aged above 50 years, previous trauma and a varus deformity at the knee.

Furthermore, biomechanical mechanisms have an important role in understanding the initiation and progression of knee osteoarthritis. Measuring joint forces and moments using gait analysis can aid in the early detection of deviating knee joint loading. The knee adduction moment is an often used parameter to indicate the amount (and excess) of medial knee loading. Furthermore, gait analyses offer the possibility to investigate possible coping strategies in order to reduce the knee adduction moment.

Although gait analyses provided increased knowledge on pathomechanics, it is unable to determine internal knee forces. Therefore, information on ligament and muscle forces is required. Computer models offer the opportunity to simulate the musculoskeletal system, including the effect of external stimuli on internal structures. Furthermore, musculoskeletal models are able to answer "what if" questions. Moreover, these computer models can perform virtual experiments that are difficult, expensive or not ethical to perform in real life experiments.

In order to predict accurate knee loading musculoskeletal computer models dependent on reliable input parameters, such as muscle volume, bone geometry, muscle fibre length, tendon length and insertion points. To date, these parameters are derived from cadaveric measurements. In order to retrieve accurate outcomes, personalisation of these models is needed by adding anthropometrical parameters (e.g. height and mass), or estimating parameters by generic scaling. Moreover, imaging can be introduced for obtaining accurate subject-specific parameters.

The aim of this thesis is to improve our knowledge regarding knee joint loading in patients with knee osteoarthritis; and to better predict knee joint loading by personalised musculoskeletal models.

In chapter 2, knee loading during walking was examined in patients with knee osteoarthritis. Furthermore, the effect of high body mass and walking speed on knee loading was evaluated. Three homogeneous groups were included: obese patients with 
knee osteoarthritis, lean patients and lean healthy volunteers. Obese patients with knee osteoarthritis showed a significant increased knee adduction moment compared to lean patients. Furthermore, lean patients walked with similar knee adduction moments compared to lean healthy volunteers.

In chapter 3 a subset of the dataset of chapter 2 was used for further evaluation. Musculoskeletal models were able to show differences in knee loading between lean patients with knee osteoarthritis and healthy volunteers. Although, similar knee adduction moments were measured using gait analysis, musculoskeletal models showed significant increased mediolateral knee forces.

A new scaling method for personalising muscle strength in musculoskeletal models is presented and evaluated in chapter 4. In strength scaling several or all muscles are multiplied by a single factor in order to personalise musculoskeletal models. Current scaling methods use body mass, height and fat percentage, disregarding other variables (e.g. age and gender) that are independent determinants of muscle strength. Therefore, a personalised model incorporating these parameters could increase personalisation of musculoskeletal models.

Chapter 5 describes the possibility of obtaining individual muscle volumes using imaging. Moreover, a dataset derived from imaging was compared with available datasets from literature. Using magnetic resonance imaging (MRI) we were able to distinct most individual muscles. The muscle volumes were higher compared to cadaveric datasets, which could be explained by an age related hypotrophy in the cadaveric datasets. For comparison reasons we calculated muscle volume relative to total muscle volume of the quadriceps and hamstring muscles. These results showed that relative muscle size between muscles was almost similar compared to the cadaveric datasets.

Chapter 6 describes the effect of personalisation muscle strength on model predictions during walking. In a proof-of-concept study we implemented several personalisation techniques (i.e. strength scaling and MRI derived muscle volumes) and compared model outcomes. The personalisation techniques resulted in large differences in muscle volumes, whilst comparable joint forces were predicted. A possible explanation is that an increase in muscle activity compensated for the decreased muscle volume, resulting in similar absolute muscle forces and similar joint forces.

Chapter 7 discussed the key findings in a broader perspective, including their relation to current literature. Furthermore, this chapter contains future perspectives on improving personalised musculoskeletal models. 
This dissertation describes that obese patients with knee osteoarthritis walk with higher knee adduction moments compared to lean patients. Interventions targeting weight loss could significantly reduce knee joint loading. Lean patients had similar knee adduction moment compared to healthy, weight-matched volunteers. Meanwhile, applying musculoskeletal models we found significant differences in internal knee loading between lean patients and healthy volunteers. Therefore, researchers should take into account that external joint loading does not predict internal loading entirely.

Personalisation of maximal muscle force by means of scaling or imaging can aid in more accurate models. Strength scaling is straightforward and can be implemented in clinical practice; whilst imaged based models are more accurate, but have some disadvantages (e.g. time consuming and expensive) which hamper implementation in clinical practice. The level of personalisation in musculoskeletal models should be carefully considered for its specific purpose, taking into account the accuracy that is needed versus the given effort. 


\section{Valorisation}

\section{Relevance}

Knee osteoarthritis (OA) is the main cause of pain and disability in elderly affecting ten percent of elderly of 55 years or older. ${ }^{1}$ The incidence of knee OA is rising, since risk factors as high body weight and aging of the population are increasing. ${ }^{2}$ Furthermore the annual healthcare costs in the Netherlands for knee OA are immense; in 2015 they exceeded 500 million euros. ${ }^{1}$ Joint replacement is an irreversible intervention and should be considered in patients failing other treatments and who often have more severe knee OA. ${ }^{3}$ However, joint replacement surgery should be limited in order to reduce overall costs, since most $\mathrm{OA}$ related costs are associated with hospitalization in joint replacement surgery. ${ }^{1,3}$ Furthermore, patients that received surgery will need postoperative therapy or possibly need revision surgery in case of treatment failure, resulting in accompanied additional costs. Early detection in combination with an optimal management using nonsurgical treatments could prevent or retard progression of OA. ${ }^{3}$

Understanding the pathomechanics of knee OA can aid in the maintenance of healthy cartilage. $^{4}$ Therefore it is important to quantify joint loading in patients with knee OA using gait analysis. This thesis provides evidence that advanced computer models can give additional information on internal joint loading (chapter 3). These musculoskeletal computer models are, however, dependent on input parameters that are sometimes difficult to quantify. Scaling can easily personalize musculoskeletal models (chapter 4), but accuracy might be questionable for a specific individual in a clinical setting. Imaging is expected to give better estimations, but is time-consuming and expensive (chapter 5 and 6). Moreover, clinical application of these advanced methods might become challenging. Therefore, the level of personalization in musculoskeletal models should be carefully considered for its specific purpose, taking into account the accuracy that is needed versus the given effort.

\section{Target groups}

\section{Patients}

It is not anticipated that patients with knee OA directly benefit from the results of this dissertation. However, on the long term, patients will profit from a better understanding of pathomechanics of knee OA. Early stage knee OA or subjects prone to develop knee OA could be detected through non-invasive gait analysis. Furthermore, nonsurgical strategies (e.g. gait training) can be developed in order to decrease progression of knee OA or to 
cope with knee pain. ${ }^{5-8}$ The primary goal of nonsurgical treatments is to postpone or prevent joint replacement, which is accompanied with high chances of complications and intensive rehabilitation.

A direct benefit for patients or subjects prone to $\mathrm{OA}$ from this dissertation is the importance of body mass on joint loading. Chapter 2 showed that body mass in combination with $\mathrm{OA}$ presence contribute significantly to higher knee joint loading compared to the presence of knee OA alone. Literature has shown that obese patients benefit from weight loss, which might reduce knee pain on the short term and possibly delays progression of knee OA. ${ }^{9}$

A second benefit for patients is that voluntary modifications in their gait pattern can be advised. These modifications might reduce joint loading and possibly effecting disease progression and pain. ${ }^{8}$ In Chapter 2 and 3 we showed that a slower speed of propulsion decreases peak joint loads, whilst total load during a gait cycle increases, which is in accordance to literature. ${ }^{5,10}$ Other researchers suggest that trunk sway and toe-out angle are also important determinants of knee loading. ${ }^{8,11}$ Moreover, patients might benefit from implementing voluntary modifications to their standard gait pattern in order to reduce joint loads and possibly cope with the accompanied knee pain.

\section{Health care professionals}

Health care professionals can benefit from a better understanding of the pathomechanics of knee OA. Non-surgical strategies as mentioned above can be advised to patients in order to delay the progression of knee OA.

The aging population is prone to develop cartilage defects in the knee. In combination with the knowledge that joint replacements have limited life expectancy, non-surgical strategies that postpone joint replacement surgery are crucial. Non-surgical strategies with scientific evidence can provide health care professionals with additional tools for patient care.

This dissertation provides evidence that health care professionals should encourage weight loss in obese patients. Chapter 2 of this dissertation described that obese patients with knee OA have significant higher knee loads during walking compared to lean patients. These high knee loads might accelerate the progression of knee OA. Moreover, this provides evidence that weight loss programs should be recommended for obese patients.

To date, musculoskeletal models and gait analysis are increasingly used in clinical care, however, the complexity and additional procedures limit wider application. Furthermore, 
the lack of proper validation prevented the implementation of musculoskeletal models by health care professionals. ${ }^{12}$ Although musculoskeletal models and gait analysis are becoming more user-friendly, which is an important step for clinical application.

\section{Researchers}

Other researchers can build upon the scientific conclusions of this dissertation. For example, in chapter 2 we found that the external knee adduction moment was mostly altered due to a higher body mass in patients with osteoarthritis. Researchers should acknowledge the importance of body weight in gait analysis.

In chapter 3, we found that the mediolateral component of the joint reaction force (i.e. shear force) was increased in patients with knee OA using musculoskeletal models. This parameter was able to show differences between healthy and knee OA on slow walking speeds, whilst knee adduction moments were not significantly different. Therefore, the shear force derived from musculoskeletal models might be a better indicator for knee OA gait compared to the knee adduction moment. Moreover, the usage of musculoskeletal models should be considered for acquiring additional information from traditional gait analysis.

Advanced personalized musculoskeletal models are supposed to increase accuracy compared to generic models, but also demand more resources. For example, magnetic resonance imaging is able to determine soft tissue properties (chapter 5), which enables musculoskeletal models to implement detailed subject-specific parameters (chapter 6). On the other hand simple rule-based scaling can provide good estimations of these parameters (chapter 4). Therefore, researchers should consider alternative approaches to personalize musculoskeletal models that are adequate for its specific purpose, but are less time-consuming and less time-consuming than advanced imaging.

\section{Recommendation for further research}

In this dissertation we were interested in the effect of osteoarthritis on gait. Therefore, we included a group of lean patients with knee OA and a weight, gender and age matched healthy control group. Since we suggested that weight might contribute to this effect, we included also an obese knee OA group. However, we did not anticipate that weight was the major contributor to changes in the knee adduction moment. In future research a fourth group of matched healthy obese subjects might contribute to a full understanding of the relation between weight, knee OA pathology and knee adduction moments. 


\section{Chapter 8}

Advances in musculoskeletal modelling enabled fast calculations of biomechanical characteristics. For example, these computer models are capable to detect alterations in pathological gait. The future challenge of these models is the further personalization in order to acquire accurate model outcomes that are clinically applicable. Furthermore, sensitivity analyses are useful for determining the consequences of inaccuracies. 


\section{References}

1. Volksgezondheidenzorg.info. 2016.2 Available from: https://www.volksgezondheidenzorg.info/onderwerp/artrose/cijferscontext/huidige-situatie\#node-prevalentie-en-aantal-nieuwe-gevallen-vanartrose.

2. Felson DT, Lawrence RC, Dieppe PA, et al. 2000. Osteoarthritis: new insights. Part 1: the disease and its risk factors. Ann Intern Med 133:635-46.

3. Jordan KM, Arden NK, Doherty M, et al. 2003. EULAR Recommendations 2003: an evidence based approach to the management of knee osteoarthritis: Report of a Task Force of the Standing Committee for International Clinical Studies Including Therapeutic Trials (ESCISIT). Ann Rheum Dis 62:1145-55.

4. Andriacchi TP, Koo S, Scanlan SF. 2009. Gait mechanics influence healthy cartilage morphology and osteoarthritis of the knee. J Bone Joint Surg Am 91 Suppl 1:95101.

5. Mundermann A, Dyrby CO, Hurwitz DE, et al. 2004. Potential strategies to reduce medial compartment loading in patients with knee osteoarthritis of varying severity: reduced walking speed. Arthritis Rheum 50:1172-8.

6. Cho Y, Ko Y, Lee W. 2015. Relationships among foot position, lower limb alignment, and knee adduction moment in patients with degenerative knee osteoarthritis. J Phys Ther Sci 27:265-8.

7. Ogaya S, Naito H, Iwata A, et al. 2015. Toe-Out Gait Decreases the Second Peak of the Medial Knee Contact Force. J Appl Biomech 31:275-80.

8. van den Noort JC, Schaffers I, Snijders J, Harlaar J. 2013. The effectiveness of voluntary modifications of gait pattern to reduce the knee adduction moment. Hum Mov Sci 32:412-24.

9. Aaboe J, Bliddal H, Messier SP, et al. 2011. Effects of an intensive weight loss program on knee joint loading in obese adults with knee osteoarthritis. Osteoarthritis Cartilage 19:822-8.

10. Robbins SM, Maly MR. 2009. The effect of gait speed on the knee adduction moment depends on waveform summary measures. Gait Posture 30:543-6.

11. Uhlrich SD, Silder A, Beaupre GS, et al. 2018. Subject-specific toe-in or toe-out gait modifications reduce the larger knee adduction moment peak more than a non-personalized approach. J Biomech 66:103-10.

12. Lund ME, de Zee M, Andersen MS, Rasmussen J. 2012. On validation of multibody musculoskeletal models. Proc Inst Mech Eng H 226:82-94. 


\section{Dankwoord}

In dit hoofdstuk wil ik graag iedereen bedanken die heeft bijgedragen aan de totstandkoming van dit proefschrift. In het bijzonder wil ik de volgende mensen bedanken, zonder wie dit proefschrift niet mogelijk was geweest.

Allereerst wil ik mijn promotieteam bedanken voor de begeleiding, de kritische blik en de vele sparringsmomenten. Mijn waardering is onder meer groot voor al het vertrouwen dat jullie in mij hebben gesteld, vanaf het moment dat ik mijn masterstage begon. Daarnaast hebben jullie me de vrijheid gegeven om vele zijpaden te bewandelen. Jullie verschillende persoonlijkheden maakten het tot een veelzijdig team, waardoor alle invalshoeken werden meegenomen. Lodewijk, jouw overzicht en organisatievermogen zijn bewonderingswaardig, daarvan heb ik veel geleerd. Je wist met je doeltreffende opmerkingen altijd snel tot de kern te komen. Hierdoor konden wij samen snel tot de oplossingen komen waardoor het einde van het promotietraject in zicht kwam. De samenwerking met de afdeling orthopedie heb ik altijd als prettig ervaren. Maarten, ondanks dat onderwijs geven jouw belangrijkste taak is, heb je mijn stukken altijd snel van gedetailleerde feedback voorzien. Daarnaast stond je altijd voor me klaar voor een korte vraag, probleem of discussie. Daar wil ik je hartelijk voor bedanken. Jouw kennis over anatomie en imaging waren onmisbaar voor dit proefschrift. Tenslotte wil ik Kenneth bedanken die dit (kaalhoofdige) trio compleet maakt. Jouw inhoudelijke kennis met betrekking tot bewegingsanalyse en alles daaromheen hebben een grote rol gespeeld in dit boekje. Samen hebben we verschillende congressen bezocht, waarbij ook tijd was om te ontspannen. Op die manier hebben we elkaar persoonlijk ook goed leren kennen. Ik wens jullie alle drie het beste toe op wetenschappelijk en persoonlijk vlak.

De beoordelingscommissie, Prof. dr. Savelberg, Prof. dr. Poeze, Prof. dr. Koopman, Dr. ir. Janssen en Dr. Witlox wil ik bedanken voor het beoordelen van dit proefschrift, en voor het deelnemen in de promotiecommissie.

Graag wil ik alle mensen bedanken die als proefpersonen hebben deelgenomen aan mijn onderzoek. Zonder de inzet van deze gezonde vrijwilligers en patiënten was mijn onderzoek niet mogelijk geweest. Ook wil ik de mensen bedanken die zich na het overlijden ter beschikking stellen aan de wetenschap. Jullie leveren een belangrijke bijdrage in het onderwijs en in dit onderzoeksgebied.

Veel tijd heb ik doorgebracht met mijn kamergenoten met wisselende samenstelling, maar nooit minder gezellig. Allereerst Michiel, veel tijd hebben wij ploeterend met onze modellen doorgebracht. Ook hebben we elkaar vaak vergezeld naar ORMs, pizza 
meetingen en lab bijeenkomsten en congressen in binnen- en buitenland. Daarin was het fijn om een medestander te vinden tussen al het klinisch geweld. Ondanks je ZuidHollandse afkomst, bleek er een echte Bourgondische Limburger in jou te schuilen die warm is te krijgen voor vlaai en speciaal biertjes op donderdagmiddag. Brenda, kamermoeder en meesterbakker, jij zorgde ervoor dat we ons allemaal thuis voelden en wij waren graag proefkonijn voor jouw baksels. Bij jou konden we onze onderzoek frustraties kwijt, maar wellicht dat jij vooral jouw frustraties bij ons kwijt kon. Bernard, enthousiast, vriendelijk en ondernemend zijn kenmerken van jou, maar bovenal een trotse Belg. Je hebt ons bijna allemaal aan het staand werken gekregen, helaas heb je mij nooit zover weten te krijgen. Hans, een honkvaste Limburger in dit gezelschap, jij wist met foute opmerkingen altijd het ijs te breken. Jij hebt ons in het begin veel geholpen met de metingen, maar nu is de tijd aangebroken om je eigen promotie-kar naar de eindstreep te trekken. Wai-Yan, bekend van "de Wai-Yan", heeft ook een belangrijke bijdrage geleverd aan het vergaren van de KNOA-data en de analyses. Met jouw vriendelijkheid was het altijd prettig samenwerken. Ruud, zonder jou zou er geen KNOA studie zijn geweest. Jouw opmerkelijke verhalen waren niettemin boeiend. Naast deze kamergenoten wil ik ook Loek in dit rijtje zetten, al hebben wij alleen "kantoor-aan-huis" af en toe gedeeld. Loek gaat ervoor zorgen dat de KNOA-studie internationaal bekend wordt, nadat het eerste paper af is weet ik dat je de smaak te pakken hebt en dat er meer zullen volgen. Ook al hadden we het allebei druk met andere dingen, het was altijd fijn om tijd vrij te maken om samen te werken aan de KNOA papers.

Paul, Harry en Désirée wil ik bedanken voor alle ondersteuning op respectievelijk labtechnisch, IT en secretarieel gebied.

Ook wil ik mijn (voormalige) collega's Janneke, Tom, Rachel, Herman, Marike, Li-Juan, Chris, Irene, HQ, Jasper, Kyra, Wouter en Thamar bedanken voor de steun en afleiding, van het begin van de promotie tot aan de laatste loodjes. Allen wens ik veel succes toe in verdere carrière of een spoedige promotie.

Vele stagiaires heb ik tijdens hun eindfase mogen begeleiden. Daarvan wil ik de volgende studenten bedanken die op een bijzondere manier hebben bijgedragen aan dit proefschrift: Tessa DH, Desiree, Twan, Miguel, Tessa K en Roberto.

De collega's van Anatomie \& Embryologie wil ik bedanken voor de prettige samenwerking. Arno, jouw anatomische kennis van het menselijke lichaam is overweldigend. Daarnaast stond jouw positivisme en humor in aardig contrast met de werkzaamheden in de snijzaal. Leon en Johan wil ik bedanken voor alle praktische samenwerking en het meedenken in het onderzoek. Heel jammer dat de vele uren in de snijzaal niet in verhouding staan met 
de inhoud van het proefschrift, toch was het ontzettend leerzaam. Tijdens de experimenten hebben jullie het maken van gelatine naar een heel ander niveau gebracht.

De collega's van Radiologie, waaronder Axel, Etienne, Dagmar, Roland en Henk, wil ik bedanken voor assistentie tijdens de MRI metingen. En tijdens deze metingen, die soms vele uren in beslag namen, hadden we ruim de tijd om eens gezellig bij te praten.

De collega's van Orthopedie (incl. het lab en het trialbureau) Pieter, Tim, Liesbeth, Chris, Marloes, Alex, Jim, Eva, Don, Andy, Maarten, Marjolein, Ufuk, Mandy, Tessy wil ik bedanken voor de uitstekende samenwerking. In de vele bijeenkomsten kwam het gehele spectrum van orthopedisch onderzoek voorbij. Door de mix van verschillende achtergronden was de discussie achteraf altijd even interessant als onvoorspelbaar. Ook wil ik Denise bedanken voor alle organisatie in de eindfase en voor het maken van afspraken met het promotieteam. Daarnaast wil ik alle specialisten bedanken voor het selecteren en rekruteren van patiënten

De collega's bij СTCM en bij St-Anna wil ik bedanken dat ze me de kans hebben geboden te mogen werken voor deze mooie organisaties. Jullie hebben mijn ogen geopend met betrekking tot nieuwe mogelijkheden en uitdagingen.

Daarnaast wil ik ook al mijn vrienden en familie bedanken die mij tijdens het onderzoek hebben gesteund, maar vooral ook daarnaast hebben gezorgd voor de nodige afleiding. In het bijzonder wil ik mijn paranimfen bedanken voor een belangrijke bijdrage tijdens de verdediging en tijdens de voorbereidingen. Geertjan, vanaf dat we nog klein waren trokken we al veel met elkaar op. Bijvoorbeeld, wanneer het weer het toeliet waren wij hele dagen op een voetbalveldje te vinden. En sinds ik in Maastricht vertoef was jij nooit te beroerd om regelmatig naar het zuiden af te reizen. Dan verkennen we samen het heuvelland op de fiets en het uitgaansleven in Maastricht. Ik ben heel blij en trots dat jij tijdens de verdediging naast mij staat. Rob, ook jij staat tijdens de verdediging naast me. Met jouw spontane en positieve instelling weet jij echt tot mij door te dringen. Dat jij als jonge vader met Yaro naar een spontane bbq in Maastricht komt is hierbij tekenend. Daarnaast vertegenwoordigt Rob een hechte vriendengroep die sinds de studententijd in Maastricht bij elkaar is. Een opgewekte, bonte groep vrienden waar ik me altijd op mijn gemak voel. Geert, jij hebt altijd met veel interesse mijn PhD gevolgd. Je hebt een uitgesproken mening en een bijzondere visie op dingen, even een kort gesprek duurt daarom altijd langer. Mark, sportiviteit is een van de vele dingen die we gemeen hebben. Ik kijk er naar uit om weer samen een rondje te fietsen; voor de competitie, de gesprekken en de mooie landschappen. Gijs, ik ken je al sinds de middelbare school, maar in Maastricht trokken we pas echt veel met elkaar op. Naast studie- en huisgenoot, hebben 


\section{Chapter 8}

we samen gevoetbald en zijn we samen op stap geweest. Jij hebt je droom gevolgd, waar ik niets anders dan respect voor kan hebben. Lianne, de carrièretijger en heel vrolijk na enkele speciaal biertjes tijdens carnaval in Maastricht, gelukkig heb je nu in je werk balans gevonden. Mirjam, als het gezellig is ben jij tevreden, zo niet dan zorg jij ervoor. Net zoals voor de groepsfoto's tijdens alle groepsactiviteiten. Marjan, met jou kan je altijd lachen, daarnaast zet jouw nuchterheid iedereen weer met beide voetjes op de grond. Kasia, you are the latest addition to this group and more than welcome, I hope to visit Poland soon.

Lieve familie, Pa, Marjanne, Putu, Ravi, Mira, Geertjan en Manon, van dichtbij en van ver hebben jullie me gesteund tijdens mijn studie en werk. Bij een ieder van jullie zijn we welkom en voelen we ons thuis. Het geeft me een goed gevoel dat jullie en ons Mam altijd achter me zullen staan. Dat jullie trots op me zijn hebben jullie niet onder stoelen en banken geschoven, maar bij dezen wil ik ook aangeven dat ik heel trots op jullie ben. In het bijzonder ben ik trots op mijn $\mathrm{Pa}$, die na het verlies van ons Mam drie kinderen heeft opgevoed die alle drie goed zijn terechtgekomen.

En schoonfamilie, Piet, Marina, Floor, Bas, Hannah \& Iris, Guus en Lisa, bij jullie voelde ik me ook snel thuis. Daarnaast wil ik jullie heel veel bedanken voor het oppassen, waardoor dit boekje toch iets sneller is afgekomen.

Liefste Maartje, jij bent de belangrijkste persoon voor mij geweest tijdens de promotie en zoals je weet staan in de wetenschap de belangrijkste personen achteraan. Als ervaringsdeskundige heb ik alles met je kunnen delen en begreep je het reilen en zeilen(!) van een promotie. Als ik het even niet meer zag zitten bood jij de steun die ik nodig had. Een $\mathrm{PhD}$ is zowel een eindpunt vol met uitdagingen als een beginpunt met nieuwe uitdagingen, maar met jou erbij kan ik die allemaal aan! En Samuel, het is onbeschrijfelijk hoe trots ik op je ben. Dagelijks kijk ik er weer naar uit om met jou te gaan voetballen, rennen, verhaaltjes lezen, diertjes zoeken, etc. Vanaf nu zal dit boekje niet meer voor afleiding zorgen. 


\section{About the Author}

Pieter Oomen was born on April $29^{\text {th }}, 1986$ in Oirschot, the Netherlands. After finishing pre university education in 2004 at Heerbeeck College Best, he studied Health Sciences at Maastricht University with a major in Human Movement Sciences. After obtaining a bachelor degree, he continued with the master Physical Activity and Health. After obtaining his master degree in 2009 he continued working as a junior researcher within the department of Human Movement Sciences and worked on musculoskeletal models for the

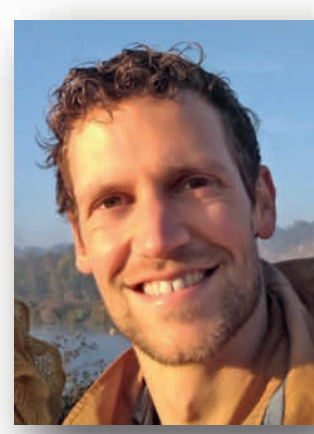
automotive industry.

In 2011 he started his PhD project at the department Nutrition and Movement Sciences of Maastricht University in collaboration with the department of Orthopaedic Surgery. During his PhD, Pieter performed studies on the biomechanics of gait in patients with knee osteoarthritis. In the past few years Pieter facilitated researchers in performing clinical research at Maastricht UMC. Besides, Pieter worked as a senior researcher at the department of Orthopaedic Surgery of St. Anna hospital.

Pieter lives together with Maartje and their son Samuel (2) in Maastricht. 


\section{List of publications}

- $\quad$ Oomen PW, Annegarn J, Rasmussen J, Rausch J, Siebertz K, Verdijk L, Drost MR and Meijer K. (2015) Development and validation of a rule-based strength scaling method for musculoskeletal modelling Int. J. Human Factors Modelling and Simulation, Vol. 5, No. 1, pp.19-32.

- $\quad$ Oomen PW, Garcia van der Westen R, van Rhijn LW, Emans PJ, Drost MR, Meijer $\mathrm{K}$. The mediolateral component of knee joint loading as predicted by musculoskeletal models is increased in patients with mild knee osteoarthritis (under review).

- $\quad$ Oomen PW \& Verlaan L, Schmitz T, Liu WY, Peters MJM, Emans PJ, van Rhijn LW, Drost MR, Meijer K. Obese knee OA patients have increased knee adduction moments during gait (under review).

- $\quad$ Oomen PW, Meijer K and Drost MR Comparison of in vivo muscle volumes of the lower extremity to cadaveric data sets (submitted).

- Verlaan L, Boekesteijn RJ, Oomen PW, Liu WY, Peters MJM, Emans P, van Rhijn LW, Meijer K. Biomechanical alterations during sit-to-stand transfer are caused by a synergy between knee osteoarthritis and obesity (accepted).

- Verlaan L, Vangeneugden J, Oomen PW, Liu WY, Peters MJM, Natour N, Emans P, Meijer K. Signatures of knee osteoarthritis in the temporal and fractal dynamics of human gait. (submitted).

- Verlaan L, Boekesteijn RJ, Oomen PW, Liu WY, Peters MJM, Emans PJ, van Rhijn LW, Meijer K. Similarity of EKAM parameters during stair negotiation may be explained by increased stance time of obese knee osteoarthritis patients (submitted). 
